\title{
UNCLASSIFIED
}

OEFICIAL USE ONLY BNWL-444

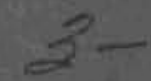

\section{PACIFIC NORTHWEST LABORATORY MONTHLY ACTIVITIES REPORT FOR APRIL 1967}

DEVELOPMENT REPORT

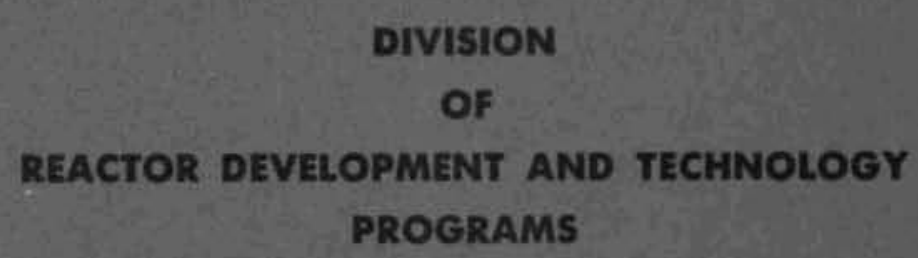

MAY 1967

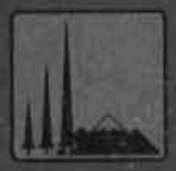

\section{BATTELLE=NORTHWEST}

BATTELLE MEMORIAL INSTITUTE / PACIFIC NORTHWEST LABORATORY

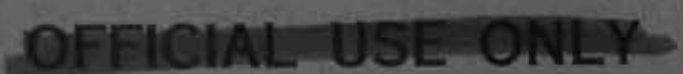




\title{
PATEYTSFWow
}

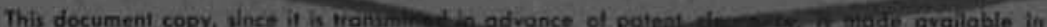

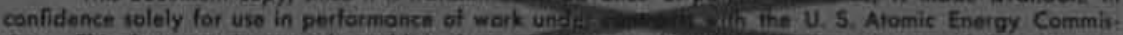

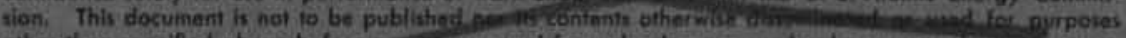

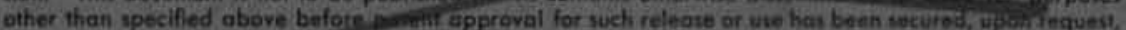

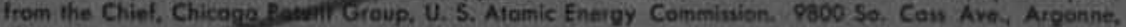
Illinoiz.

\section{PRELIUINARY REPOKT}

This report contain information of o preliminary nature prepared in the course af work under Alomic Energy Commission Contract AT(45-1)-1830. This information is subject to correction ar modifica. tion upon the collection and evaluation of additional data.

\section{LEGAL NOTIEE}

This teport was prepored as on account of Gavernment sponsared work. Nelther the United States nor the Commission, nor any person acting on betialf of the Commlasion:

A. Mokes ony warranty or representation, expressed or implied, with respect to the nccuracy, som pleteness, of usefulness of the informotion contained in this report, $u$ that the use of any information, apparatus, method or proceis disclased in this report may not infeinge petivately owned rights ar

8. Assumes any liabilities with reipent to the vie of or for domages resulting from the use of any infarmation, opporatus, method, or process disclosed in this report.

As used in the obove, "persen acting on behalf of the Commistion" includes any employee :o controctor of the Commission, or employes of such contractor, to the extent shat such entiployee of cont tracior of the Commissios. or enployse of wuch controcter prepores, disentinates, or provides actess to any information pursuant to his employment or contract with the Commissien, of his etuplayment with such eontractor.

\author{
PACIFIC NORTHWEST LABORATORY \\ RICHLAND, WASHINGTON \\ operated by \\ BATTELLE MEMORIAL INSTITUTE \\ for the \\ UNITED STATES ATOMIC ENERGY COMMISSION UNDER CONTRACT AT(45-1)-1830
}

PRINTED BY/FOR THE 0,5, ATOMIC ENERGY COMMISSION 


\title{
33679000605784
}

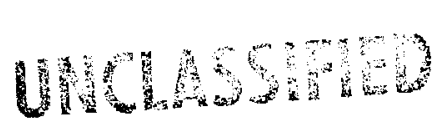

BNWL -444

$\mathrm{UC}-2$

Special Distribution

\author{
PACIFIC NORTHWEST LABORATORY \\ MONTHLY ACTIVITIES REPORT
}

FOR APRIL 1967

\author{
AEC DIVISION \\ REACTOR DEVELOPMENT AND TECHNOLOGY PROGRAMS
}

By

The Staff of Battelle-Northwest

S. L. Fawcett, Director

$$
\text { May } 1967
$$

PACIFIC NORTHWEST LABORATORY

RICHLAND, WASHINGTON

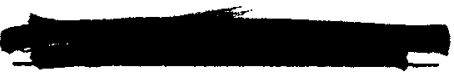


CIVILIAN POWER REACTORS

Liquid Metal Fast Breeder Reactor . . . . . . . . . 20

Nuclear Systems and Concepts Analysis . . . . . . . 24

Conceptual Reactor Design Studies . . . . . . . . . 26

USAEC-AECL Cooperative Program . . . . . . . . . . . 29

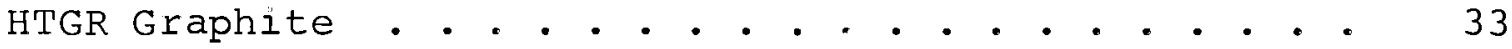

APPLIED AND REACTOR PHYSICS

Plutonıum Crıticalıty Studies . . . . . . . . . . 33

Phoenıx Fuel Reactor Program . . . . . . . . . . . 37

High Temperature Reactor Lattice Physics Studies . • . 42

REACTOR FUELS AND MATERIALS

Fast Fuels Oxides and Nitrides . . . . . . . . . 48

Basic Swelling Studies . . . . . . . . . . . . . 51

Nondestructive Testing . . . . . . . . . . . . . . 53

Nuclear Ceramics . . . . . . . . . . . . . . 59

Nuclear Graphite . . . . . . . . . . . . . 61

Irradiation Damage to Reactor Metals . . . . . . 65

ATR Gas Loop Operation and Maintenance . . . . . . 80

Metallic Fuels Development . . . . . . . . . . . . 82

Fast Reactor Dosimetry and Damage Analyses . . . . . 83

ENGINEERING DEVELOPMENT

Neutron Flux Monitors . . . . . . . . . . . . . . 85

Microwave and Infrared Detection of Coolant Impurities

and Measurement of In-Reactor Temperatures . . . .

PLUTONIUM UTILIZATION PROGRAM

Fuels Development . . . . . . . . . . . . . . 89

Reactor Physics . . . . . . . . . . . . . . . . . 91

Reactor Englneering Development . . . . . . . . . 97

Materials Development . . . . . . . . . . . . 99

Cycle Analysis . . . . . . . . . . . . . . . 101

Test Reactor Operation ............... 104

EBWR Demonstration Program . . . . . . . . . . . 109

NUCLEAR SAFETY

Containment Systems Experiment . . . . . . . . . 110

Radioactive Waste Solidification . . . . . . . . . . 114

Intermediate Level Waste Treatment . . . . . . . . . 119

Fission Product Aerosol Containment . . . . . . . . 119

Disposal of Reactor Off-Gas into Soll Systems . . . . 120

Geophysical Exploration of Rattlesnake \#l Well . . . . 120

Columbia River Sedimentation Studies . . . . . . . . 121

Simulation Modeling of Expected Thermal Generation in

Selected River Systems . . . . . . . . . . 121

Pressure Vessel Crack Monıtoring . . . . . . . . 122 


\section{SUMMARY}

\section{CIVILIAN POWER REACTORS}

\section{Liquid Metal Fast Breeder Reactor}

Irradiations to investigate the effects of oxygen migration and stoichiometry on heat transfer in oxide fuels operating near but below center melting are in progress.

Capsules for irradiation experiments to investigate stoichiometry effects $10 / \mathrm{M}$ 's of $1.92,1.97,1.99$, and 2.001 on the heat rating required for melting in 95\% dense, mechanically-mixed $\mathrm{UO}_{2}-25 \mathrm{wt} \% \mathrm{PuO}_{2}$ are being fabricated.

Two full scale fuel pins were fabricated for an analysis of the effect of wire wrapping on vibration nodes. The pins were loaded with depleted $\mathrm{UO}_{2}$.

Destructive examination of two $\mathrm{PuO}_{2}$-SS cermet pins irradiated in EBR-II subassembly X009 was begun. Samples of the helium cover gas contained no fission products.

Eighteen mixed oxide restrictor screening capsules were fabricated. The capsules, to be irradiated in the VH-4 facility of the MTR, are designed to operate at a power generation of $28 \mathrm{~kW} / \mathrm{ft}$.

A thorough review of swelling and growth in mixed oxide fuel led to the formulation of FFTF fuel characteristics that would allow an average burnup of 45,000 $\mathrm{MWd}$ /tonne without cladding deformation.

Drawlngs of the fuel motion restrictor test specimens and capsules for encapsulated irradiations in EBR-II were reviewed and approved. Procurement of components was begun.

\section{Nuclear Systems and Concepts Analysis}

In behalf of the systems analysis task force activities, successful introduction of coal plants into the linear programming model was demonstrated although only a token number were included in the optimal solution reached because of the apparently high cost assumption that was supplied by the coal plants. A better representation of the costs of fossil plants is being prepared. The LP model is being modified to reduce computation times. So far, a 50\% reduction has been achieved.

The PACTOLUS and POWERCO program complexes are being modified to generate data for a market place model. 
CIVILIAN POWER REACTORS

Conceptual Reactor Design Studies

The portion of the MIMIC design analysis simulation which constrains the number of fuel subassemblies in a specific core to achleve a specified maximum clad temperature have been debugged to the point of insuring operability. Limited sensitivity studies are being made to determine the accuracy of these calculations over a range of desıgn variables.

The fuel cladding desıgn calculations are being modified to better reflect current design philosophy and irradiation data generated in the EVESR program for Incoloy-625.

The assumptions made for the parameter survey have been modified after reviewing the results of calculations to date.

The breeding ratio was found to be very sensitive to the start of cycle assumptions.

\section{USAEC-AECL Cooperative Program}

Data obtained on in-reactor creep rates at $300 \mathrm{C}(680 \mathrm{~F})$ and $25.6 \mathrm{~kg}-\mathrm{mm}^{-2}(36,500 \mathrm{psi})$ stress have confirmed a value of $4 \times 10^{-7} \mathrm{hr}^{-1}$. This value represents an increase over the unirradiated control tests.

Experiments were performed on an electrically heated test section to study turbulent mixing between two adjacent flow channels formed by simulated fuel rods arranged in a square array. The quantity of mixing during nonbolling conditions was found to be approximateiy equal to that found earlier with a test section which simulated a coolant passage formed by rods on a square array located adjacent to one formed by rods on a triangular array. The improvement of mixing resulting from bolling was found to range from 0 to $300 \%$, depending on test section heat flux, flow rate, and pressure.

Construction is continuing on two electrically heated test sections for the study of the effects of rod spacing on boiling burnout in multirod bundle fuel elements. One test section simulates a fuel rod completely surrounded by other fuel rods, and the second simulates a rod adjacent to an uriheated surface such as a pressure tube or flow guide. 
Three tubular test specimens were pressure cycled to produce fatıgue cracks. Two specimens failed at hoop stresses of 28,000 psi when the fatigue crack had grown to a length of about $1 \frac{1}{2}$ inches. The other failed at a hoop stress of 62,000 psi and a crack length of 0.68 inch.

The analog computer study of hydraulic and nuclear stability of $\mathrm{D}_{2} 0$ moderated, boiling light-water cooled reactor systems has been resumed. Modifications have been made to the simulation, and test cases have been run to check out the simulation prior to start of the parametric study of fuel types.

\section{HTGR Graphite}

Dounreay Fast Reactor irradiations will include some ten varieties of graphites. These are conventional CSF, TSX, NC-8, and seven others selected on the basis of promising behavior in earlier tests.

\section{APPLIED AND REACTOR PHYSICS}

\section{Plutonium Critıcality studies}

A series of neutron activation measurements were completed with small pins of indlum, manganese, and plutonium for determining intracellular reaction rates in three undermoderated heterogeneous plutonium fueled assemblies. The H/Pu ratios of the three assemblies were: 22, 35, and 45. The data wlll be used as a check on cross section sets and methoas of calculation.

Pulsed neutron source experiments were performed on two undermoderated plutonium assemblies for determining decay constants and reactivities over a range of subcriticality. The work is preparatory to proposed measurements of reactivity on actual in-plant systems for nuclear safety evaluations.

An analysis was made of criticality data on plutonium solutions in slab geometry yielding critical bucklings and extrapolation lengths for the $58 \mathrm{~g} \mathrm{Pu/l}$ solution. A one-inch thick Lucite reflector was found to have a reflector savings about $60 \%$ of that for a thick water reflector. Computed critical thicknesses for the slabs were found to depart by up to $10 \%$ from measurement.

\section{Phoenix Fuel Reactor Program}

CAF-Phoenix calculations are now within $1 \% k$ experimental for all cases. 
Restacking of the beryliıum reflector adjacent to the core tank in the PRCF-Phoenix fuel core has reduced the critical mass 13.6\% and has increased the safety sheet worths $50 \%$.

PRCF-Phoenix calculations are high by over $5 \circ$ in $k$. At least half of this should be removed by more refined calculations.

Fifty percent Pu-239 burnup still seems obtainable in the MTRPhoenix experiment.

The digltal computer code, MACABRE II, for thermal hydraulic analysis of the MTR is still not operational on local computing faclities. With no flux suppressors, it is estimated that the MTR with the Phoenix core could operate initially at 24 MWt.

Design of a flux monltor wire for the Phoenix core is essentially complete.

Thirty shortened plutonium fuel plates were prepared for an Irradiation test in the MTR. The plates are currently being evaluated and assembled into test sections.

Work has started on analysis of the compact pressurized water reactor concept as a possible Phoenix application Preliminary plans were made for a PNL-ORNL meeting to discuss the possible application of Phoenix Fuel in the HFIR.

\section{High Temperature Reactor Physics Studies}

The vertical safety rods were installed on the High Temperature Lattıce Test Reactor (HTLTR). The electrical heating elements were tested in place in the reactor. Checkout of various instrumentation continued.

The gas system was accepted by the Operatıons and systems Unit.

The light duty oscillator, its coupling, and various samples were tested to a temperature of $500 \mathrm{C}$. The mockup is scheduled to go to $1000 \mathrm{C}$.

Varıous adminıstratıve documents are approaching completion.

Operational programs for the control of the reactor systems are being integrated in preparation for post-acceptance design tests.

Planning and calculatıons of experiments contınued. 


\section{REACTOR FUELS AND MATERIALS}

Fast Fuels Oxides and Nitrides

The first two mixed-nitride capsules were fabricated and shipped to the ETR. Fabrication of two additional capsules is nearly complete.

Improvements in ballmilling of (U-Pu) $N$ have resulted in an increase in sintered density of (U-Pu) N pellets from the 83-84\% TD range to about the $88 \% \mathrm{TD}$.

Thermal testing and metallographic examinations were conducted on the first sodium-bonded mixed oxide fuel compatibility test capsules.

A graphite tube furnace which will be used for studies of nitride synthesis by carbothermic reduction of oxides was recerved.

A particle-bed reactor assembly for use with the furnace was designed.

Experiments were begun on compatibility studies of UN - 20 wt\% PuN, sodium-bonded in 304 stainless steel cladding.

\section{Basic Swelling Studies}

Capsule P-15 (700 C, 1000 psi, 0.2-0.8 at. $\frac{\circ}{0}$ BU) was discharged after successfully reaching its goal exposure. Two other capsules continue to operate as designed and construction is either complete or in the final stages on four more capsules.

Electron microscopy revealed that no tearing had occurred in a specimen of $U+4$ Mo - 0.I Si irradiated to 0.34 at. $\frac{1}{\mathrm{~B} U}$ at $450 \mathrm{C}$. Specimens of this alloy irradiated to 0.45 at. $\frac{\circ}{8}$ BU at $525 \mathrm{C}$ developed a small amount of tearing consistent with the small amount of swelling that was measured.

Analysıs of the compatıbility tests between NaK, U, Ta, Zircaloy-2 and 304 stainless steel at $900 \mathrm{C}, 15,000 \mathrm{psi}$, and 96 hours revealed that a reaction had taken place between the constituents. Examinations show that U - Fe, U - Ni, and U - Cr eutectics had formed. Follow-up tests are now in progress to isolate the exact cause of the reaction.

\section{Nondestructive Testing}

Twelve test specimens, for use in the development of an ultrasonic method for detecting radiation embrittlement in pressure vessel 
steels were encapsulated, mounted in a multıspecimen capsule, and sent to the ETR for low temperature, low flux exposure during cycle \#89. Four specimens each will be exposed to $2.7 \times 1018$, $4.5 \times 1018$, and $6.4 \times 1018$ nvt, respectively. A monitor specimen, with low melting point alloy wire, is included in each capsule to permit determination of approximate maximum temperatures encountered. Three different steels will be irradiated to these exposures. These are: ASTM A-542 Class II, AISI 304, and ASTM A-302B. Sixteen additional specimens are being prepared for exposure in ETR cycle \#90.

Work to provide an EDTM Program to predict ultrasonic pulse characteristics through the use of Kautz function analysis methods continued. Current investigatıons involve a search for programming errors which may be contributıng to the currently unsatisfactory results. If no programming errors can be found, other methods of pulse analysis may be necessary in order to properly represent the measured ultrasonic signals.

Output wave forms from a pulsed eddy current test were analyzed, and means for expandlng the components were studied in preparation for applying the multiparameter test principles to a pulsed system. Additional input admittance loci simulating variations in test metal conductivity and thickness were obtained using a resistance-capitance network to simulate the eddy current test situation. Construction of the multichannel eddy current tubing tester is continuing, and completion of the transceiver section awalts delivery of electronic parts.

A study of the general waveform of ultrasonic test signals is being made to select parameters and signal analysis techniques for evaluating the feasibility of applyıng the multiparameter test concept to the interpretation and display of ultrasonic signals. A pulsed generator and an electrical network were used to simulate the signals from a back surface echo.

Development work is contınuing on both the remote transient and the sinusoidal steady state thermal testing method. A new, more stable, thermal transducer has been fabricated, and preliminary performance testing was conducted.

\section{Nuclear Ceramics}

Single crystal UO2 speclmens were prepared, characterized, and sent to Oak Ridge Natıonal Laboratory and Lawrence Radiation Laboratory for use in basic studies.

The etching behavior of $\mathrm{UO}_{2}$ - 25 wt: $\mathrm{PuO}_{2}$ solid solutions depends on the $O / M$ ratio. Stoichiometric material $(0 / M=2.00)$ is more resistant to grain boundary attack than hypostolchiometric material $(0 / \mathrm{M}=1.96)$. 
Work continued on characterization of mixed $\mathrm{UO}_{2}-\mathrm{PuO}_{2}$ and on development of methods for transmission electron microscopy of oxide fuels.

Decomposition behavior and melting points were determined for UN - 25 wto PuN, UN - 50 wto PuN, and UN - 75 wto PuN under nitrogen pressures between one and fifty atmospheres and in one atmosphere of helium.

An ice-mantle drop calorimeter was received and installed.

Thermal diffusivitıes of five uranıum oxycarbide samples were determined from room temperature to $1500 \mathrm{C}$.

Lattice parameters for $\mathrm{Pu}(\mathrm{N}, \mathrm{O})$ specimens synthesized in nitrogen atmospheres containing 30,100 , and 300 ppm oxygen were determined to be $4.9048 \AA, 4.9053 \AA$, and $4.9054 \AA$, respectively.

Attempts to evaporate ce from a tungsten filament for use in the $\mathrm{Pu}$ - O - N ternary equilibria apparatus were not successful.

\section{Nuclear Graphite}

The high temperature capsule GEH-13-13 was damaged in the ETR and discharged after two cycles. Damage occurred during core rearrangement. The capsule, modifled for increased ruggedness, will be rechargeä in June.

After accurate calibration, Geminol, Chromel-Alumel, W-(W-26\% Re), (W-5\% Re)-(W-26\% Re), and Pt-(Pt-10\% Rh) thermocouples are being encapsulated for EBR-II irradiation to exposures of 1022 nvt.

Both the long term capsule $\mathrm{H}-3-15$, and the prooftest capsule H-3-25 were charged in the GETR. Both are running satisfactorily.

Temperature cycling tests showed a hysteresis in thermal expansion of transverse TSX samples when heated above $2000 \mathrm{C}$. Parallel samples showed no hysteresis even when heated to $2400 \mathrm{C}$. The hysteresis is characteristic of many polycrystalline ceramic materials.

The microscopic examination of oxidation attack upon TSX and AGOT-LS graphites by reactions with thermal and microwave-exclted oxygen has produced more translucent areas and other interesting structures. Impurities are apparent with various crystalline structures including cubes. The thermal reaction of oxygen gives rise to extensive pitting due to selective attack. This pitting is more extensive in the more impure graphite.

The yield of methane in the radiolysis of mixtures of $\mathrm{CO}_{2}$ and $\mathrm{H}_{2}$ are highly dependent upon the purity of the reactants. 


\section{Irradiatıon Damage to Reactor Metals}

Alloy selection has been extended to include two new stalnless steels, a family of V-Cr alloys, and a material for an FFTF in-core application.

Test results on the effect of Irradiation during in-reactor creep of AISI. Type 304 stainless steel have indlcated a two order of magnitude increase in creep rate and an even greater change in

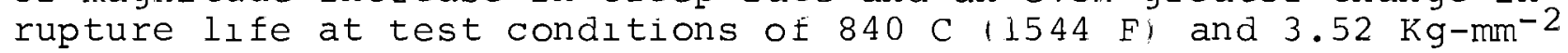
(5000 psi) stress. Plans are being made to repeat these tests to check the reproducibility of the results.

AISI Types 304 and 348 stalnless steel tensile specimens, 25\% cold worked, have been irradiated in the ETR hot water loop at $290 \mathrm{C}$ $(554 \mathrm{~F})$ to a fast neutron fluence of $6.0 \mathrm{x} 10^{21} \mathrm{n} / \mathrm{cm}^{2}(\mathrm{E} 1 \mathrm{MeV})$ and tested at temperatures to $750 \mathrm{C}(1362 \mathrm{~F})$. A Iarge amount of radiation hardening and consequent increase in the yield strength was observed at $750 \mathrm{C}(1362 \mathrm{~F})$ for 348 stainless steel. For irradiated 304 stainless steel the strength had increased only slightly over its unirradiated value at $750 \mathrm{C}: 1362 \mathrm{~F})$.

Two papers on nickel-base alloys have been submitted for oral presentation, one at the International Conference on the strength of Metals and Alloys in Tokyo in september 1967, and the other at the Fall Meeting of the Metallurglcal society of the AIME to be held in Cleveland in October 1967. Another paper, for journal submission, is in draft form.

Analyses of data from thermomechanlcally-treated Hastelloy $\mathrm{x}-280$ specimens irradiated at $1250 \mathrm{~F}(676 \mathrm{C})$, and their controls, after tensile testing at $1350 \mathrm{~F} \quad 1732 \mathrm{Cl}$ showed that thermal exposure alone resulted in significant embrittlement. Some experimental treatments showed better thermal stablilty and three times the postirradiation ductility of the standard solution treatment.

The program to determine the effects of irradiation on sintered aluminum products (SAP) has been discontınued. The work requests have been recalled on sheath capsule development, specimen fabrication, and materials characterization. The sheath capsule mockup being discharged this week will be examined. Examination of high exposure Zircaloy-2 tensile specimens from the G-7 loop continues to show thick ( $5 \mathrm{mlls}$ ) oxlde fllms and hydrogen contents up to 1400-1500 ppm.

Results have been received from four of the eleven laboratorles participating in the intercalibration counting program. An analysis of the preliminary data indıcates poorer agreement between sites than was obtained in the 1964 intercalıbration test.

A basic study of the effect of irradiation-produced point defects on the fracture characteristics of crystalline materials has been completed. This stuày was conducted on single crystal lithium 
fluoride by means of DCB tests. Noteworthy observations made during this investigation include the measurement of a minimum in the effective surface energy for forward crack propagation at an exposure of $1 \times 10^{7} \mathrm{r}$ and the occurrence of crack healing which occurs most readily in crystals irradiated to $1 \times 10^{7} \mathrm{r}$. A report on this investigation has been completed.

Development of an ultrahigh vacuum environmental chamber is nearing completion. The chamber will be used with the Instron testing machine to determine the effect of external environment on the rate of subcritical cracking in steels. Tests are now being performed on cold worked Zircaloy-2 specimens irradiated in the ETR G-7 loop to a neutron fluence of 1 x $1021 \mathrm{n} / \mathrm{cm}^{2}$ at $290 \mathrm{C}(540 \mathrm{~F})$. Irradiated, hydrided Zircaloy-2 specimens are also being tested to determine the fracture toughness, $\mathrm{K}_{\mathrm{Ic}}$.

Five structural materials capsules containing 50 specimens of 348 and 304 stainless steel have been discharged from the EBR-II after a total fluence of $1.7 \times 10^{22} \mathrm{n} / \mathrm{cm}^{2}$. The effect of one hour anneals on the substructure of 304 stainless steel Irradiated in the EBR-II has been established.

Design, installation, and use of equipment for testing materials in air, inert gas, and liquid sodium environments have progressed. Current modifications and improvements to facliities in the $321 \mathrm{~A}$ Building have been concerned with radiation shieiding requirements, safety requirements, anà sodium cleanup.

Examination of the Irradiated liquid sodium capsule GEH-22-3 is providing metallurgical and design data for future capsules. GEH-22-4, now under irradiation, shows evidence of failure of the vacuum annulus.

The hydrogen permeation characteristics of thin membranes of 18-8 type stainless steel have been investigated using gas phase hydrogen charging techniques; phase boundary processes at the absorption and desorption surfaces do not appear to be rate controlling in these alloys at normal permeation temperatures even for specimens of less than normal cladding thickness.

The model gas loop has operated a total of 3408 hours since installation of the new heater, and this includes 300 hours during the past month. A new vacuum Jacketed liquid nitrogen line was installed during the month.

Corrosion coupons exposed at temperature for times to 1500 hours in the ATR model loop continue to show the weight change trend previously reported. Nioblum and nioblum alloys are readily contaminated, even during short exposure times at $1148 \mathrm{C}$. The weight gain of the niobium also appears to be independent of successive loop "startups." 
Nioblum and niobium alloys absorb oxygen and/or nitrogen during model gas loop exposure; such contaminated specimens show increased strength and reduced ductility. Pure refractory metals exhibit surface metal contamination ( $\mathrm{Cr}, \mathrm{Mn}$, Fe) after exposure in the vertical test section of the model gas loop. Nickel-base alloys also exhibit surface contamination or reaction as a result of model loop exposure in the vertical test section.

Two reports on thermally activated flow in iron have been completed during this period, one for presentation at the Battelle colloquium on Dislocation Dynamics and the other for submission to a journal.

A document, "Desıgn and Calibratıon of a Hıgh Pressure X-Ray Cell," has been approved for publication. An in-reactor, highpressure hydrostatic cell has successfully completed 60 days of testing at $17 \mathrm{kbars}$. High pressure forms of $\mathrm{Zr}$, InTe, and $\mathrm{PbF} 2$ have been produced and quenched to ambient conditions. Calibration of the High Pressure "Belt" system to $60 \mathrm{kbars}$ has been completed. An unknown compound and/or alloys of $\mathrm{MO}, \mathrm{Ta}, \mathrm{NaK}$, and 303 stainless steel have been formed at $20 \mathrm{kbars}$ and $900 \mathrm{C}$.

\section{ATR Gas Loop Operation and Malntenance}

T'ests are being designed to determine neutron flux levels for the A'T Gas Loop. Mockups of the gas loop in-reactor pressure tube wlll be used in the ATR critical facllity for these tests.

Analytical instrumentation for the ATR loop is progressing and measurements of less than 1 ppm total impurities are now possible using ATR instruments.

Several meetıngs have been held with gas loop vendors to guarantee quality control and section III compliance on all pressure bearing components.

\section{Metallic Fuels Development}

The successful irradiation of three tubular fuel elements of Th - 2.5 wto $U-1.0$ wto $\mathrm{Zr} \mathrm{clad}$ with $\mathrm{Zr}-2$ continued in the $\mathrm{P}-7$ hot water loop at the ETR. The estimated exposures at the end of the current cycle range from 8900 to 18,100 MWd, tonne.

Hollow core uranium fuel elements being tested in the ETR M- 3 water loop continue to operate successfully in their fourth reactor cycle of irradiation. Estimated maximum exposure at the conclusion of this cycle will be 4200 MWd/tonne. 
Fast Reactor Dosimetry and Damage Analyses

A variety of candidate flux monitor materials has been irradiated in two low-power tests in the EBR-II and returned to Pacific Northwest Laboratory for analysis. Preliminary evaluation of these low-power tests indicate that nickel, iron, scandium, copper, and cobalt will function as effective flux monitors. Spectral calculations and spectral-averaged activation cross sections are now available, and the large body of experimental data is being reduced and analyzed.

\section{ENGINEERING DEVELOPMENT}

\section{Neutron Flux Monitors}

Evaluation of the improved $\mathrm{U}-234$ - U-235 regenerative thermal neutron flux detectors in a test faclilty at ETR moved toward realization with acquisition of eight of the ten needed detectors and design completion of the test assembly.

$\frac{\text { Microwave and Infrared Detection of Coolant Impurities }}{\text { and Measurement of In-Reactor Temperatures }}$

Three chopper wheels for the experimental hygrometer, to be used in infrared detection of moisture in helium gas, were successfully fabricated and tested.

\section{PLUTONIUM UTILIZATION PROGRAM}

Fuels Development

Maximum fuel temperatures of approximately $1800 \mathrm{C}$ and $2300 \mathrm{C}$ were achieved in pelleted and vibrationally compacted $\mathrm{UO}_{2}-\mathrm{PuO}_{2}$ fuels, respectively, in FRTR.

The results of zero power tests in the PRTR, physics calculations, and thermal hydraulics studies indicate that the present 8-rod FERTF test element design will provide the flexibility required to achieve the objectives of the fuels testing program planned for the FERTF.

Two fuel elements containing four fuel rods instrumented to measure fuel rod plenum temperature and pressure were charged into PRTR. The instrumentation functioned satisfactorily at various power levels up to $35 \mathrm{MW}$--the maximum power level obtalned by the reactor. 
A study was initiated to determine minimum enrichment requirements in future thermal reactor-type TREAT test capsules, and still achleve the destruction energy levels desired.

Isotopic analyses were completed upon the Shippingport samples, and analyses are continuing on the Yankee samples.

Three PRTR fuel rods containing cold pressed and sintered mixed oxide pellets are being procured from a commercial fuel fabricator.

A 7-rod cluster, intentional defect test to be performed in the ETR P-7 loop was designed. The irradiation conditions proposed for this experiment in ETR are approximately the same as the conditions that are ultimately plannea in the FERTF testing program in PRTR.

\section{Reactor Physics}

Further measurements have been made of the effect of varlations in the makeup of the FERTF test element upon the power generation in the rods in the element.

Experiments using the reactivity oscillator have been completed in PR'TR. Measurements of reactor nolse were not successful.

A burnup calculation has been performed for a metallic thoriumfueled loading in the PRTR.

Calculations have been made to determine the sensitivity of effective cross sections to changes in cell characteristics for a PRTR cell fueled with plutonium-aluminum 19-rod clusters.

Eleven sets of data have been successfully fitted using an empirical fitting formula for critical mass data.

Attempts have not been successful to flt burnup data from Yankee reactor using the least-squares analysis method which assumes the cross section ratios are constant with exposure.

Fabrication of an initial quantity of about 250 rods of $\mathrm{UO}_{2}$ 4 wts $\mathrm{PuO}_{2}$ has been initiated.

Theory-experiment correlation studies for $\mathrm{UO}_{2}-2$ wto $\mathrm{PuO}_{2}-\mathrm{UO}_{2}$ lattices contınued. Calculations have been made of power sharing and the temperature coefflcient of reactivity. The calculated results are compared to measured values.

Approximately 30 PRCF fuel rods were opened, and the fuel material in them was used to load 49 similar rods to be used in a PCTR experiment. 
Work continued on the preparation of $\mathrm{PuO}_{2}$ particle fuels. Plasma spheroidized $239 \mathrm{PuO}_{2}$ is being prepared using several types of feed particles.

Substantial ımprovements were made at a number of stages in the treatment of neutron cross section data, including improvements In the data evaluation codes UNICORN and CHAD, improvements in the quality of data for thirteen isotopes, improvements in the data processing code BARNS II, and improvements in the library of the slowing down code HRG. In addition, adaptation of a number of codes associated with the ENDF/B library system to the UNIVAC 1107/1108 was started.

Reactor Engineering Development

Development of a digital computer code for preliminary design of BWR's and PWR's is essentially complete. Future efforts will be directed toward applications related to optimum plutonium utilization in commercial water reactors. Simultaneously, a coordinated program to develop a more detalled design code has been started.

A report was issued presenting the results of an analysis of the thermal operating limits for an 8-rod fuel element to be irradiated in the FERTF. These limits were based upon the criterion of avoidance of both bulk boiling and boiling burnout.

\section{Materials Development}

Tube \#5690 has been pi taped and cut up in the PRTR basin. The pi taping indicated that there was about a three-mil growth in the irradiated region of the tube. A 3/4" crack propagation test was run at $150 \mathrm{C}$ and $275 \mathrm{ppm}$ hydrogen and showed no weakening of hoop strength due to increased hydrogen.

Metallographic examination of oxide thicknesses and hydrogen distributions is complete for PRTR Tube 5696. Postirradiation examination is under way in Radiometallurgy on Tube 5690. Hydrogen analyses of tubular Zircaloy-2 and Zircaloy-4 specimens (Test 72) exposed in the PRTR indicate relatively low in-flux hydrogen pickups except in the case of Zircaloy-2 specimens prefilmed to prebreakaway weight gains.

\section{Cycle Analysis}

Considerable activity was devoted to code development and cross section library updating used in fuel cycle analysis. The possibility that metallic thorium may allow higher specific power than $\mathrm{U}_{2} \mathrm{O}$ is being examined to see if this would allow a more economic use of 
$\mathrm{D}_{2} 0$ reactors which together with the crossed progeny fueling system may lead to a particularly important application for advanced converters prior to fast breeder reactor buildups.

\section{Test Reactor Operation}

The PRTR operated to 50 MW to produce 226.16 MWd during April. Four of the Batch Core Power Tests were completed, and two others were partially completed. The Critical Tests 14-4 and 14-5 for the 8-rod FERTF fuel element were completed. Alr activities and radiation readings, whlch might result from any residual fuel debris, were much lower than expected.

Axial peaking factors, at a power level of $45 \mathrm{MW}$ and at moderator level of 97.5 and 99.0 inches, were measured as 1.29 and 1.288 , respectively. Boron removal at a rate of 50 pounds of moderator $\mathrm{D}_{2} 0$ per minute through the ion exchange unit was easily controlled by the automatic controller. An excessive rate of injection of boron--20 pounds of makeup solution per hour--resulted in a slight overcompensation by the automatic controller.

Preliminary results indicate a fuel coolant temperature coefficlent of about $-1.9 \times 10^{-5} \Delta \mathrm{k} / \mathrm{F}^{\circ}$ for temperature range from 180 to $350 \mathrm{~F}$.

The rupture loop was reactivated and operated satisfactorily under FERTF Test. \#22.

\section{EBWR Demonstration Program}

whe last EBWR, VIbrationally compacted $\mathrm{UO}_{2}-\mathrm{PuO}_{2}$ capsule was discharged from the MTR. The Zircaloy-clad $11.07 \mathrm{~cm}$ OD capsule which initially operated with an estimated maximum linear power of about $15 \mathrm{k}$ /ft was in the MTR for 925.7 effective full power days and

attained an estimated burnup of 26,300 MWditonne.

\section{NUCLEAR SAFETY}

\section{Containment Systems Experiment (J. M. Batch)}

The amount of condensate held on the walls of the stainless steel tank in the Aerosol Development Facılıty was measured as 500 ml under equilibrium conảensation conditions. Retention of elemental lodine on various particle filter media was measured as part of the continuing program of evaluating Maypack performance uncier conditions of representatıve contalnment vessel atmospheres. Two potential methods of generating a barıum aerosol were tested, and the direct evaporation 
of barium metal in a helium sweep gas was determined to be most suitable for CSE use. Two blowdowns were performed with the reactor simulator vessel to evaluate instrument performance. In both runs cold water was expelled by a 600 psig nitrogen dome. The data from the total welght load cell and liquid level probe on weight of water versus time agreed well with calculated values.

\section{Radroactive waste Solidification}

Although other solids present in $\mathrm{PW}-2$ feed solutions are about as voluminous as the sodium rare earth sulfates present, the latter appear responsible for caking and plugging problems experienced with the feed.

Design verification tests of the phosphate glass unit showed the PW-2 flowsheet and equipment acceptable for radioactive operation. Confirmation of $\mathrm{PW}-1$ flowsheets remains.

A run was made with a $\mathrm{PW}-2$ flowsheet, an internal mix spray nozzle, and alr atomization. The calcine and powdered $\mathrm{NaPO}_{3}$ were added directly to the receiver pot, and the melting of the calcine was performed in the receiver pot. The primary objective of the run was to achieve an operating condition wherein there would be no deposition and accumulation of scale in the calclner; a secondary objective was to explore the feaslbility of melting directly in the receiver. The principal purpose of the run was successful since there was only a thin film of dry, powdery calcine throughout the calciner at the conclusion of the run. Erratic flux addition caused nonuniform and incomplete melting toward the end of the run. Nothing occurred, however, to disprove the approach of melting directly in the receiver, and this technique will be investigated further.

The helium leak check system for radioactive pots was successfully tested, and final leak checking of pots can be started.

Haynes LT-1B cermet ( $59 \mathrm{Cr}-20 \mathrm{Mo}-19 \mathrm{Al}_{2} \mathrm{O}_{3}-2 \mathrm{TlO}_{2}$ ) showed good resistance to $\mathrm{PW}-1$ and $\mathrm{PW}-2$ melts when exposed at $1000 \mathrm{C}$.

Acid descaling of the WSEP spray calciner was completed. Unit was started on a run at month end.

\section{Intermediate Level Waste Treatment}

Experiments are continuing on the development of a scavengingIon exchange model for hydrous oxides. Results show that for hydrous manganese dioxide $\mathrm{Cs}^{+}$exchange with $\mathrm{Na}^{+}$and $\mathrm{K}^{+}$on the hydrous oxide obeys the law of mass action. 
Fission Product Aerosol Containment

Airborne methyl iodide removal was $99 \%$ in two experiments in which 6.3 and 8.6 wto hydrazine was sprayed into a $3.7 \mathrm{~m}^{3}$ chamber containing methyl iodide, steam, and air during six hours of solution recirculation.

The reaction between methyl iodide and hydrazine at low concentrations of hydrazine was found to be first order with respect to methyl iodide over a 300-fold range of methyl iodide concentrations.

\section{Disposal of Reactor Off-gas into Soil systems}

Computer programs were modified to accommodate the variable grid spacing necessary for economical solution to the heterogeneous (layered) soils problems at the NRTS site.

\section{Geophysical Exploration of Rattlesnake \#l Well}

Some temporary contractual problems were encountered concerning Rattlesnake Hills \#l Well re-opening, cleanout, and mud reconditioning. These are being resolved, and it is anticipated that the work will proceed at a rate which will allow accomplishment in this fiscal year.

\section{Columbia River Sedimentation Studies}

Measurements of radionuclide concentrations in water and suspended sediment at various depths in the columbia River estuary showed that they were distrubuted as expected except where the salt water wedge underlying the estuary was encountered. This wedge diluted the concentrations of most radionuclides; however, the salt water contained a higher concentration of Cs-137 than did the overlying fresh water.

Simulation Modeling of Expected Thermal Generation in Selected River Systems

Evaluation of the effects of Dresden 2 and 3 on the upper Illinois River indicate significant temperature effects in the river a considerable distance downstream.

\section{Pressure Vessel Crack Monitoring}

Development continued on a system to detect crack growth and metal overstress by acoustic emission. Data derived from ductile 
failure of two burst test specimens, showed better definition between the various stages of acoustic emission than had been observed with flat plate specimens of similar materials. Observed signals occurred as sparodic emission bursts starting at about 50\% of fallure pressure; continuous emission with occasional bursts at $70 \%$ of failure; and a profusion of burst signals which started at 90\% of failure and continued through to specimen failure. Twelve reusable, fuzed quartz, substrate elements have been completed for use in fabrication of multilayer electrostatic transducers. These units are expected to be ready for lab evaluation during the next month. Two commercial, low noise amplifiers are being evaluated for possible incorporation into the acoustic emission system. 
DIVISION OF REACTOR DEVELOPMENT AND TECHNOLOGY PROGRAMS (F. W. Albaugh)

CIVILIAN POWER REACTORS

Liquid Metal Fast Breeder Reactor

Stoichiometry Effects in oxide Fuels (R. E. Nightingale)

Irradiations to investigate the effects of oxygen migration and stolchiometry on heat transfer in oxide fuels operating near but below center melting are in progress. This work is an extension of experiments on $\mathrm{UO}_{2}$ fuel elements operating with center melting. Uranium dioxide fuel powders with $\mathrm{O} / \mathrm{U}^{\prime} \mathrm{s}$ of $1.90,2.00,2.02,2.05$, and 2.15 were synthesized and are ready for pneumatic impaction into integrally clad irradiation specimens.

Standard reliability was established by simultaneously irradiating two, $\mathrm{UO}_{2} .00$ specimens in the two planned capsule positions. The heat rating required for melting, as determined from postirradiation metallography, differed for the two specimens by less than 5\%, thereby justifying the assumption of identical fluxes in the two positions. This work on $\mathrm{UO}_{2}$ will establish standard procedures for work on mixed $\mathrm{UO}_{2}-\mathrm{PuO}_{2}$ materials.

Experiments to study effects of stoichiometry, heat rating, density, and fabrication method on heat transfer in $\mathrm{UO}_{2}-\mathrm{PuO}_{2}$ under exactly reproducible peak and average neutron flux conditions were continued. The initial series of six experiments will investigate stolchiometry effects (O/M's of $1.92,1.97,1.99$, and 2.00) on the heat rating required for melting in 95\% dense, mechanically mixed $\mathrm{UO}_{2}-$ 25 wto $\mathrm{PuO}_{2}$. Two heat rating levels will be achieved by using two different fuel diameters. The first draft of the design-drawing package was completed and forwarded to DUN project engineering for comments. A request for production test approval was completed by DUN and is being circulated.

Mixed Oxide Fuel Fabrication (W. E. Roake)

Equipment modifications and relocations have been completed to establish an integrated mixed $\mathrm{UO}_{2}-\mathrm{PuO}_{2}$ pellet fabrication facility. This new hood line is equipped with an automatic pellet press to facilitate fabrication of pellets for full size, EBR-II subassemblies. Each $37-p i n$ subassembly will require 2000 pellets representative of the proposed fabrication process for FFTF driver fuel.

This new facility will be available for fabrication of irradiation test fuel as soon as the hood air balance and flow control is established. 
The molbydenum heating element for the Harper sintering furnace was replaced. A furnace run to obtain thermocouple calibration curves was completed.

Fabrication of $\mathrm{UO}_{2}$ and $\mathrm{UO}_{2}-25$ wt: $\mathrm{PuO}_{2}$ pellets included:

- Completion of 27,000 depleted $\mathrm{UO}_{2}$ pellets for flow test pins and a 169-rod full size subassembly.

- Three-hundred-fifty cored, high density $\mathrm{UO}_{2}$ 25 wt: $\mathrm{PuO}_{2}$ pellets.

- one-hundred-fifty $\mathrm{UO}_{2}$ - 25 wto $\mathrm{PuO}_{2}$ (nominal 这" diam.) pellets for evaluating thermal conductivity as a function of $\mathrm{O} / \mathrm{M}$.

Design of the FFTF driver fuel pin and subassembly requires a thorough analysis of the mechanical characteristics. Vibration modes of the individual pins is one of the required analyses.

Two full scale fuel pins were tabricated for vibrational studies of the effect of wire wraps. The pins were loaded with depleted $\mathrm{UO}_{2}$ pellets and plenum hardware.

Irradiation Testing of Cermet Pins (W. E. Roake)

Destructive examination of two PuO2-SS cermet pins irradiated in EBR-II subassembly X009 was begun. Samples of the helium cover gas contalned no fission products. This indicates that cladding integrity was maintained during irradiation. Pin measurements were completed, and cutting of burnup and metallographic samples is in progress.

Mixed Oxide Fuel Irradiations (W. E. Roake)

Fabrication of $18 \mathrm{mlxed}$ oxide restrictor screening capsules to be irradiated in the VH-4 facility of the MTR was completed. Irradiation wili begin during MTR cycle 259. These capsules are designed to operate at a power generation of $28 \mathrm{~kW} / \mathrm{ft}$. At this power generation, the fuel is expected to be molten to approximately $50 \%$ of the radius. Information from these tests will be used to determine the effectıveness of various fuel motion restrictor materials and restrictor designs. The following table specifies restrictor materials and geometries. 


\section{Restrictor Information}

\begin{tabular}{|c|c|c|c|}
\hline BNW-1- & Material & Geome try & Remarks \\
\hline 19 & Tungsten & Hole & Fixed \\
\hline 20 & $304 \mathrm{SS}$ & $"$ & " \\
\hline 21 & Molybdenum & $"$ & $"$ \\
\hline 22 & Tungsten & $"$ & Floating \\
\hline 23 & $304 \mathrm{SS}$ & $"$ & " \\
\hline 24 & Molybdenum & $"$ & $"$ \\
\hline 25 & Nickel & $"$ & $"$ \\
\hline 26 & Tungsten & Grooved & Fixed \\
\hline 27 & $304 \mathrm{SS}$ & $"$ & " \\
\hline 28 & Molybdenum & $"$ & $"$ \\
\hline 29 & Tungsten & $"$ & Floating \\
\hline 30 & $304 \mathrm{SS}$ & $"$ & " - 2 \\
\hline 31 & Molybdenum & $"$ & $"$ \\
\hline 32 & Nickel & $"$ & $"$ \\
\hline 33 & $\mathrm{ZrO}_{2}$ & Solid Pellet & t " \\
\hline 34 & $\mathrm{ThO}_{2}$ & " " & $"$ \\
\hline 35 & Depleted $\mathrm{UO}_{2}$ & $"$ & $"$ \\
\hline 36 & None & -- & Reference \\
\hline
\end{tabular}

Fuel Swelling (W. E. Roake)

An in-depth review was made of swelling and growth in mixed oxide fuel due to the accumulation of gaseous and solid fission products. This analysis of existing data and their application to the FFTF driver fuel design led to the following conclusions:

a. Based on the available data, a reference FFTF driver fuel design that would confidently be expected to attain an average burnup of 45,000 MWd/tonne without cladding deformation due to fuel swelling would have:

1) Cold fuel smeared density of $88 \% \mathrm{TD}$,

2) Cold fuel cladding diametral gap of $6 \mathrm{mils}$, and

3) Cold solid pellet density of 93\% TD.

These parameters are based on a cladding inside diameter of 0.218 inch and an average burnup of 45,000 MWd/tonne at a rod power of $8.73 \mathrm{~kW} /$ ft (core average). Further, the premise assumes no fuel cladding mechanical interaction occurs until the end-of-life.

b. Swelling data directly applicable to FFTF fuel design are extremely limited. The most applicable data seem 
to be the very limited and incomplete information obtained under the US/UK Fast Reactor Exchange Program.

c. The apparent inconsistency between the British mixed oxide swelling data and the GE/APO data seems to arise from the large differences in fuel temperatures. It is concluded that swelling, as manifested by cladding deformation, is quite sensitive to temperature.

d. No satisfactory model development for describing swelling and growth in mixed oxide fuel at high burnups exists.

e. The British data indicate that there is not a satisfactory correlation between fuel form (vibrationally compacted versus high density and annular pellet) and swelling.

f. The available data suggest that swelling, as manifested by cladding deformation, can be controlled by stronger claddıng, increased fuel cladding gap, or higher fuel temperatures.

Evaluation of the swelling expected in the peak FFTF fuel pin (15 kw/ft, 75,000 Mwd/tonne burnup) indlcates that the swelling will be accommodated by the same design used for the average pin. Uncertainties in this case are greater than those for the average rod since the applicable data in this region are more limited. British data at 61,000 MWd/tonne burnup and GE/EPO data at 100,000 MWd/tonne burnup indicate that 75,000 MWd/tonne peak burnup in FFTF driver fuel should be attainable without cladding deformation.

Based on the results of the study, tests involving larger fuel cladding gaps and annular pellets were defined for the irradiation testing program. The following table lists the fuel parameters for these tests.

\section{Alternate Fuel Parameters for Irradiation Testing}

\begin{tabular}{lccc} 
Fuel Form & $\begin{array}{c}\text { Pellet } \\
\text { Density, }\end{array}$ & $\begin{array}{c}\text { Smeared } \\
\text { Density, TD }\end{array}$ \\
\cline { 1 - 1 } Solid pellet & 89.9 & 85 \\
Solid pellet & 91.6 & 85 \\
Annular pellet & 96 & 85
\end{tabular}

Fuel Cladding

Gap, mils
6
8
6 ipellet ID
$=54 \mathrm{mils}$

Testıng will be accomplıshed in 37-pın (unencapsulated subassemblies in EBR-II. 
EBR-II Irradiation Tests (W. E. Roake)

Drawings of the fuel motion restrictor test specimens and capsules for encapsulated irradiations in EBR-II were reviewed and approved. Procurement of components was begun.

Design and analysis of the (GETR/TREAT) capsules for steady state irradiation of prototypic length fuel specimens in a thermal flux followed by transient irradiation in the TREAT facility were continued. A capsule design review meeting disclosed the need for only minor revisions of the drawings prior to approval and issue. Procurement of long-lead time items was started.

\section{Nuclear Systems and Concepts Analysis (E. A. Eschbach)}

Systems Analysis Task Force Activities

Successful introduction of coal plants into the linear programming model was demonstrated. As expected from the relatively high cost assumptions used for even the most economical coal plants in the model, only a token number were included in the optimal solution reached. A better representation of the costs of fossil plants is being prepared.

The modification of the LP model to simplify the calculations and decrease computation time is complete. The coefficients in the "condensed" problem have been hand checked by back tracking to the "full" problem and found completely consistent. Comparison of the two models are shown in the table:

\begin{tabular}{|c|c|c|}
\hline & $\begin{array}{c}\text { Full } \\
\text { Problem } \\
\end{array}$ & $\begin{array}{c}\text { Condensed } \\
\text { Problem } \\
\end{array}$ \\
\hline Rows (Equation) & 983 & 481 \\
\hline Columns (Variables) & 1,451 & 947 \\
\hline Coefficients & 110,615 & 33,486 \\
\hline Initial Infeasibilities \& & & \\
\hline Artificials & 393 & 215 \\
\hline Total Iterations Needed to Optimize* & 1,420 & 1,921 \\
\hline $\begin{array}{l}\text { Total Computation Time, Hrs. } \\
\text { Iterations/Hr. }\end{array}$ & $140^{9 \frac{1}{2}}$ & $300^{6 \frac{1}{2}}$ \\
\hline
\end{tabular}

ॠ Many iterations were probably saved by starting the full problem from a previous optimal basis. The condensed problem was started from scratch. 
In previous calculations, it was assumed that end effects in the model could be approximated by (1) considering a model representing a period lasting 20 years further into the future than the period of particular interest to the task force, and (2) accounting, in the last year of the model, for the life remaining after the end of the period of all reactors in operation at the end of the period. The effects of these assumptions have been checked by recalculation of the results for periods ending in 2038, 2028, and 2018. The end effects perturb the solution during the last ten years of the period noticeably but on ly incidentally more than about 16 years before the end of the period.

Major modifications of the computer code, LPOUT, are nearing completion. LPOUT now provides a title page, table of contents, glossary of reactor codes, data by reactor type ifor reactors considered for the solution, reactor and material costs, reactor power cost (Mll $\mathrm{ls} / \mathrm{kWhj}$, and reactor performance data), data by year and. reactor type ltor reactors built in the optimal solution--capacity bullt, capacity operating (glgawatts), and capacity operating $1 \%$ of total capacity). These modifications are now being debugged.

Reactor Systems Analysis

The three cost breakdowns currently furnished by POWERCO have been verıfıed for accuracy.

The PACTOLUS and POWERCO program complexes are being modified to Include state and local taxes, equipment replacements, and property insurance. Adding these costs is expected to make the calculated results compatible with other power cost analyses.

Analysıs of Sodıum Coolant Systems

The Westinghouse and Allis-Chalmers fast reactor designs have been run through PREPY4 (a fast reactor core designs model) successfully. The next step will be to use this output from PREPY 4 as input for both PYRE (a code which collapses 26-group cross section to 4groups) and ALTHAEA (a 4 -group burnup code). Two other fast reactor designs are being modeled at the present time--the General Electric and Combustion Englneering designs. It is anticaipated that there will be trouble in modeling the pancake core of the General. Electric designs because of the one-dimensional limitations of ALTHAEA. 
Conceptual Reactor Design Studies (J. C. Fox)

Steam-Cooled Fast Reactor

The calculations in the MIMIC design analysis simulation, which adjust the number of subassemblies in the core to yield the desired maximum clad temperature, have been debugged. The simulation will not yield reactors which precisely meet the constraints at each time step when some variable such as core volume is swept. The accuracy is adequate for purposes of selecting approximately optimum design and operating parameters. However, to get detailed comparison of a specific design, the approach which will probably have to be used is to make an initial condition sweep and then use the reactors from such a sweep as initial conditions for a second run. This second run would give the simulation time to remove the errors in each reactor and yield reactors meeting the constraints.

The simulation is presently being used in a limited sensitivity study to detect any additional bugs in the simulation and to get a feel for how the reactor designs are changed by varying certain parameters.

The design of fuel cladding for steam-cooled fast reactor was reviewed and discussed with GE-APO and $B \& W$ personnel. As a result of these discussions, the calculations used in the design simulation will be modified to reflect different allowable stresses of Incoloy 625 and to eliminate arbitrarily penalizing large diameter pins.

The initial set of parametric cases as shown in the table was completed using ORNL cross sections. Large differences between these results and the earlier results using PNL data have led to a reevaluation of the survey. As a result of this re-evaluation, several of the survey assumptions have been altered.

\begin{tabular}{|c|c|c|c|c|}
\hline & Fuel Volume & 45 & 30 & 15 \\
\hline & Steam Volume & 40 & 55 & 70 \\
\hline 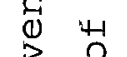 & structure V. & 15 & 15 & 15 \\
\hline$-1 m$ & 0.367 & $1 a$ & $2 a$ & $3 a$ \\
\hline$\underbrace{E}_{0} \underbrace{4-1}_{-0}$ & 1.18 & $\mathrm{lb}$ & $2 \mathrm{~b}$ & $3 \mathrm{~b}$ \\
\hline 虫 & 2.83 & IC & $2 \mathrm{C}$ & $3 c$ \\
\hline
\end{tabular}

The 3 series with 70 vol\% steam has been dropped, and a 0 series wlth 25 volo steam has been added. The old blanket thickness of $25 \mathrm{~cm}$ has been increased to $95.7 \mathrm{~cm}$ or 18 inches. An iron reflector or shield has been added. Depleted uranium containing 0.25\% U-235 11980 condition from D. Deonigi) replaces the straight U-238 in both core 
and blanket. Inconel-625 wlll be used for all structures. A pin diameter of 0.276 inch or $0.701 \mathrm{~cm}$ replaces the homogeneous assumption. The range of core sizes has shifted somewhat with 60001 , 80001 , and 10,0001 replacing $67121,10,0791$, and 13,4791 .

The selection of one initial reactivity for all conditions will be replaced by an as yet to be determined scheme. The following section illustrates the need for a new method of determining initial enrichment.

Computations had been made for nine cases, lA through $3 \mathrm{C}$, which gave the enrichment and total breeding ratio. The assumption was made that the initial value of $k_{\text {eff }}$ was 1.1 for each case.

It was telt that this value did not allow valid comparisons to be drawn, For systems with a core breeding ratio greater than unity, it required a higher enrichment than needed. For systems with a low core breeding ratıo, it would not provide the required burnup.

An attempt was made to obtain a better comparison by calculating each case on the basis of lts own reactivity requirements rather than using one initial value for all. Values of core and total breeding ratios calculated with ORNI cross sections at two or more values of enrichment were available for each case.

The given enrichment was used to interpolate a value of the core breeding ratio for the case. If the core breeding ratio was greater than unity, the enrichment was decreased to give an initial keff of 1.01, an initial value, it was felt, would allow sufficient margin for operatıons. The formula used for this was:

$$
\Delta \mathrm{k}=\frac{r-1}{r_{1}} \frac{\Delta M}{M}
$$

where $\mathrm{k}$ is the variation $1 \mathrm{n}$ reactivity, the effective eta of the fuel, $M$ the mass of the fissile fuel, and $\Delta M$ the variation in the fissile fuel mass, and 1 s taken from Astley, et al, ANL-7120. (r-1)/r was approximated as 0.5 and $\triangle M$ as (M-M') where $M^{\prime}$ was the new mass of fissile fuel. Since it made no difference and was considerably handier, enrichments were used instead of masses. Values of core and total breeding ratios were interpolated for the new concentrations. This calculation implies that a system whose core breeds will not be limited by reactivity until its fertile material has been consumed.

Cores with breeding ratios less than unity were calculated on the basis of providing an average burnup of 50,000 MWd/tonne. The mass of fissile material was calculated using an assumed density of $9.13 \mathrm{gm} / \mathrm{cm}^{3}$ times the enrichment. The change in fissile mass was calculated using the required burnup, the fissile mass, and a figure of $1 \mathrm{gm}$ fissile material per $\mathrm{MWd}$. The change in reactivity due to 
burnup was that given by the previous equation multiplied by $\left(1-B_{C}\right)$. This was added to the required 1.01, and the following calculations were identical to those for cores with breeding ratios greater than unity.

\begin{tabular}{|c|c|c|c|c|}
\hline Case & $\begin{array}{c}\mathrm{k}_{\mathrm{eff}} \\
\text { Initial }\end{array}$ & $\begin{array}{l}\text { Enrichment } \\
\circ \text { Fissile } \\
\end{array}$ & ${ }^{B R}{ }_{C}$ & $\mathrm{BR}_{t}$ \\
\hline $1 \mathrm{~A}$ & $\begin{array}{l}1.10 \\
1.01\end{array}$ & $\begin{array}{l}12.4 \\
10.5\end{array}$ & 1.168 & 1.097 \\
\hline $1 \mathrm{~B}$ & $\begin{array}{l}1.10 \\
1.012\end{array}$ & $\begin{array}{l}11.5 \\
10.0\end{array}$ & 0.9767 & $\begin{array}{l}0.982 \\
1.1007\end{array}$ \\
\hline $1 \mathrm{C}$ & $\begin{array}{l}1.10 \\
1.015\end{array}$ & $\begin{array}{r}10.3 \\
8.8\end{array}$ & $=0.7985$ & $\begin{array}{l}0.875 \\
>0.8879\end{array}$ \\
\hline $2 \mathrm{~A}$ & $\begin{array}{l}1.10 \\
1.01\end{array}$ & $\begin{array}{l}15.5 \\
13.2\end{array}$ & 1.054 & $\begin{array}{l}0.920 \\
1.216\end{array}$ \\
\hline $2 B$ & $\begin{array}{l}1.10 \\
1.017\end{array}$ & $\begin{array}{l}14.5 \\
12.5\end{array}$ & 0.8519 & $\begin{array}{l}0.833 \\
0.980\end{array}$ \\
\hline $2 \mathrm{C}$ & $\begin{array}{l}1.10 \\
1.018\end{array}$ & $\begin{array}{l}13.3 \\
11.5\end{array}$ & 0.756 & $\begin{array}{l}0.761 \\
0.8571\end{array}$ \\
\hline $3 \mathrm{~A}$ & $\begin{array}{l}1.10 \\
1.026\end{array}$ & $\begin{array}{l}28.3 \\
24.8\end{array}$ & 0.614 & $\begin{array}{l}0.537 \\
0.730\end{array}$ \\
\hline $3 B$ & $\begin{array}{l}1.10 \\
1.025\end{array}$ & $\begin{array}{l}25.7 \\
23.5\end{array}$ & 0.571 & $\begin{array}{l}0.540 \\
0.679\end{array}$ \\
\hline $3 C$ & $\begin{array}{l}1.10 \\
1.025\end{array}$ & $\begin{array}{l}22.1 \\
19.3\end{array}$ & 0.529 & $\begin{array}{l}0.547 \\
0.613\end{array}$ \\
\hline
\end{tabular}

Thermal Sink Limitation Study

Volumes 6-B, Missouri River Basin, and 9, Colorado River Basin, of the United States Geological Survey Water Supply Papers, "Compilation of Records of Surface waters of the United States," have been obtained.

This completes the 20 volume series of stream flows for the United States, including Alaska and Hawaii. 


\section{USAEC-AECL Cooperative Program (J. J. Cadwelli}

In-Reactor Measurements of Creep in $\mathrm{Zr}-2.5 \mathrm{Nb}$ Alloy

Data obtanned on $1 \mathrm{n}$-reactor creep rates at $300 \mathrm{C}$ and $25.6 \mathrm{~kg}-\mathrm{mm}^{-2}$ (36,500 psi) stress have conflrmed the validity of a previously obtained, questionable value. The earlier obtained value was questionable because it may pertain only to transient creep. However, a value of $4 \times 10^{-7} \mathrm{hr}^{-1}$ has recently been observed under conditions where sufflclent creep in the specimen occurred at higher stresses and temperatures to place the specimen well into second stage creep. This. value $1 \mathrm{~s}$ the same as that reported previously, namely, $4 \times 10^{-7} \mathrm{hr}^{-1}$. Thıs rate represents an increase of creep rate over the $1.5 \times 10^{-7} \mathrm{hr}^{-1}$ observed earlier for the unirradiated control test. Because the creep rate for the control test may have been obtained during transient creep only, lts value during second stage creep will be established when the conditions for second stage creep have been met.

In-Reactor Corrosion of Zirconium Alloys

The final quadrants 1233 and 234 , from the FY-1967 USAEC-AECL Cooperative Program are scheduled for discharge from the ETR G-7 loop near the end of April. On two occasions during the 8-cycle exposure oxygen analyses were above $0.05 \mathrm{ppm}(0.06$ and $0.10 \mathrm{ppm}$ ). Otherwise, water chemistry control was satisfactory. No fuel element failures occurred in the companion $\mathrm{M}-3$ loop during the 8-cycle exposure. One loop decontamination was performed during the 8-cycle exposure, two cycles prior to discharge. The specimens were removed from the loop during decontamination and flushing.

Quadrants 233,234 , and 243 will be delivered to BattelleNorthwest for postirradiation examination early in May.

Cross Flow Mixing Between Parallel Flow Channels During Boiling

The purpose of this program is to develop methods of predicting cross channel mixing during two-phase flow in rod bundle fuel elements. This information is important in the analysis of fuel element performance and the determination of operating limits from the boiling burnout standpoint. This program consists of two phases, an analytic phase and an experimental phase. A major part of the analytic phase has been completed, and a report was issued presenting the results (BNWL-371). The experimental phase is still in progress.

In the experimental phase of the program, electrically heated test sections of two types are being considered. The first type simulates two adjacent subchannels formed by rods on a square array located adjacent to rods on a trianguiar array. Earlier, experiments 
were performed on a test section of this type. Measurements were made of subchannel flow rates and exit enthalpies, and this information was used to determine cross-flow mixing during boiling. The results showed that with a simulated rod spacing of 0.084 inch, mixing during boiling was doubled over the nonboiling case; however, for a spacing of 0.020 inch, no significant improvement in mixing was observed. A report describing and analyzing these results is under preparation.

During the current month experiments were completed on the second type of electrically heated test section. This test section simulated two adjacent flow channels formed by fuel rods on a square array. Because the two channels had equal flow areas and heat inputs, the only significant mixing that occurred was the result of turbulent mixing through the gap between the two channels. The amount of mixing occurring over the length of the test section was measured by injecting tracers into the inlet stream of one of the two parallel channels and measuring the tracer concentrations at the exits of the channels. Two tracers were used--heavy water and lithium hydroxide. The heavy water tracer was used to determine the total mixing of both phases between the adjacent channel during boiling. The concentration of heavy water in the samples taken at the exits of the channels was measured by means of infrared spectrophotometry. This technique compares the infrared absorption band of hydrogen-deuterium against a predetermined standard. The lithium hydroxide tracer provided information on mixing between liquid phases only, because it remains in the liquid phase during vaporization. Ilthium ion concentrations were measured by flame photometry. This technique compares the emission of excited lithium to a laboratory standard.

Experiments were performed with simulated rod spacings of 0.084 inch and 0.020 inch. With a simulated spacing of 0.084 inch, experiments were performed at 750 psia $(490 \mathrm{~F}(255 \mathrm{C})$ inlet temperature) with mass velocities of 1,2 , and $3 \times 10^{6} \mathrm{lb} / \mathrm{hr}-\mathrm{ft}^{2}$ and heat fluxes up to $0.4,0.5$, and $0.55 \times 106 \mathrm{Btu} / \mathrm{hr}-\mathrm{ft} 2$, respectively. Data were also taken at a pressure of 400 psia $1420 \mathrm{~F}(215 \mathrm{Cl}$ inlet temperature) at mass velocities of 1 and $2 \times 10^{6} \mathrm{lb} / \mathrm{hr}-\mathrm{ft} 2$ and at the same heat flux values as for the 750 psia case.

Injection of the tracers was accomplished through the use of two positive displacement pumps. Normally, one pump was designated for $\mathrm{LiOH}$ injection and the other for $\mathrm{D}_{2} 0$ injection. Transport times through the lines and pumps were visually measured with a 500 ppb solution of Rotamene B dye. A 99.6\% pure anhydrous lioH powder was mixed with an amount of water necessary to obtain a concentration of $10 \mathrm{ppm}$ (lithium lons to $\mathrm{H}_{2} 0$ ) at the polnt of injection. Dilution of the $\mathrm{D}_{2} \mathrm{O}$ at injection was approximately $100: 1$ (parts $\mathrm{H}_{2} 0$ to parts $\mathrm{D}_{2} 0$ ). The concentrations of the tracers at the injection point were selected to yield recommended concentrations for optimum results in the chemical analyses process. 
Preliminary analysis of the data revealed the following:

- The relative heavy water and lithium ion tracer concentrations at the test section exit were nearly the same indicating that both the vapor and liquid phases were active in the mixing process during bolling.

- The improvement of mixing during bolling was found to range from 0 to $300 \%$, depending on test section heat flux, flow rate, and pressure.

- Reducing pressure from 750 to 400 psia caused increased mixing during boiling at a glven flow and heat flux.

- A reduction in flow rate caused increasea mixing during bolling at a given heat flux and pressure.

- If mixing is assumed to be a function of quality only for a glven flow rate and pressure, it appeared that a peak in mixing occurred in roughly the 5 to $10 \%$ quality range.

Following the experiments with the 0.084 inch spacing, shims were removed from the test section support blocks. Reassembly of the test section then deflected the sides of the test section inward to give a simulated rod spacing of 0.020 inch. Experiments with this spacing were performed at 750 psia $(490 \mathrm{~F}(255 \mathrm{C})$ inlet temperature) and at 400 psia $1490 \mathrm{~F}(255 \mathrm{C}$ ) inlet temperature) with mass velocities of 1 and $2 \times 106 \mathrm{lb} / \mathrm{hr}-\mathrm{ft}^{2}$ and heat fluxes ranging up to 0.25 and $0.35 \times 10^{6} \mathrm{Btu} / \mathrm{hr}-\mathrm{ft} \mathrm{t}^{2}$ for the two flow rates, respectively. About the same conclusions were made for 0.020 irich spacing as with the 0.084 inch spacing except that Improvements in average mixing during bolling were much less for the 0.020 inch spacing for a given pressure, mass velocity, and heat flux.

The values of mixing found in these experiments for nonbolling conditions were in excellent agreement with the previous experiments in which unequal channels were considered. Agaln, the amount of mixing was not proportional to the spacing, and, in fact, it appeared that the mixing was equal to or slightly greater than that observed with the 0.020 inch spacing. The reason for this behavior has not been resolved. For bolling conditions, detailed comparison of the amounts of mixing between the present and previous experiment have not been made; however, the present data indicate that good agreement could be expected.

Effects of Rod Spacing on Bolling Burnout

Construction is continuing on two electrically heated test sections for the study of the effects of rod spacing on boiling burnout in multirod bundle fuel elements. One test section will 
be used to investigate the influence of adjacent heated rods on boiling burnout by using a single rod surrounded by four simulated rods. The simulated outer rods are formed by a 4-lobe tube. The four convex surfaces facing inwards simulate the adjacent heated surfaces, and the concave inner surfaces form the flow subchannels. The wall thickness of the concave inner surfaces is reduced at the outside to provide the proper heat generation in the vicinity of the subchannels. Design of the test section allows different diameter inner rods to be insertea, thus allowing adjustment of the rod spacing. Several inner rods will be fabricated to allow spacings from 0.015 to 0.080 inch.

The second test section is designed to investigate the effect of an unheated wall adjacent to a heated rod. The unheated wall is simulated by a square tube surrounding a heated central rod. Design of this test section allows interchangeability of the center rod in similar fashion as the previously described test section to allow consideration of various rod surface spacings.

Evaluation of $\mathrm{Zr}-2.5$ wto $\mathrm{Nb}$ Pressure Tubing

The general objective of this program is to evaluate $\mathrm{Zr}-2.5 \mathrm{Nb}$ as a pressure tube material with reference to the tests and reactor experience that has been obtained on Zircaloy-2 pressure tubes.

Crack propagation tests were completed at room temperature on one specimen that was previousiy creep tested for 12,000 hours and on two specimens quenched from $880 \mathrm{C}$ and vacuum aged 24 hours at $500 \mathrm{C}$. The artificial through-the-wall flaws in these tubes were $0.68,1.50$, and 1.48 inches long, respectively, and they were extended prior to fracture by low-stress, high-cycle fatigue. This procedure gives a minimum fallure stress for a given crack length.

Calculated critical stress intensity factors ( $\mathrm{K}$ ) for the creep tested tube specimen was $152 \mathrm{KsI} \overline{1 \mathrm{nch}}$ and for the helat treated tubes was 115 Isi $\sqrt{1 \text { nch. }}$. The tube with the higher fracture toughness was previously tested for 12,000 hours at $300 \mathrm{C}$ and a stress of 60,000 psi. This tube had an average creep straln of $2 \%$ prior to fracture testing.

Hydraulic and Nuclear Stability in Parallel Flow Channel Systems

The analog computer study of hydraulic and nuclear stability of $\mathrm{D}_{2} \mathrm{O}$ moderated, boiling light-water cooled reactor systems has been resumed following receipt of additional funds for this program. A Visit by Bill Cooper of AECL and Dave Robinson of Canadian-Westinghouse was made to PNL to observe the computer program in operation and to compare results with studies performed by AECL personnel using a simplified model. Basıcally, the agreement was satisfactory; however, 
some modıflcations have been made. Most are minor, the major changes being a doubling of steam-arum size and a new calculation of average coolant density to account for axlal varlation of reactivity associated with changes in coolant density.

Special functions required for the simulation are now being generated on the digital computer, replacing the function generators used previously.

Several cases have been studied to test the latest simulation. It was found that ralsing the reactor power level about 50\% introduced more reactivity through the coolant density coefficient than the maximum control strength available in control rods $13.5 \mathrm{mk}$ ). Consequently, above this power level, the reactor was uncontrollable in the simulation. Further checking of the entire simulation is planned before the parametric study of varıous fuel types is performed.

$$
\text { HTGR Graphıte (R. E. Nightıngale) }
$$

$\underline{\text { Advanced HTGR Studies }}$

The following table itemizes the samples and irradiation conditions for the first graphite irradiation capsule in the Dounreay Fast Reactor. The capsule, scheduled for startup in cycle 60 the week of June 5, will operate for 55 days at full reactor power. All samples are 0.194 inch dia. by 0.40 inch length. One parallel and one transverse sample is included of each graphite type at the positıons indicateả.

\title{
$\underline{\text { APPLIED AND REACTOR PHYSICS }}$
}

\author{
Plutonium Criticality Studies (E. D. Clayton)
}

Integral Neutron Spectra Measurements in Undermoderated Heterogeneous Plutonıum Assemblies

A series of activation measurements were completed with small pins for determining intracellular reaction rates in three undermoderated heterogeneous plutonlum tueled assemblies. Data were obtained for determining the intracellular distribution of the Pu-239

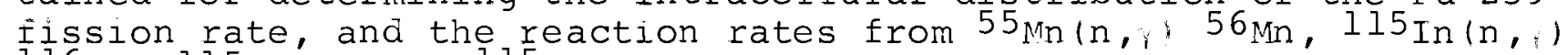
li6 In, li5In(n, n') Inll5m. The critical assemblies were comprised of alternate slabs of $\mathrm{PuO}_{2}$-polystyrene at an $\mathrm{H} / \mathrm{Pu}$ of 15 and Plexiglas. The fuel and moderator slab thicknesses were varied in the rectangular parallelepipeds to obtain H/Pu atomic ratios of 22,35 , and 45 . To obtain these $\mathrm{H} / \mathrm{Pu}$ ratios, fuel slab thicknesses of 3,2 , and 1 inch were used with corresponding Plexiglas thicknesses of 1,2 , and 1.5 


\section{FIRST DFR GRAPHITE IRRADIATION CAPSULE}

\begin{tabular}{|c|c|c|c|c|c|}
\hline Graphite & Description & $\begin{array}{l}\text { osule } \\
\text { sition }\end{array}$ & $\begin{array}{r}\text { Est: } \\
\text { Tempe }\end{array}$ & $\begin{array}{l}\text { imated } \\
\text { erature, } \\
\text { oC }\end{array}$ & $\begin{array}{l}\text { Goal } \\
\text { Exposure } \\
\text { nvt } \times 10^{21} \\
\end{array}$ \\
\hline $\mathrm{NC}-8$ & $\begin{array}{l}\text { Extruded, Continental Lake Charles } \\
\text { coke, coal tar pitch binder, one } \\
\text { coal tar pitch impregnation, } \\
\text { graphitized at } 2800 \mathrm{C} \text {. EGCR } \\
\text { graphite. }\end{array}$ & $\begin{array}{r}1 \\
7 \\
9 \\
12 \\
15 \\
16\end{array}$ & $\begin{array}{l}600 \\
900\end{array}$ & $\begin{array}{lr}- & 800 \\
- & 1100 \\
" & \\
" & \\
- & 800\end{array}$ & $\begin{array}{r}3 \\
9 \\
10 \\
10 \\
8 \\
7\end{array}$ \\
\hline $\mathrm{CSF}$ & $\begin{array}{l}\text { Extruded, Cleves coke, coal tar pitch } \\
\text { binder, one coal tar pitch impregna- } \\
\text { tion, graphitized at } 2800 \mathrm{C} \text {. }\end{array}$ & $\begin{array}{r}1 \\
16\end{array}$ & $\begin{array}{l}600 \\
600\end{array}$ & $\begin{array}{l}-800 \\
-\quad 800\end{array}$ & $\begin{array}{l}3 \\
7\end{array}$ \\
\hline T'SX & $\begin{array}{l}\text { Extruded, Continental Lake Charles } \\
\text { coke, coal tar pitch binder, one } \\
\text { coal tar pitch impregnation, } \\
\text { graphitized at } 3000 \mathrm{C} \text {. NPR graphite. }\end{array}$ & $\begin{array}{r}1 \\
16\end{array}$ & $\begin{array}{l}600 \\
600\end{array}$ & $\begin{array}{l}-800 \\
-\quad 800\end{array}$ & $\begin{array}{l}3 \\
7\end{array}$ \\
\hline $66-7$ & $\begin{array}{l}\text { Extruded, petroleum coke, coal tar } \\
\text { pitch binder, two resin impregna- } \\
\text { tions, graphitized at } 2800 \mathrm{C} \text {. } \\
\text { MSRE graphite. }\end{array}$ & $\begin{array}{r}1 \\
16\end{array}$ & $\begin{array}{l}600 \\
600\end{array}$ & $\begin{array}{l}-\quad 800 \\
-\quad 800\end{array}$ & $\begin{array}{l}3 \\
7\end{array}$ \\
\hline $65-21$ & $\begin{array}{l}\text { Extruded, complex petroleum coke, } \\
\text { coal tar pitch binder, no impregna- } \\
\text { tions, graphitized at } 2800 \mathrm{C} \text {. }\end{array}$ & $\begin{array}{r}7 \\
9 \\
12\end{array}$ & 900 & $\begin{array}{l}-1100 \\
"\end{array}$ & $\begin{array}{r}9 \\
10 \\
10\end{array}$ \\
\hline
\end{tabular}




\begin{tabular}{|c|c|c|c|c|c|}
\hline Graphite & Description & $\begin{array}{l}\text { osule } \\
\text { sition }\end{array}$ & $\begin{array}{r}\text { Esti } \\
\text { Tempe } \\
\end{array}$ & $\begin{array}{l}\text { imated } \\
\text { erature, } \\
\text { oC }\end{array}$ & $\begin{array}{l}\text { Goal } \\
\text { Exposure, } \\
\text { nvt } \times 1021 \\
\end{array}$ \\
\hline $65-22$ & $\begin{array}{l}\text { Extruded, petroleum coke, coal } \\
\text { tar pitch binder, no impregnations, } \\
\text { graphitized at } 2800 \mathrm{C} \text {. }\end{array}$ & $\begin{array}{l}7 \\
9\end{array}$ & 900 & $\overline{-} 1100$ & $\begin{array}{r}9 \\
10\end{array}$ \\
\hline $66-14$ & $\begin{array}{l}\text { Molded, petroleum coke, graphitized } \\
\text { at } 2800 \mathrm{C} \text {. }\end{array}$ & $\begin{array}{r}9 \\
15\end{array}$ & 900 & $\overline{-} 1100$ & $\begin{array}{r}10 \\
8\end{array}$ \\
\hline $67-1$ & $\begin{array}{l}\text { Molded, no impregnations graphitized } \\
\text { at } 2800 \mathrm{C} \text {. }\end{array}$ & $\begin{array}{l}12 \\
15\end{array}$ & 900 & $\overline{-} 1100$ & $\begin{array}{r}10 \\
8\end{array}$ \\
\hline $63-16$ & $\begin{array}{l}\text { Molded, raw Texas Lockport coke, } \\
\text { coal tar pitch binder, no impregna- }\end{array}$ & $\begin{array}{l}12 \\
15\end{array}$ & 900 & $\overline{-} 1100$ & $\begin{array}{r}10 \\
8\end{array}$ \\
\hline $62-21$ & $\begin{array}{l}\text { Extruded GLC needle coke, coal } \\
\text { tar pitch binder, no impregnations, } \\
\text { graphitized at } 2900 \mathrm{C} \text {. Five per- } \\
\text { cent aluminum added during mixing. }\end{array}$ & 7 & 900 & -1100 & 9 \\
\hline
\end{tabular}


inch. The pins used in the measurements were about 0.5 inch in length with diameters ranging from 24 to $40 \mathrm{mils}$, depending on the kind of material. By means of the small pins, the flux could be well defined near regions of rapidly changing flux, such as at the interface between the fuel and Plexiglas. The results of experiments are under analysis. As a check on the methods of calculation and cross section sets used, the measured reaction rates are being computed with the HAMMER, GAMTEC-II, and DTF IV Codes.

\section{Pulsed Neutron Source and Reactor Noise Measurements}

A series of pulsed neutron source experiments were performed with the recently received Kaman Nuclear A-808 Neutron Generator. The modifications made by Kaman to the control circuitry appear to have corrected the previous difficulties with this unit. Data were obtalned for determining reactivity over a subcritical range on two different heterogeneous plutonium assemblies. The first assembly consisted of a rectangular parallelepiped reflected on two sides with $\frac{1}{2}$ inch of Lucite. The core was made up from three slabs of $\mathrm{PuO}_{2}$-polystyrene fuel ( $\mathrm{H} / \mathrm{Pu}$ of 15$)$, each three inches thick and separated by one inch of Lucite. This resulted in an average $\mathrm{H} / \mathrm{Pu}$ ratio for the core of 22 . The base dimensions of the assembly were

$31 \mathrm{~cm} \times 31.8 \mathrm{~cm}$. Preliminary values of the neutron decay constant as a function of height are presented below. The estimated height for delayed criticality was $33.4 \mathrm{~cm}$.

\section{Measurement of Neutron Decay Constant}

\begin{tabular}{|c|c|c|}
\hline $\begin{array}{c}\text { No. of } \\
\text { Pulsed } \\
\text { Sequences }\end{array}$ & $\begin{array}{l}\text { Ass embly } \\
\text { Helght }\end{array}$ & $\begin{array}{r}\text { Decay } \\
\text { Constant, sec-1 } \\
\end{array}$ \\
\hline 2 & $30.8 \mathrm{~cm}$ & $\begin{array}{l}3277 \pm 14 \\
3255 \pm 14\end{array}$ \\
\hline 3 & $31.4 \mathrm{~cm}$ & $\begin{array}{rrr}2486 & \pm \\
2425 & \pm 14 \\
2477 & \pm\end{array}$ \\
\hline 2 & $32.1 \mathrm{~cm}$ & $\begin{array}{l}1687 \pm 5 \\
1681 \pm 6\end{array}$ \\
\hline 2 & $32.7 \mathrm{~cm}$ & $\begin{array}{l}1162 \pm 5 \\
1162 \pm 5\end{array}$ \\
\hline
\end{tabular}

Estimated crltical height $=33.4 \mathrm{~cm}$.

The second assembly was comprised of similar geometry but reflected on two sides with one inch of Lucite. The core contained four slabs of $\mathrm{PuO}_{2}$-polystyrene fuel each two inches thick, separated by two inches of Lucite, giving an over-all H/Pu ratio of 35 . 
Analysis of the data from the two assemblies is in progress. These experiments, together with others planned at the Critical Mass Laboratory, are preparatory to proposea measurements of reactivity for nuclear safety evaluations on actual in-plant systems.

Criticality of Plutonium Nitrate solution in slab Geometry

Analysis of data on the criticality of plutonium nitrate solutions in slab geometry was continued. The experiments were previously performed with an expandable slab tank whose thickness was varied to obtain criticality as a function of thickness and height, or geometrical buckling. The length and width of the slab tank were $42^{\prime \prime} \times 42 "$. The sides of the vessel were of $0.062^{\prime \prime}$ stainless steel reinforced with a low density lattice framework for rigidity. The concentration of plutonlum in the solution here analyzed was $58 \mathrm{~g}$ $\mathrm{Pu} / \mathrm{l}$ with the nitric acld molarity being five; the Pu-240 content was 4.6 wto. Values of the critical bucklings (B2) and extrapolation lengths (1) which appear to fit the data for the bare, partially reflectea, and water reflected slabs are presented below:

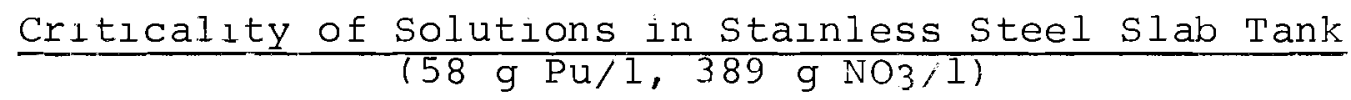

Extrapolation Critical Buckling Critıcal Thickness Length $($, of Infinite Slab

Bare Slab

$3.68 \mathrm{~cm}$

$18,000 \times 10^{-6} \mathrm{~cm}^{-2}$

$16.0 \mathrm{~cm}$

Reflected with

1 " of Lucite

$5.20 \mathrm{~cm}$

$18,000 \times 10^{-6} \mathrm{~cm}^{-2}$

$13.1 \mathrm{~cm}$

on sides

Reflected with water

$6.40 \mathrm{~cm}$

$17,200 \times 10^{-6} \mathrm{~cm}^{-2}$

$11.2 \mathrm{~cm}$

Attempts to compute the critical thickness from theory by means of the HFN and GAMTEC codes have fallen somewhat short of success, with the computed critical thicknesses differing from measurement by as much as $10 \%$ in the reflected cases. The reasons for the discrepancy are being examıned.

\section{Phoenix Fuel Reactor Program (D. D. Lanning)}

CAF-Phoenix Fuel Experiments

The fitting of the nolse data from the CAF experiments which used Phoenix fuel has not been completed. Deviations in the data caused by a possibly faulty detector have made it difficult to get good fits using a parallel set of instruments and detector. These duplicate data are being examined to determine if they can be used to correct the data now being analyzed. 
CAF-Phoenix Fuel Calculations

Refinement of the representation of the three experimental configurations in the 17-group diffusion theory calculations has brought the experimental and calculated values of keff closer together. The beryllium reflector, which consisted of a ring of 1.960" diameter beryllium metal logs on 2.250" center, had previously been represented as a single region with the appropriately smeared nuclei concentrations of water and Be. A new model was used to represent the beryllium reflector in which half of the reflector interstitial water is represented as an annular ring of pure water at the core boundary followed by a ring of pure beryllium metal. This turned out to lower the calculated $\mathrm{k}_{\text {eff }}$ by $4 \mathrm{mil} \mathrm{k}$. Other refinements included using the array template dimensions to slightly alter the core radil, and including the effect of interstitial water trifultes in the reflector treatment. The refinements represent the actual experimental assembly with increased fidelity. Comparisons of experimental and calculated keff are shown below:

Experimental keff Calculated

1. Water reflected assembly $0.95 *$ 0.945

2. Beryliium reflected assembly 1.0 1.012

3. Berylilum reflected with center cd control rod

1.0

0.998

*Calculated from the experimental extrapolated critical buckling.

PRCF-Phoenix Fuel Experiments

The berylilum reflector region adjacent to the core tank wall has been restacked to improve the similarity between the PRCF core and the planned MTR Phoenix core. The beryllium volume fraction in this region was increased from about $70 \%$ to nearly $94 \%$, with a corresponding reduction in the volume of $\mathrm{H}_{2} \mathrm{O}$.

All fuel assemblies have been boiled in $\mathrm{H}_{2} \mathrm{O}$ for $6-8$ hours to improve the aluminum oxide film on the surfaces of the assemblies. This was done in an attempt to eliminate a possible source of reactivity loss due to formation of $\mathrm{H}_{2}$ bubbles on the assembly surfaces. Subsequent measurements have shown that the problem has not been completely eliminated but has been reduced in magnitude.

After restacking the beryllium and boiling the fuel elements, a new shim-free critical loading was achieved with $14 \frac{1}{4}$ fuel boxes arranged in a $3 \times 4-3 / 4$ box array. The new critical mass was about $5.6 \mathrm{~kg} \mathrm{Pu}$, as compared with the critical mass of $6.5 \mathrm{~kg}$ Pu before restacking. The worths of the safety sheets were increased about $50 \%$ due to the improvement in beryllium density between the core tank and 
the sheet locatıons, from about $14 \mathrm{mllli-k}$ to about $21 \mathrm{mllli-k}$ for the total sheet package. The worth of a single fuel plate in this core was found to be about $25 c$.

A three-dimensional power traverse of the shim-free core has been achieved with banked shims withdrawn 59\% as compared with 65\% withdrawn prior to restacking of the beryllium

\section{PRCF-Phoenıx Fuel Calculations}

The PRCF-Phoenix core with restacked Be reflector was calculated using 4-group diffusion theory in two dımensions. These calculations indicated a clean critical configuration of about 11.2 fuel boxes. If a correction of between 2 and $3.5 \%$ in $k$ as determined by the CAF experiment is applied, the clean critical configuration should be from 12.4 to 13.1 fuel boxes.

The experimental value of 14.25 fuel boxes corresponds to an error in $k$ at about 5.5\% from the 4-group calculations or between 2 and $3.5 \%$ greater than the CAF-Phoenıx experiments.

The fully loaded core with banked control rods was calculated by a combination of 2 and $3-D$ codes. The following predictions of the critical rod position were made prior to the experiment:

Calculated position:

$51 \%$ withdrawn

Calculation adjusted by CAF experience:

Calculation adjusted by previous PRCF experience:
$56 \%$ withdrawn

$59.6 \%$ withdrawn.

The experimental value is $58.8 \%$ withdrawn. The total rod travel is $78 \mathrm{~cm}$. The difference between the highest and lowest prediction is about $6.7 \mathrm{~cm}$, whlch 15 about $6 \%$ in $\mathrm{k}$.

MTR-Phoenix Fuel Calculations

3-D Calculations. Continued emphasis has been placed on $1 \mathrm{~m}-$ proving the degree of flux convergence for the MTR-Phoenix core of most interest, the core with the control rods partially withdrawn. This case had the control rods positioned $43.1 \mathrm{~cm}$ from the top of the active fuel which yielded $\mathrm{a} \mathrm{k}$ eff $=1.036$ and $\mathrm{a} \dot{\mathrm{P}} / \overline{\mathrm{P}}$ ratio of 3.47 . The measure of flux convergence, $\left|\frac{\phi n}{\phi n t}\right|-1$, for this case was $1.007 \times 10^{-2}$. In previously reported calculations, the degree of convergence was $\left|\frac{\phi n}{\phi n t I}\right|-1$ max $=3.4 \times 10^{-2}$, which gave $P / \bar{P}=3.38$. 
Thus, it appears that the magnitude of $\hat{P} / \bar{P}$ will increase as the degree of convergence is improved.

The location of $\hat{\mathrm{P}} / \overline{\mathrm{P}}$ is the bottom of the stationary fuel in both of the above cases. However, as the degree of convergence improved, the position of the $\bar{P} / \overline{\mathrm{P}}$ ratio moved from the bottom center of the core to the center of the bottom edge of the core at the core-reflector interface.

To estimate the effect on the magnitude and position of the $P / \bar{P}$ ratio of various control rod insertions, additional calculations have been initiated with the tips of the control rods $34.7 \mathrm{~cm}$ from the top of the active fuel. These calculations are continuing, and comparisons with PRCF experiments will be made.

MTR Burnup Calculations. The burnup calculations reported in the March 1967 monthly report have been found to be in error. The initial composition used was that typical of the PRCF-Phoenix fuel rather than the MTR-Phoenix fuel. The initial composition should read 2.116-4/7.532-5/2.506-5/1.130-5 for the $\mathrm{Pu}$ isotopes. Compositions at 3200 MW days for the one and five region burnups using constant cross sections are given in the following table:

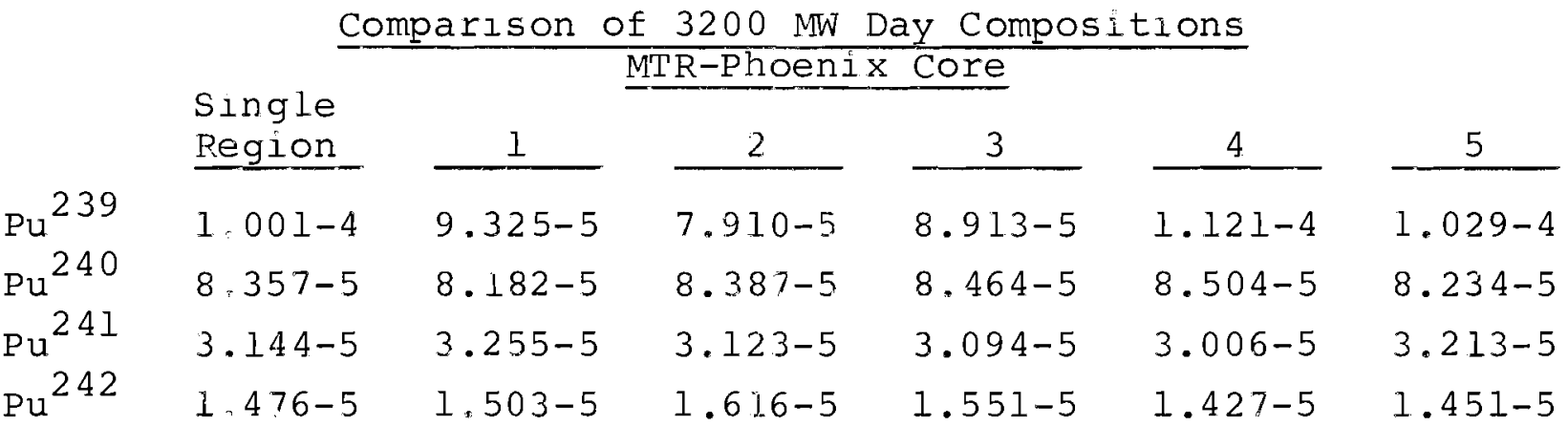

Implications of Current Calculations. A question which needs to be continually asked and answered $1 \mathrm{~s}:$ How do the latest results affect the estimated MTR-Phoenix burnup experiment? In this report we indicate that we are still overpredicting the reactivity by almost $6 \%$. We have also uncovered an error in the earlier burnup calculations.

It is not yet clear that the entire uncertainty of $6 \%$, found by comparison with the PRCF experiment, should carry over to the MTR calculations, but if it does, the exposure would be reactivity limited at about 2500 MW days. Current calculations would indicate a core average $\mathrm{Pu}-239$ burnup of over $41 \%$. Detailed spatial burnup within the core would then be in a range of between 36 and $50 \% \mathrm{Pu}-239$ burnup. A more detailed subdivision of the core would, of course, predict $a$ still greater range of attainable burnup. 
The digital computer code, MACABRE II, obtalned recently from MTR personnel, has been adapted to the Univac 1107 , and a test problem has been run. Results differ from those supplied with the code, however, and considerabie difficulty has been experienced in locating the trouble. A hand calculation is being made to determine the correct results. The possibility of doing the thermal hydraulic analysis of the Phoenix Core in the MTR on the Idaho Falls computing facility is being explored.

In the meantime, hand calculations have been made to estimate maximum MTR operating power with the Phoenix Core as governed by heat transfer limitations. The calculation is based on a power map supplied by Engineering Physics for a clean core, 1.e., with no flux suppressors. The maximum power peak from this map is 3.47 and is located at the bottom of a stationary fuel element next to the reflector in locations 25 and 45 . The follower fuel was assumed to be $25 \%$ of the way into the core. Under these conditions, the reactor could operate at 24 MWt at beginning of $1 \perp f e$. The hot spot temperature would be about $230 \mathrm{~F}$, and the heat flux would be $7.8 \mathrm{x} 105 \mathrm{Btu}$, hr-ft ${ }^{2}$. The saturation temperature at the hot spot is estimated to be $233 \mathrm{~F}$.

\section{MTR Core-Mechanical Design}

A method of installing a flux monitor wire in the fuel boxes has been scoped and drawings submitted to the physics and fuel fabrication people for comments. The concept was discussed in the 4/20/6? regular Phoen $\perp x$ tuel meeting and accepted with some modification to better facilitate tabrication. The concept consists of inserting a fueled flux monitor wand down beside the side plate between the second and third fuel plates from the concave side of the fuel box. A nonfueled strip approximately $\frac{1}{4}$ inch wide would be required in the two plates adjacent to the flux wand. The wand extends up the inside corner and through the top of the upper fuel box end fitting for removal.

Further work with the flux monltoring wand will be to complete the design of a removal and handling device which should be checked out in a mockup. Simultaneous with completing the work on the flux wire arrangement, the concept should be reviewed with Idaho Nuclear.

Prints were obtained from Idaho Nuclear on the arrangement used to suppress the flux at the end of the ETR fuel. This consists of $\frac{1}{2}$ inch wide boron containing stalnless steel plate extensions at the end of the fuel plates. This is held to the plate by a large comb. This method appears to be adaptable to the MTR fuel and could be used If a bottom Ilux suppressor is found necessacy. 
MTR-Phoenix Fuel Fabrication and Development

An irradiation experiment is being prepared to test shortened plutonium fuel plates under the operating conditions proposed for the MTR Phoenix experiment. The purpose of the test is to demonstrate fuel stability and in-reactor corrosion resistance as a function of exposure in the Phoenix fuel geometry. Thirty plutonium fuel plates are being evaluated for the irradiation test in the L-5l loop of the MTR. The plates were made by a roll-cladding process using the plcture frame technique. Two plates were rejected for nonbonds; several plates had areas of internal core porosity. The dogboning observed in the 1100 alloy clad plates was reduced by using an insert of $6061 \mathrm{Al}$ to cover the core ends. The best sections were being assembled for tests in the PRCF.

\section{Applications}

Compact Pressurized Water Power Reactor. As a part of the Phoenix fuel application program, the compact pressurized water reactor concept is being studied. For comparison purposes, the base case of the maritime reactor is being used. This base case for comparative economic evaluations will use the original designed uranium core with burnable poison. Fabrication cost for this core has been estimated through calculations and extrapolations from the case 1 Vibrational-Compaction plant model described in BNWL-273. With this as a reference, subsequent core designs including plutonium fuel, dimensional changes, and different fabrication processes may be evaluated.

An additional telephone contact with $R$. D. Cheverton was made. Preliminary plans for a meeting to be held in conjunction with the San Diego American Nuclear Society Meeting were made. Tentative ORNL attendees would include R. D. Cheverton and G. M. Adamson, Jr.

High Temperature Reactor Lattice Physics Studies (R. E. Heineman)

Reactor Construction and Design Tests

Painting of the reactor was completed, and painting of the piping and equipment is about $90 \%$ complete. Identification of piping by applying decals still remains to be done.

The insulating brick on the oscillator opening on the front door was put into place. Repair of damaged brick on the inner side of the large door is essentially the only work on the shell itself which remains to be done.

Design changes and revisions to the gas sampling lines and to the electrical controls were completed. Final checkouts were started 
on the gas chromatographs and on the molsture monitors by the Architect-Engineer personnel.

Final calibrations of all flow and pressure transducers were completed by Battelle personnel. One unit was returned to the vendor for repair or replacement. The limit switches on all control valves were set to their proper positions. A new flow test was written and completed with the dryer in place. The entire gas system, including all equipment, was turned over to the HTLTR operations and Systems Unit.

All four vertical safety rods and enclosures have been installed and successfully tested for gas tightness. Final checkout of two of the VSR units and all wirlng back to the control room remains to be comp leted.

All horizontal control rod drive assemblies were delivered to the 318 Bullding, and checkout of the wirlng was started.

The rear face oscillator door was made operable after correcting a warp due to welding. The proper check valves necessary to make the front face oscillator door operate have been ordered.

The flux wire monitors were tested. The silicone rubber valve liners ruptured due to over-pressurization. The proper pressure regulator valves and new liners were ordered. The recorders for the independent flux monitor channels arrived, completing the original order. A significant nolse problem was found on these units which originates in the pre-amplifiers. Work was started to improve the signal-to-nolse ratio.

Each of the four banks of electrical heaters was separately heated and the temperatures of the surrounding graphite raised to about $200 \mathrm{~F}$. Indlcated surface temperatures of the heater rods varied trom $15 \mathrm{~F}$ to $250 \mathrm{~F}$ above the surrounding graphite. The exact positioning of the thermocouple tip was found to be critical. Also, an apparently unequal distribution of the electrical load in the bus bars that are connected in parallel is being investigated. The heaters worked well from the simulated control signal.

Reactor Equipment

Oscillators. The light duty oscillator is now being tested in the HTLTR mockup. The only fabrication work left on this oscillator is completion of the electrical wiring and modification of the position locking device.

The heavy duty oscillator is currently being prepared for pressure and vacuum testing. Work remaining includes installation of the position readout equipment connecting cables, carrier strip 
and buckets, electrical wiring, and reinstallation of the drive system.

It is estimated that the oscillators are $94 \%$ complete.

Vertical Safety Rods. The four vertical safety rods were delivered to the 318 Bullding and were installed on the reactor. Initial operation of these assemblies, utilizing a portable power supply, was completed satisfactorily.

Horizontal Control Rods. None of the ten rod drive assemblies have been checked out and adjusted at the 314 Burlding. Four of these have been delivered to the 318 Building and operated using the installed power supply and assoclated equipment. The other five are ready to move to the 318 Bullding. The stepping motor of the tenth drive made irregular steps when under test. The motor was removed, and the erratic operation is being investigated to evaluate the need for returning this motor to the manufacturer.

HTLTR Mockup. Preparations were completed for the use of the mockup for oscillator and connector tests and heatup started durlng the month.

A total of $320 \mathrm{ml}$ of water were collected in the vacuum pump discharge line during two evacuations. Carbon monoxide, carbon dioxide, and oxygen concentrations are negligible to date.

The light duty oscillator was connected to the mockup, and tests were performed at $520 \mathrm{~F}, 720 \mathrm{~F}$, and $920 \mathrm{~F}$. The test sequence was:

1. Open the valve, insert the oscillator rod into the mockup, and connect to the graphite sample.

2. Osciliate the sample ten times.

3. Remove the sample from the core into the osclilator and allow the sample to cool. This procedure involves a two-step connect and disconnect sequence; thus, the oscillator must be opened to change rod length. After sample cooling, the oscillator is opened and the sample inspected.

4. Close the oscillator, evacuate and back-fill, open the valve, and re-insert the sample into the core.

No sealing problems were encountered during the numerous evacuation and back-fill operations performed on the oscillator. 
In the first tests at low temperature, one of the prototype graphite connectors was broken due to improper operating procedures. The procedure was modified, and no further difficulties were encountered.

The small light duty valve is used during hot testing to connect the oscillator to the mockup. There has been some concern about the temperature that the seals in this valve will reach when the core is at $1000 \mathrm{C}$. A thermocouple was mounted in this valve to monitor the valve gate temperature during mockup operation. With the mockup at $910 \mathrm{~F}$, the valve gate temperature is only $110 \mathrm{~F}$.

Programmed Measurement and Control System (PMACS). Work continued during the month in checking out the operation of the PMACS for control of the reactor and its assoclated systems. The deadman interlock has been wired to include all gas system valves controlled from PMACS, the annunciator chime, the remote manned facility alarm, and the previously included heater control. However, no deadman function will be available on the added points until the necessary logic cards are received.

It was found that the watch channel inputs required an additional bias resistor to change the capacitance in the long lines connected to the system. These bias resistors have been installed, and the watch channels are functioning properly.

Reactor Operations

The final drafts of the Systems Design Tests and the operating Specifications were completed.

The final draft coples of about 90\% of the Operating Procedures are being typed.

The Operator Qualification Test was completed in rough draft for review and editing.

Training on the operation of the light duty oscillator was glven to Operations personnel during the osclllator hot tests at the HTLTR mockup. A preilminary flow diagram for the program to operate the oscillators was written.

Work on the HTLTR operational programs for PMACS passed through a critical phase at the end of the month when, for the first time, 15 programs were integrated, in preparation for the Gas and Heat System Design Tests. These programs include most of the basic set, plus GASCYC, HEAT, and GAP from the functional set. The remaining functional programs (ROD, SCRAM, SCRAM CHECK, and NUCLEAR) will be assembled into the master program network prior to the Nuclear system 
Design Tests. Rigld procedures are now being followed to reduce the multiplicity of master tapes and to assure that only up-to-date listings are used. One master listing notebook has been established in the control room which matches the MAIN master tape and the programs on tape \#4 (PMACS 4). Changes can be made in the master tape by permission only. ATP's and Design Tests will use the PMACS \#4 updated tape. Planning has been under way to demonstrate the operability of both hardware and software prior to the execution of each design test.

Flow charts for the gas and heater systems programs were completed and presented to the operating groups for approval. Suggested changes have been made. One change in program specification requires that the teletype messages indicating the computer states be typed after the valves reach their inltial positions. Program debugging disclosed a previous misconception in valve operation and corresponding errors in the programs. These were corrected by rewriting the pre-initialization routine, adding a fourth magnetic tape program link, and modifying the valve position routine to assure that the valve closes completely despite backlash.

Revised flow diagrams for the ROD, SCRAM, SCRAM CHECK, and NUCLEAR programs were completed for review. These programs will complete the functional set when approved. Flow diagrams for the TIME and the newly written CAIIBRATION (A/D) program are also being reviewed. Some time was spent in studying and revising the Equivalence Table. Methods of conserving core memory and making better use of the single Equivalence Table concept were explored. Work on the GAP, ROD, NUCLEAR, ROD MAINTENANCE, SCRAM CHECK, and SCRAM programs could not proceed further because some of the reactor equipment needed has not been completely checked out or calibrated.

The neutron generator was operated several hours during the month for training purposes.

Reactor Physics Program

Startup and Calibration Experiments. The prototype oscillatortest core coupling has been operating adequately in the oscillator hot tests. Designs of the connectors for the poison specimen and central cell are under way.

Ali machined graphite pieces for the test cell were delivered to the 318 Building. Remaining graphite plugs for holes in the test core and driver region are being prepared in the graphite shop.

A good candidate for a material to be used as a flux wire monitor at high temperature is monel (32\% $\mathrm{Cu}, 66 \% \mathrm{Ni}, 1 \% \mathrm{Mn}, 1 \%$ other). To check the nuclear characteristics of this wire, a sample of 0.040" diameter was irradiated in the PCTR and compared to 0.036 " diameter 
copper wire. The counting rates of a $\frac{1}{4} "$ length of copper was the same as $\frac{1}{2} "$ of the monel wire. The cadmlum ratio for the monel was about $15 \%$ below the copper due to the greater surface to mass ratio. The only significant difference in the gamma ray spectra between monel and copper is the $0.845 \mathrm{MeV}$ gamma of $2.58 \mathrm{hr} \mathrm{Mn}-56$. At about 18 hours after irradiation, this gamma had a peak height about $2 \%$ of the $0.511 \mathrm{MeV}$ annihilation radiation from copper. Therefore, if it is desired to count sooner than 24 hours after irradiation, this peak should be set outside the window of a single channel analyzer, or a multichannel analyzer may be used.

$\mathrm{U}^{233} \mathrm{O}_{2}-\mathrm{ThO}_{2}$ Experiments. Planning continued for the first $\mathrm{U}^{233} \mathrm{O}_{2}-$ $\mathrm{ThO}_{2}$ lattices. The calculations previously performed for a 1.0 "diameter $\mathrm{ThO}_{2}$ rod $\left(1.5 \mathrm{wt} \frac{\mathrm{O}}{\mathrm{U}} \mathrm{U}^{233}\right.$, in a $7 \frac{1}{2} "$ square graphite array were extended to fuel rods approximately $30 \%$ more dense $(\mathrm{C} / \mathrm{Th}=370)$. The calculations utilized the GAMTEC II - THERMOS code combination over the temperature range 0 to $1000 \mathrm{C}$. Princlpal characteristics of the calculations were use of (1) Park's kernel for thermal neutron scattering with graphite, and (2) NR and NRIA treatment of resonance absorption in Th232 over the entire temperature range. The coefficient $\frac{l}{\mathrm{k}} \frac{\mathrm{dk}}{\mathrm{dT}}$ lıgnorıng thermal expansion) remained positive but decreased from $6 \times 10^{-5}$ to $3 \times 10^{-5},{ }^{\circ} \mathrm{C}$ over the range of increasing temperature. The fuel coefficient, $\frac{1}{p_{0}} \frac{d p}{\bar{d} T}$, due primarily to Doppler effects in $T h 232$, decreased in maghitude with increasing temperature from $-1.5 \times 10^{-5}$ to -7.7 to $10^{-6} /{ }^{\circ} \mathrm{C}$; the corresponding moderator coefficient, $\frac{1}{r_{1} \mathrm{f}_{\mathrm{O}}} \frac{\overline{\mathrm{d}} \cdot \mathrm{f}}{\mathrm{dT}}$, decreased from $+8.6 \times 10^{-5}$ to $3.9 \times 10^{-5},{ }^{\circ} \mathrm{C}$.

Similar calculations are presently under way for a 2.86-inch diameter graphite rod $50 \%$ by volume graphitel admixed with $\mathrm{ThO}_{2}$ 11.5 wto U-233:. This tuel element more closely corresponds to the fuel concepts planned for the HTGR's where partial homogenization of the fuel and moderator occurs by means of the mixed fuel assemblies.

Measurements of effective resonance integrals and Doppler coefflclents for a number of $\mathrm{ThO}_{2}$ rods were recently reported by Palowltch and Hardy (WAPD-TM-627, December 1966). Comparisons with calculated resonance integrals using data and techniques avallable in GAMTEC II gave computed values 10 to $20 \%$ smaller than these experimental values. A recent evaluation iSehgal, Nucl. Sci. \& Eng., January 1967 of the Palowitch and Hardy experiments showed good agreement between experiment and theory. This work used data for the resolved resonances recommended by stehn, et al, (BNL-325, February 1965). Unresolved contributions were computed using both $\mathrm{S}$ and $\mathrm{P}$ wave capture. A similar set of data is presently being incorporated into the GAMTEC II library. P wave parameters are being included under a separate isotope identıfication, thus, eliminating the necessity of modifying the GAMTEC II code. 
Safety Analysis Report. Additional information regarding the Final Safeguards Analysis report was transmitted to the AEC Division of Reactor Development and Technology.

REACTOR FUELS AND MATERIALS

Fast Fuels Oxides and Nitrides (R. E. Nightingale)

Mixed Nitrides

The first two mixed-nitride irradiation test capsules (GEH-14-743 and 744) were fabricated and shipped to the ETR. These capsules are to be irradiated in the ETR core for eight cycles starting with Cycle 89 on April 24. GEH-14-743 contains about 85\% TD pellets which are sodlum bonded to stain less steel cladding; GEH-14-744 contains about 84\% TD pellets which are helium bonded to stainless steel cladding. Both capsules will be irradiated to generate about $26 \mathrm{~kW} / \mathrm{ft}$ to exposures of $50,000 \mathrm{MWd} / t$ onne with cladding surface temperatures of about $650 \mathrm{C}$.

Fabrication of two additional capsules (GEH-14-745 and 746) is nearly complete. These two capsules will be irradiated in the MTR for one cycle under conditions similar to those for GEH-14-743 and 744. Irradiation of these two capsules will begin approximately May 8 .

Components and hardware for an additional 12 capsules are being fabricated.

(U-Pu)N Pellet Process Development

Process development continued on the (U-Pu)N pellet fabrication process. Previous experiments indicated that particle size of the (U-Pu)N powder after ballmilling was too large to give optimum sinterability. Several steps were taken to improve ballmilling conditions.

The critical milling speed ispeed at which centrifugation of the balls begins) for the 3-inch ID half-pint ballmill was experimentally determined to be $132 \mathrm{rpm}$. Since the optimum miling speed should be 50 to $70 \%$ of this, the speed of the ballmill was increased from the previously used speed of $40 \mathrm{rpm}$ to $80 \mathrm{rpm}$.

An additional step taken to improve ballmilling performance was to replace the 0,40-inch diameter alumina balls with $\frac{1}{4}-i n c h$ diameter tungsten-carbide balls. Ballmilling efficiency increases as the ball diameter decreases and as the density of the balls increases. The density of the tungsten-carbide balls is $14.7 \mathrm{~g} / \mathrm{cm}^{3}$, compared to $3.65 \mathrm{~g} / \mathrm{cm}^{3}$ for the alumina balls. The effectiveness of the tungstencarbide balls can be seen from the data shown in the following table. 
Effect of Ballmill Speed and Ball Material on (U-Pu)N Particle size and Sinterability

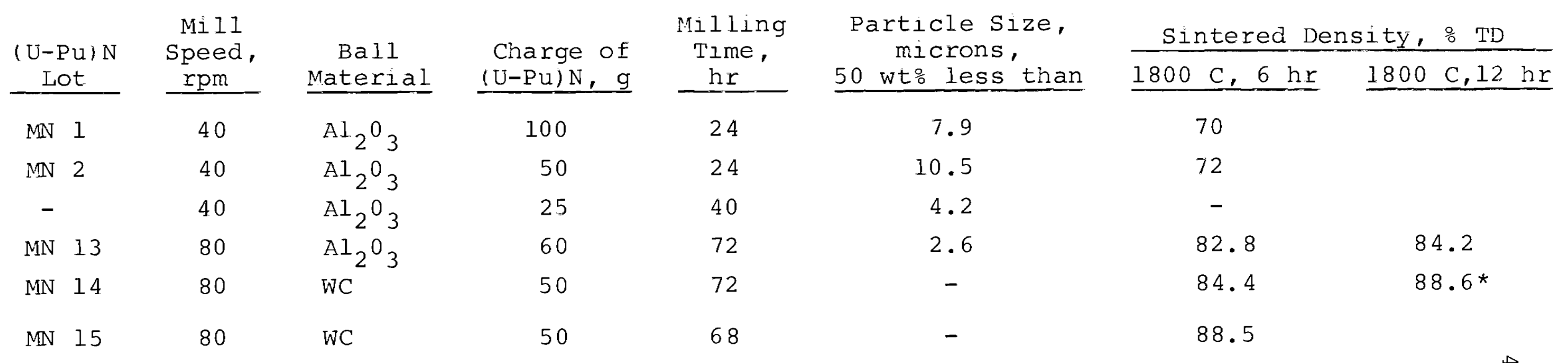

* This result obtained on a single pellet which had a density of $85.8 \%$ TD after the first 6 hours of sintering. 
The first lot milled with tungsten-carbide balls sintered to an acceptable density of $84.4 \%$ TD after only six hours; one of these pellets sintered for an additional six hours attained a density of $88.6 \% \mathrm{TD}$. The second lot milled with tungsten-carbide balls sintered to an average density of $88.5 \%$ TD after six hours at $1800 \mathrm{C}$.

Particle size determinations reported in the table were obtained using a coulter counter. No attempt was made to prevent oxidation of the particles during analysis. The particle size reported is probably slightly greater than that of the starting powder. However, the relative differences between powders prepared by different procedures is believed to be significant.

Evaluation of the tungsten-carbide-lined vibratory ballmill was continued using $\mathrm{UO}_{2}$ as a stand-in. It was discovered that after a few minutes of miling, the powder was packed in the bottom of the jar. Packing was prevented, however, by loosening the strap holding the jar sufficiently to permit the jar to slowly rotate during vibration (approximately $2 \mathrm{rpm}$. A serles of experiments has been run, and samples are being analyzed for specific surface area to determine optimum ballmill parameters of frequency and amplitude of vibration, amount of powder charge and milling time. Preliminary results indicate that one hour of vibratory milling may be equivalent to several hours of milling in a rotary mill.

Although there is some question as to the accuracy of the analytical method, the results reported indicate excessively high carbon content of the sintered (U-Pu) N pellets, 1.e., $1000 \mathrm{ppm}$. The source of carbon contamination, if any, has not been determined as yet.

A pellet-pressing technique has been developed which does not require the use of naphthalene binder. In some cases the binder has caused sintering difficulties in completely eliminating it from the furnace atmosphere. The procedure consists of loading the powder in the 0.218 inch ID die, prepressing by inserting the punch and applying hand pressure only on the punch, removing the punch, and applying one drop of benzene to the powder in the die and finally pressing at 3040 tsi. The powder may or may not have to be pre-siugged at 30 tsi before the final pellet pressing, depending upon the particle size and degree of agglomeration of the ballmilled powder. A 0.375 inch ID die has been procured for pre-slugging the (U-Pu)N powder, when necessary, prior to final pellet pressing. Some difficulty is still being experienced in obtaining pressed pellets without capping or cracking. Additional pressing experiments will be performed to attempt to improve the yield of acceptable pellets.

Compatibility Experiments on Mixed Oxide Fuels

Four $\mathrm{UO}_{2}$ - 25 wto $\mathrm{PuO} 2$ sodium-bonded 304 stainless-steel-clad test capsuies prepared previously were sealed into evacuated tubes to provide safety containment in case of primary capsule fallure 
durirg compatibility testing. Furnaces and controls for conducting the testing were completed, and tests were begun on two of the mixed oxide specimens. These two specimens are undergoing a prolonged period of repeated melting and freezing to determine effects on sodium penetration and pellet stability; internal pressure is estimated to be over 12,000 psi upon melting of the sodium in the capsule. Additional test capsules now in preparation will contain a sodium expansion plenum to permit unpressurized thermal testing to $800 \mathrm{C}$ or higher.

Two of the specimens were used to develop metallography techniques for the sodium-fuel system and to characterize the fuel capsules before testing. Techniques were developed for mounting, cpening, and polishing the test capsules. Because of the softness of the sodium, it was not possible to produce uniform surface relief across the sodium interfaces during polishing.

\section{Synthesis of Mixed Nitrides by Carbothermic Reduction}

A graphite tube furnace which will be used for studies of nitride synthesis by carbothermic reduction of oxides was received. Tests revealed some areas in which the furnace does not meet specifications. The vendor has taken action to correct the difficulties by shipping a new power transformer. All services and components required for glove-box installation of the unit are ready.

A particle-bed reactor assembly for use with the furnace was designed. Rhenium appears to be a suitable metal for construction of the reactor; preliminary compatibility tests indicate that it does not react wlth UN or carbon to $1900 \mathrm{C}$. Other, less expensive materials are also being tested.

$$
\text { Basic Swelling Studies (R. D. Leggett) }
$$

The purpose of this program is to characterize and understand the behavior of fissionable materlals during irradiation. The theories developed provide a basıs for the engineering exploitation of metallic fuel materials in advanced reactor applications. Specimens under study at the present time include uranium with and without dilute alloy additions.

\section{Irradiation Program}

Capsule P-15 was discharged after operating successfully at the design conditions of $700 \mathrm{C}$ and $1000 \mathrm{psi}$. The capsule contains specimens of several dilute uranium base alloys and high purity uranium. The status of capsules currently active is indicated below: 


\begin{tabular}{|c|c|c|c|c|}
\hline $\begin{array}{l}\text { Capsule } \\
\text { No. } \\
\end{array}$ & $\begin{array}{l}\text { Control } \\
\text { Temp. , } \\
\text { OC } \\
\end{array}$ & $\begin{array}{l}\text { Contro } 1 \\
\text { Pressure } \\
\text { (psi) }\end{array}$ & $\begin{array}{l}\text { Goal } \\
\text { Burnup } \\
\left(\mathrm{at} . \frac{\circ}{0}\right) *\end{array}$ & Status \\
\hline$P-10$ & 450 & 5000 & $0.2-0.8$ & Under irradiation \\
\hline $\mathrm{P}-11$ & 550 & 5000 & $0.2-0.8$ & Construction complete \\
\hline $\mathrm{P}-12$ & 625 & 5000 & $0.2-0.8$ & Under construction \\
\hline$P-13$ & 700 & 5000 & $0.2-0.8$ & Under construction \\
\hline$P-14$ & 700 & 500 & $0.2-0.8$ & Ready for charging \\
\hline$P-15$ & 700 & 1000 & $0.2-0.8$ & Discharged \\
\hline$P-16$ & 625 & 1000 & $0.35-0.7$ & Under irradiation \\
\hline
\end{tabular}

The above irradiation capsules will provide data needed to evaluate the effects of temperature (alpha and beta phase), pressure, burnup, burnup rate, and minor alloying additives on the irradiation behavior of uranium.

\section{Postirradiation Examination}

Metallographic examination is complete on selected uranium alloy specimens recovered from capsules 35 (525 C, 300 psi, 0.5 at. $\frac{\circ}{8}$ BU) and 36 (450 C, $30 \mathrm{psi}, 0.38$ at. $\left.\frac{\circ}{\circ} \mathrm{BU}\right)$. The bulk of the optical microscopy was described in the March monthly report (BNWL-425), and the results of density measurements were summarized in February (BNWL-404). Electron microscopy confirmed the presence of large, irregular tears that had been identified optically in the U $+\mathrm{Fe}-\mathrm{Al}-\mathrm{Si}$, Sicral F-l, and $\mathrm{U}+1.1$ Mo specimens.

No evidence of $\alpha+0$ lamellae was observed after irradiation in the $U+1.1$ Mo specimens. This is in contrast to the fine pearlitic structure that was observed prior to irradiation. It is not known whether the irradiation altered the basic structure or whether the etching characteristics of the matrix are now different as a result of the irradiation. The possibilities could be evaluated by determining the present structure with x-ray diffraction techniques.

Little or no porosity was observed in the solution treated U + 4 Mo - 0.1 Si specimen that had been irradiated to 0.35 at. $\frac{\circ}{8}$ BU at $450 \mathrm{C}$. This conflrms the lack of swelling observed in this specimen by density measurements. The specimens of this alloy irradiated to 0.45 at. $\%$ BU at $525 \mathrm{C}$ contained small tears scattered throughout the matrix and a large number of tiny spherical voids presumed to be fission gas pores. It is significant that this alloy appears to be 
completely free of the tearing in the 400-500 C temperature range and highly resistant to the tearing in the 500-600 C range that is normally encountered with more dilute uranium base alloys at these low exposures.

\section{High Pressure Postirradiation Annealing}

Analysis of the compatibility tests between NaK, U, Ta, Zircaloy-2, and 304 stainless steel at $900 \mathrm{C}, 15,000$ psi, and 96 hours revealed that a reaction had taken place between the constituents. The can and samples had completely fused or alloyed, thus eliminating any possibility of sample analysis. Subsequent examinations show that $\mathrm{U}-\mathrm{Fe}, \mathrm{U}-\mathrm{Nl}_{1}$, and $\mathrm{U}-\mathrm{Cr}$ eutectics had formed, and the resulting molten alloy (melting points range from 725-860 C) dissolved the tantalum baskets and liner materials. Microprobe analysis shows that potassium was distributed through the reaction product. The sodium originally present in the NaK was probably dissolved by storing the assemblies for two weeks in ethylene glycol monoethyl ether.

A search of the literature shows that there is no data on the $\mathrm{NaK}-\mathrm{U}$ interaction above $750 \mathrm{C}, \mathrm{NaK}-\mathrm{Ta}$ reaction above $650 \mathrm{C}$, or the NaK-Zircaloy-2 reaction above $650 \mathrm{C}$, although tests in sodium indicate that there should be no problem up to $900 \mathrm{C}$.

Follow-up tests at low pressures are now in progress to isolate the exact cause of the reaction. It is felt that the application of high pressures has little, if any, effect on this alloying. Tests are being run for 100 hours to determine:

1. If the NaK (at $900 \mathrm{C}$ ) can act as a carrier medium to transport the $\mathrm{Fe}, \mathrm{Cr}$, and $\mathrm{Ni}$ from the can to the $\mathrm{U}$ where it reacts to form the eutectics,

2. The interaction between $\mathrm{Ta}$ and $\mathrm{NaK}$ at $900 \mathrm{C}$, and

3. The interaction between $\mathrm{Zircaloy}-2$ and NaK at $900 \mathrm{C}$.

\section{Nondestructive Testing (J.C. Spanner)}

Detection of Irradiation-Induced Shift in Nil-Ductility-Transition Temperature

Ultrasonic test apparatus has been fabricated, and test specimens are being irradiated to continue the ultrasonic "critical angle" studies on neutron irradiated pressure vessel steels.

Twelve test specimens were individually encapsulated, mounted in a multispecimen capsule, and sent to the ETR for low temperature, low flux exposures during Cycle 89. Three exposures levels are expected 
With four specimens each at about $2.7 \times 10^{18}, 4.5 \times 10^{18}$, and $6.4 \mathrm{x}$ 1018 nvt $1 \mathrm{MeV}$. A fifth specimen at each level contains "fusible sentinels"--low melting temperature alloy wires--which will permit determination of the approximate maximum temperature during irradiation. Three steel alloys are included at each level: ASTM A-542 Class II, AISI 304 , and ASTM A-302B. Two samples of the A-302B steel include material from the top and from the middle of a plate-both cut with the same orientation with respect to rolling direction.

Sixteen additional specimens are being prepared for exposure in Cycle 90. A high flux, low temperature hole in the reactor will be used. Wide gap capsules will be employed on four of the capsules in an attempt to force a high temperature (above $450 \mathrm{~F}$ ) exposure. Other specimens will also be prepared for exposure in a high flux, high temperature hole in the reactor, but such space is not expected to become available for several months.

Several problems must be overcome before the interim hot cell facilities in 324 Building become operational. Two approaches to the irradiated specimens storage problem are being explored: (1) using a $3 \frac{1}{2}-t$ on storage cask on a loan basis from Radiomet which, however, must be decontaminated, or (2) building a new storage box--probably with honeycomb-type construction for individual specimen retrieval. Frequent entry into the cell without excessive disturbance to the alr balance will be accomplished by installation of a portable personnel door inserted in the entryway of the partially open air-lock door. The personnel door and frame are being bullt. Various items of lab furniture and apparatus previously sent to the 324 hot cell for storage while awaiting usage are now missing and must be replaced.

\section{Eddy Current Probe Design}

A study is being conducted to investigate the theoretical and practical aspects of eddy current sensing probe design and to apply the information obtained to the development of guidelines for general probe construction.

During this reporting period the development of a precise technical definition of test probe sensitivity and stability was attempted. it appears that complete analysis will require that: (1) sensitivity and stability be expressed as vector quantities, and (2) several different types of sensitivity and stability be specified for each probe. For example, a separate value of sensitivity and stability should be specified for each quantity to be detected or measured such as thickness, spacing, conductivity, permeability, or defects of a given shape. Since sensitivity and stability are quite frequently dependent near resonance, performance of a single probe is characterized by a family of sensitivities and stabilities. This results in a rather complicated description for a single probe. It appears desirable, therefore, to seek practical approximations to reduce the number of probe parameters to a minimum. 
It should be noted that probe sensitivity and stability are different than tester sensitivity and stability, which include the probe characteristics, but which are also affected by amplifier characteristics, detection methods, etc.

Fundamentai Ultrasonic Studies

The EDPM Program involving ultrasonic pulse propagation in the presence of losses continues to be modified in an attempt to incorporate Kautz function analysis. Methods for scanning and imaging using acousto-optical interactions are also being studied.

Previous studies have provided basic assumptions about the expected ability to represent a given pulse with a set of Kautz functions. One of these dealt with the supposition that the coefficients decreased enough so that relative differences in the squares of successive palrs of Kautz coefficients could be made negligible compared to the precision of pulse data measurements. The program results thus far indicated that the first four coefficients were nearly equal when attempts were made to represent previously measured pulses. This makes the algorithm for isolating pulse frequencies and decay rates unworkable unless there is some oversight or mistake in the analysis.

Current investigations involve a search for program errors or over-sights which could cause the difficulties. Input pulses having known constituents will be tested for kautz representation. If the program appears to be calculating the proper results, then methods of pulse analysis other than those currently being used may be necessary in order to represent measured ultrasonic pulses.

Discussions in the previous monthly report included a method for scanning an ultrasonic beam using a wedge. This was made possible by sweeping the ultrasonic frequency. Further studies and discussions with colleagues have indicated a similar method is avallable for optical beam scanning. In the optical case the FabryPerot interferometer principle can be used to obtain a thin line of light. The line can be made to scan by inserting a Kerr cell for other cell for altering the refractive index) between the FabryPerot flats. Another such system can then be used orthogonal to the first to confine the beam to a spot that is then movable to any two dimensional position.

Other methods for optical scanning involve the use of diffraction by ultrasonic beams. Good quality television images have been produced with acousto-optical modulating and deflection systems. These methods employ novel features which appear to be directly applicable to lmaging the ultrasonic flelds used in nondestructive testing. 
One combination using acousto-optic methods, which appears to show promise for imaging work, uses a modified schlieren system for imaging. The modification consists of the replacement of spherical lenses with cylindrical. Images are therefore formed in cross section to the ultrasonic beams. Such a system using continuous ultrasonıc energy was demonstrated and discussed in the literature.

To make the imaging method more adaptable to nondestructive testing, other modifications to the above method appear worthwhile. The use of continuous ultrasonic signals causes poor contrast for small changes due to effects that are desirable to observe in nondestructive testing. To improve contrast, pulses are used, and in conventional test applications in which imaging is not provided, signal contrast is improved by using low pulse repetition rates and electronic gates which eliminate unwanted background signals.

To permit simllar rejection of unwanted signals in the imaging system, pulses can also be used, but the relatively low repetition rates that are necessary to avoid unwanted reflections do not permit good optical sensitivity. The optical light source can be pulsed in synchronization with pulse repetition rates, and a line optical beam can be made to "slice" through the ultrasonic beam to provide the same gating function that permitted good contrast in the electronic method. To build sensitivity to compensate for the low duty cycle repetition rate, the optical beam line can be made to scan using one of the aforementioned methods. In this way the line can be made to travel at the speed of sound and follow the pulse for an appreciable portion of the pulse repetition period. Then the beam can be made to return to follow the subsequent pulse, etc. In this way sensitivity for Imaging can be made comparable to the continuous system and still provide good contrast.

In addition to the contrast provided above, it may also be advantageous to further improve the method by using two scanning, line source optical beams in slightly different spatial positions. The system could be adjusted to produce lmages of ultrasonic beams which have features similar to phase contrast optical microscopes. This may be accomplished by adjusting for proper phase and amplitude relationships between the scanning beams. Here, as well as for other methods for image improvements which may be of interest, it is necessary to have coherent ultrasonic and light sources. Conventional ultrasonic sources are coherent, and a laser is being ordered to fulfill the optical requirements.

Electromagnetic Research

Output waveforms of a pulsed eddy current test were further observed, and means to expand them into components were studied prior to application of the multiparameter test principles to a pulsed eddy 
current test. Favorable results were obtained with a new mounting arrangement of a group of four potentiometers in the transformation section of the multiparameter eddy current tubing tester to give fingertip control and to provide ready visual appraisal of relative settings. Additional input admittance loci simulating variations in test metal conductivity and thickness were obtained using a resistance-capacitance network being evaluated for use in the simulation of eddy current tests. Construction of the multichannel eddy current tubing tester is continuing, and completion of the transcelver section awaits delivery of electronic parts.

Output waveforms of a pulsed eddy current test were observed for several test conditions in which defects at different depths within a metal were simulated by separating a stack of 0.032 " thick aluminum plates at different levels. Several different methods are under study for analyzing the observed pulses for use in a pulsed multiparameter eddy current test.

Four of the 16 matrix element value adjusting potentiometers of the multiparameter tester transformation section have been mounted in a new arrangement that has been partially evaluated with favorable results. Only one set of four potentiometers was mounted for this test, a composite photograph showing outside-wall, inside-wall, and within-the-wall simulated defects could not be made, but the potentiometers were adjusted in turn for each type of defect and three separate photographs were made.

Input admittance locl measurements of an $\mathrm{R}-\mathrm{C}$ network being used to simulate an eddy current test further confirm that these input admittance loci are similar to the impedance loci of an eddy current test coil for simulated changes in metal conductivity and metal thickness. The similarity is not exact, but this is not expected because of the great difference between the metal case and the network case. The metal is three dimensional, whereas the network is essentially one dimensional. However, the similarity in results is believed to be sufficient to make its use practical in analytical and experlmental studies of different excltation waveforms in the eddy current test.

The transformation section is now complete and ready to be installed as soon as the carrying case is received. Completion of the transceiver section is awalting recelpt of new transformers and bridge adjustment potentiometers.

\section{Composite Methods Research}

A study of the waveform of ultrasonic test signals is being made to determine the selection of parameters and signal analysis techniques to be used in demonstrating the feasibility of applying the multiparameter test concept to the interpretation and display 
of ultrasonic signals. A pulse generator and an electrical network were used to simulate a back surface echo signal.

Ultrasonic nondestructive test signals obtained in an immersion type pulse-echo test using nonfocussed and focussed transducers were observed. Most observations were made with a PZT focussed trans-

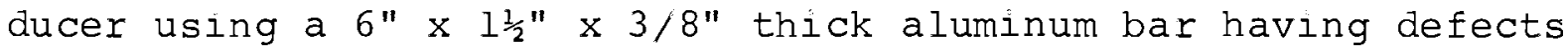
simulated by four slots, sawed across the width of the bar to a depth within $0.016,0.032,0.064$, and $0.125 "$ from the front surface. Echo signals obtained from the front surface of the bar, the back surface of the bar, and from the bottom of each of the four slots were photographed. A study of these signals showed that the analysis of signals due to defects close to the test specimen surface would be aided by use of artificial signals which could be readily controlled in time of occurrence to simulate the depth parameter. A back surface echo signal was selected for simulation. This signal was very closely simulated using a seven-element, doubly tuned network driven by a pulse generator. The time of occurrence of the signal was readily adjusted by the pulse generator delay control.

Infrared and Thermal Research

Work is continuing on both the remote transient and the sinusoidal steady state thermal nondestructive testing methods. Previous work has shown that the initial experimental transducers used in the sinusoidal steady state method were not stable enough for accurate measurements on high conductivity samples. A new, more stable transducer has been fabricated. An attempt was made to initiate a series of tests on the new transducer. However, it was not possible to carry them out due to a failure in the electronic drive system. Repairs are under way, and a complete series of tests on the new transducer is planned.

Last month the Barnes research radiometer used in the system was observed to be defective. As a result, an alternate radiometer system was set up in the laboratory and tested. Preliminary results indicated that it would work satisfactorily but is not as sensitive as the research radiometer. The collector optics used in the original setup was a 0.5" focal length germanium lens. Since the initial installation, several other lenses have been obtained for installation in the radiometer system.

In addition, repair of the Barnes radiometer was attempted by a Barnes field representative during a visit here last month. Presently, the Barnes instrument is being set up for tests to determine whether or not the repalrs corrected the drift which was previously observed. 
Transducer Development

In order to fabricate a vacuum deposited cas transducer, certain temperature conditions must be maintained during deposition. The approach that is presently being used requires that the bell jar surface be held at $150 \mathrm{C}$, the substrate be maintained at 180-200 C, and that the $\mathrm{Cd}$ and $\mathrm{S}$ be evaporated from separate crucibles simultaneously during deposition. The hardest temperature to acquire is the $150 \mathrm{C}$ bell jar surface. Test runs have been made heating the bell jar to $150 \mathrm{C}$. This was done using heading tape and variable transformers to control the temperatures of the tapes.

The vacuum system is presently being used to do other work and should be available again by April 26. The next step will be to deposit Cas on a quartz substrate and determine its axial orientation.

Nuclear Ceramics (R. E. Nightingale)

Materials and Information Exchange

Single crystal specimens of $\mathrm{UO}_{2}$ were prepared, characterized, and sent to Oak Ridge National Laboratory (ORNL) and Lawrence Radiation Laboratory (LRL) for their use in basic studies. About 200 single crystals of $\mathrm{UO}_{2}$, enriched to about $50 \% \mathrm{U}-238$, were received from ORNL for heat treatment and spheroidizing. Preliminary arrangements have been completed with LRL to exchange some of their UN powders which will be pneumatically impacted, characterized, and returned. In addition, $\mathrm{PuO}_{2}$ pellets were provided to our research personnel for use in basic property and spheroidizing studies.

Ceramography of $\mathrm{UO}_{2}-25$ wt: $\mathrm{PuO}_{2}$ Solid solution

Grain boundary etching in $\mathrm{UO}_{2}-25$ wto $\mathrm{PuO}_{2}$ solid solution depends on the O/M ratio. A material with an O/M ratio of 1.96 was etched with an etchant of nine parts $\mathrm{H}_{2} \mathrm{O}_{2}$ (30\%) and one part $\mathrm{H}_{2} \mathrm{SO}_{4}$. A material with an $O / M$ ratio of 2.00 was not attacked by the above etchant, but an etchant of $15 \mathrm{ml} \mathrm{HNO}_{3}, 5 \mathrm{ml} \mathrm{H}_{2} \mathrm{O}$, and three drops $\mathrm{HF}$ (52\%) attacked the grain boundaries in 25 minutes. When the HF addition exceeded six drops, surface staining occurred.

Microstructure of Mixed Plutonium-Uranium Oxides

Two mixed oxide specimens $\left(\mathrm{UO}_{2}-25\right.$ wto $\left.\mathrm{PuO}_{2}\right)$ reported previously to contain prominent areas of a dispersed white phase were subjected to electron microprobe analysis. The white material was found to be primarily uranium, as platelets, in the coprecipitated oxides and as needles in the mechanically-blended materials. 
Work continued on preparing brittle oxide specimens for transmission electron microscopy. Excellent thinning of the material over large areas was achieved by paying special attention to preparation of parallel faces during initial steps and skillful application of polishing techniques. One small sintered $\mathrm{UO}_{2}$ specimen was examined, and several additional sintered and pneumatically-impacted $\mathrm{UO}_{2}$ specimens are being prepared.

Phase Studies on Mixed Nitrides

Decomposition behavior and melting points were determined for UN - 25 wto PuN, UN - 50 wto PuN, and UN - 75 wto PuN under nitrogen pressures between one and 50 atmospheres and in one atmosphere of helium. The data showed considerable scatter; nitrogen pressures for congruent melting varied from 10-20 atm at $2780 \pm 50 \mathrm{C}$ for UN 25 wt: PuN to 20-30 atm at $2700 \pm 50 \mathrm{C}$ for UN - 75 wt\% PuN. Decomposition temperatures in one atm of nitrogen varied from $2730 \pm 50 \mathrm{C}$ for UN - $25 \mathrm{wt} \%$ PuN to $2630 \pm 50 \mathrm{C}$ for UN - $75 \mathrm{wt} \%$ PuN; decomposition temperatures in one atm of helium varied from $2350 \pm 50 \mathrm{C}$ for UN 25 wto PuN to $2250 \pm 50$ C for UN - 75 wto PuN.

Samples were prepared by hydriding and nitriding of U-Pu alloys of the stated compositions. Mixtures of uranium and plutonium metal were arc melted four times in pure argon to homogenize the alloys. All three compositions were hydrided at room temperature in pure hydrogen. The standard nitride synthesis procedure was used, but the samples were also annealed for two hours in vacuum at $1400 \mathrm{C}$ and two hours in nitrogen at $1600 \mathrm{C}$ to insure single phase, homogeneous nitrides.

Lattice parameters were determined, and a slight negative deviation from a Vegard's law plot was observed for the nominal compositions. This may be due to minor losses of plutonium during arc melting.

Ice-Mant le Drop Calorimeter

An ice-mantle drop calorimeter was received and installed. The calorimeter will be used to measure heat contents and specific heats of materials, including those containing plutonium, from room temperature to $1650 \mathrm{C}$. Chekcout and calibration of the instrument is in progress.

Thermal Diffusivity of Uranium Oxycarbide

Thermal diffusivities of five uranium oxycarbide samples ranging

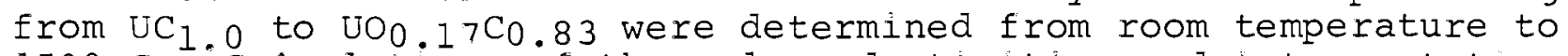
$1500 \mathrm{C}$. "Calculations of thermal conductivities and interpretation of the data are under way. 
Phase Equilibria in the Pu-O-N System

Lattice parameters for $\mathrm{Pu}(\mathrm{N}, \mathrm{O})$ specimens synthesized in nitrogen atmospheres containing 30, 100 , and 300 ppm oxygen were determined to

be $4.9048 \AA, 4.9053 \AA$, and $4,9054 \AA$, respectively. Samples prepared in nitrogen atmospheres containing 10 and $1000 \mathrm{ppm}$ oxygen are now being analyzed. A calibration curve for determining the amount of $\mathrm{PuO}_{2}$ phase in PuN by $\mathrm{x}$-ray diffraction was obtained from mixtures of $\mathrm{PuO}_{2}$ and $\mathrm{PuN}$.

Attempts to evaporate ce from a tungsten filament for use in the $\mathrm{Pu}-\mathrm{O}-\mathrm{N}$ ternary equilibria apparatus were not successful. Problems similar to those encountered with a tantalum heater occurred. An electron-beam evaporation source has been ordered, and work on the ternary evaporator will be suspended until this is installed.

\section{Nuclear Graphite (R. E. Nightingale)}

High Temperature Irradiations

The high temperature capsule, GEH-13-13, damaged during the ETR Cycle 88 shutdown, was discharged after two cycles of operation. Maximum exposure on the samples is estimated to be $1.5 \times 10^{2} 1 \mathrm{nvt}$ (E $0.18 \mathrm{MeV})$. Average temperatures of the graphite samples ranged from 800 to $1250 \mathrm{C}$.

The failure occurred when the capsule was being moved during reactor core modifications. The capsule fliler plece was fitted in position quite snugly, and the efforts to free it ruptured the capsule lead tube at one of its bends. The capsule was removed from the reactor and disassembled in a hot cell where it was determined that less than one cup of water had entered the capsule. It was noted at disassembly that the stainless steel gas exit tube had melted at one point and deposited steel onto several of the graphite dials. Future gas tubes in the application will be of molybdenum to avoid this problem.

Other modifications will increase the ruggedness of the capsule. All external parts of the capsule will be 304 stainless steel. The lead tube that falled on GEH-13-13 was aluminum, and the use of stainless steel will considerably reduce the chance that such an incident will recur.

The scheduled recharge of the high temperature capsule is early June. Sample loading will probably remain the same if the samples have not been damaged. 


\section{EBR-II Irradiations}

Two graphite pins in the core of EBR-II are scheduled for discharge in June. Exposure on the capsules should be more than $10^{2} 2$ nvt $(\mathrm{E}>0.18 \mathrm{MeV})$.

Twenty-four thermocouples have been accurately calibrated and are being encapsulated in two pins for irradiation in the EBR-II to exposures of 1022 nvt. It appears the irradiations will not commence before June. The thermocouple types included in the first two pins are Geminol, Chrome1-Alume1, W-W 26\% Re, W 5\% Re - W 26\% Re, and Pt - Pt 10 \% $\mathrm{Rh}$.

\section{Irradiation of Nuclear Graphite}

Graphite irradiation capsule H-3-15 was charged in the GETR, position D7, on March 20. The capsule is now operating at design temperatures of 325 to $800 \mathrm{C}$. One Chromel-Alumel thermocouple was lost at startup. The other elght thermocouples 15 Geminol and 3 Chromel-Alumel, are operating satisfactorily. The capsule is scheduled for discharge in July.

Irradiation of "Proof-Test" Graphites

Graphite irradiation Capsule H-3-25 was charged in the GETR, position \#5, on March 8 at the start of Cycle 84. The capsule is operating at design temperatures of 600 to $1100 \mathrm{C}$. One Geminol thermocouple was lost after about two weeks of operation. The remaining eight thermocouples (six Geminol, two $W$ 5\% Re - W 26\% Re) continue to operate satisfactorily. The capsule is scheduled for discharge in June.

Thermal Expansion of Polycrystalline Graphite

A number of anisotropic ceramic materials form polycrystalline composites whose physical properties resemble those of polycrystalline graphite. Some of the similarities are: a low thermal expansion coefficient $(\bar{\alpha})$ at room temperature; a relatively low value of mechanical strength (S) and Young's modulus (E) at room temperature; an increase of $\mathrm{S}$ and $\mathrm{E}$ with increasing temperature; and a nonelastic stress-strain behavior. These ceramics also exhibit a hysteresis in the thermal expansion as a function of temperature, a characteristic not yet reported in graphite.

To determine if graphite has a hysteresis in thermal expansion, parallel and transverse samples of TSX were cycled to various temperatures. The transverse sample showed a decrease in length at a given temperature on the cool-down curve if cycled to $2400 \mathrm{C}$ and 
$2200 \mathrm{C}$. Below $2000 \mathrm{C}$, no hysteresis was observed. The parallel sample had no measurable hysteresis even when heated to $2400 \mathrm{C}$.

Gas-Graphite Reactions

Examination continues on the nature of oxidation attack upon TSX and AGOT-LS graphite by reactions with thermal and microwaveexcited oxygen. The investigation to date has included two specimens whlch are given as nearly the same treatment as possible. The thermal and exclted oxygen reactions have been carried out with varied sequence and length of reaction time to observe their effects upon specımen structure.

To the present time, the specimens have been given a thermal oxldation following a microwave oxidation treatment. It has now been found that if the specimen is glven another microwave oxidation after receiving a thermal oxidation, it once again takes on the characteristics possessed initially before being given any thermal oxidation. The structural changes produced by either type of treatment tend to be enhanced by extending the speciflc treatment time.

Further structural detalls have been uncovered by repeated use of the thermal treatment. It now appears that the very thin, almost transparent, layers produced in both types of graphite are themselves sheets of graphite. The relatively dense objects which have been seen in sharp contrast distributed over the thin graphite layers appear to be of at least two types. The most frequently encountered type seems to be thick pieces of graphite which remain after most of surrounding material has been selectively removed. These remaining pleces of graphite tend to have a rounded profile with very few sharp corners. They are distinguished in this respect from a second type of dense particles which has also been found on the thin graphite layers. The latter particles tend to have stralght edges and sharp corners. A variety of these polyhedra, including cubes, has been found. They are believed to be impurities, with the various shapes observed being characteristic of specific crystal structures.

Another structural feature resulting from the thermal oxidation reaction is the appearance of extensive pitting through multiple graphite layers. The effect is quite common in both TSX and AGOT-LS graphites; however, pits with a general hexagonal shape appear to be more common in AGOT-LS graphite. This may be due to specific effects of Impurities present. The specific kind of pitting which is common to both types of graphite apparently comes about by edge attack upon the highly defected crystal structure characteristic of both polycrystaline materials. Whenever pitting is observed at a very advanced stage, many loose graphite layers can be found. 
The effect of a heavy thermal oxidation treatment has been investigated by giving both TSX and AGOT-LS specimens a single 30minute oxldation rather than the 5-minute treatments used initially. After the longer oxidation treatment, both specimens were found to have more delicate structures, but AGOT-LS was found to be much more fragile than TSX. One posslble benefit that might be achieved from such heavily oxidized specimens is the creation of more translucent areas in the interior of the sample which would be sultable for further microscopic examination. A number of translucent areas were indeed created by the first attempt, and some new types of structures were seen. In one case it appeared that less-ordered graphite, resembling binder material, may have been selectively removed from contact with adjacent well-ordered crystallites. However, much further investigation will be required to determine the value of these new areas created by heavy thermal oxidation.

Whıle the present specimen preparation techniques used in this study appear to work quite well for studying gas reactions, most of the samples have been made translucent by oxidation rather than by a mechanical process. For this reason, it is particularly important that any artifacts produced by such chemical preparation techniques be properly interpreted with regard to the structures originally present. In order to aid in such interpretation, two different mechanical procedures have been employed to prepare additional graphite specimens. In the first procedure graphite discs, with a drilled conical depression in the center, are cut from rod stock by sawing through the bottom of the depression with a high-speed alumaum cutoff wheel. It has been found that the edges of the central hole thus created contain many translucent areas potentially suitable for microscopic examination. The second procedure for specimen preparation involves the use of grinding and polishing techniques to mechanicaliy thın graphite while it is supported in an epoxy resin. The latter procedure has been developed by the Materials Process Development Unit and was used recently to produce a number of TSX specimens suitable for microscoplc examination. The above two mechanical specimen-preparation techniques are expected to help in better understanding the structural changes produced chemically in other specimens.

\section{Radiolysis of $\mathrm{CO}_{2}-\mathrm{H}_{2}$ Mixtures}

Earlier studies in this laboratory (BNWL-SA-591) indicate that radiolysis of a mixture of $\mathrm{CO}_{2}$ and $\mathrm{H}_{2}$ by gamma radiation from co60 produced methane, as a minor product, with a $\left(-\left(\mathrm{CH}_{4}\right)\right.$ value of 0.3 at $100 \mathrm{C}$ and decreasing to 0.1 at $500 \mathrm{C}$. English workers ( $A E R E-R$ 5286) have found a $G$ value of 0.025 between 200 and $400 \mathrm{C}$ for $2 \% \mathrm{H}_{2}$ in $\mathrm{CO}_{2}$.

In repeating some of these experiments, we find that the extent of outgassing of the Pyrex ampoules decreases the observed rate of production of methane. Also, the presence of small quantities of 
oxygen in the gas mixture decreases the rate of production of methane to a value that is a factor 5 lower than that observed by Hummel. We are currently rechecking this work with highly purified gases in quartz vessels outgassed at $800 \mathrm{C}$.

\section{Irradiation Damage to Reactor Metals (A. I. Bement)}

\section{Alloy Selection}

Several new alloys and/or areas of investigation have been initiated under alloy selection. Arrangements have been made to obtain samples of two new stainless steels, JS-700 (21 Cr, $25 \mathrm{Ni}, 4$ Mo) and a U.S. Steel stainless alloy $(18 \mathrm{Cr}, 18 \mathrm{Ni}, 2 \mathrm{Si})$. Studies have been initiated with Fabrication Development Unit (BNW) to determine the feasibility of fabricating a series of $\mathrm{V}-\mathrm{Cr}$ alloys. A proposal has been written to Douglas United Nuclear, Inc., for study of irradiation damage on Haynes 25 (a co-base alloy). In addition, a program to select a material for an in-core pressure device for FFTF has begun. Materials in thin section (0.005") will be examined for tensile properties, low-cycle fatigue, and aging reactions after exposure in $1200 \mathrm{~F}(648 \mathrm{C})$ sodlum. The effect of metal-sodium interactions on mechanical properties will also be studied. Materials contemplated for this study are $304,316,348$, JS-700, and Incoloy 800 of the austenitic stainless steel group; Hastelloy-X and Inconel 600 of the nickel-base group; and Haynes alloys 25 and 188 of the cobaltbase group.

In-Reactor Measurements of Mechanical Properties

The purpose of the in-reactor measurements program is to determine the effects of irradiation on the mechanical properties of reactor structural materials. The present effort involves measuring creep in AISI 304 stainless steel and nickel-base alloys during neutron irradiation,

In-reactor creep rupture test results on AISI 304 stainless steel have indicated a much greater effect of irradiation on rupture life at $840 \mathrm{C}$ than at lower temperatures. An in-reactor test ruptured

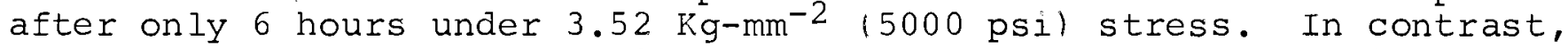
an unirradiated control specimen tested under the same conditions of temperature and stress did not rupture until 926 hours. The total elongation for the in-reactor specimen was about $8 \%$, while that for the control specimen was about $28 \%$. These data suggest about a 100 times faster creep rate during the in-reactor creep test and an even greater difference between the rupture lives. Unfortunately, the extensometer in the in-reactor creep test was a new design which failed during service. Plans are being made to repeat these tests and to check the reproduciblity of these results. 


\section{Irradiation Effects in Structural Materials}

Stainless steels. The purpose of this phase of the program is to determine the combined effects of irradiation and environment on the mechanical properties of stainless steels. Radiation-induced property changes will be determined from irradiations and tests conducted at various temperatures on several alloys. Particular emphasis will be placed on determining the existence of metallurgical instabilities and the mechanisms by which they are enhanced in a nuclear environment.

Tensile specimens of 25\% cold worked, AISI Types 304 and 348 stainless steel have been irradiated at $290 \mathrm{C}$ to a fast neutron fluence of $6.0 \times 10^{21} \mathrm{n} / \mathrm{cm}^{2}(\mathrm{E} 1 \mathrm{MeV})$ and tested at temperatures to $750 \mathrm{C}$. The irradiated yield and tensile strengths of the 304 specimens are higher than those of the unirradiated, as-fabricated material at all test temperatures. The irradiated strengths rapidly approach the unirradiated values at test temperatures above $500 \mathrm{C}$, and at $750 \mathrm{C}$ all strength values are about the same. Very little strain hardening was observed for the irradiated material in this range of test temperatures. The irradiated and unirradiated uniform elongations are about the same in the 300 to 700 C test temperature range. At other test temperatures the irradiated uniform elongation is less than that for the unirradiated specimens. The total elongation of the irradiated material is less than that for the unirradiated material at all temperatures. Very little necking strain was observed in irradiated specimens.

The irradiated AISI 348 tensile specimens exhibit higher strength values than the unirradiated specimens at all test temperatures except $600 \mathrm{C}$. At this temperature the irradiated and unirradiated, as-fabricated, yield strengths are the same as are the ultimate tensile strengths. A significant feature of the data $1 s$ the fact that hardening of the yield and tensile strengths exists at $750 \mathrm{C}$. This may be due to stable radiation-induced defects. The irradiated and unirradiated uniform elongations are about the same for all test temperatures. This is also true for the total elongations at test temperatures to $600 \mathrm{C}$. Beyond this temperature, the Irradiated total elongation values are below those for the unirradiates specimens.

Optical and transmission electron microscopy has been initiated on annealed AISI 304 stainless steel specimens which were irradiated

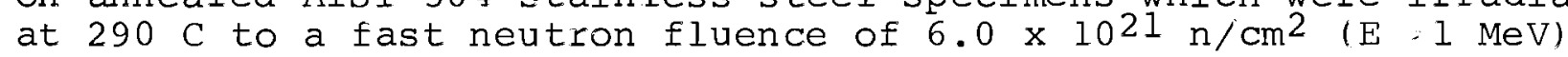
and then tested at room temperature, 500, and $750 \mathrm{C}$.

Nickel-Base Alloys. The purpose of this program is to determine the effects of modified microstructures on the irradiation stability of nickel-base alloys. Microstructural modifications are made by preirradiation thermal or thermomechanical treatments and are evaluated by tensile tests, stress rupture tests, and microstructural examinations. 
A paper entitled "The Influence of Thermomechanical Treatments on the Strength, High Temperature Stability, and Microstructure of Hastelloy X-280," by I. S. Levy was submitted for presentation at the International Conference on the Strength of Metals and Alloys to be held in Tokyo in September 1967.

A paper entitled "Thermomechanical Treatments of Hastelloy X-280 for Nuclear Reactor Applications," by I. S. Levy was submitted for presentation at the Fall Meeting of the Metallurgical society of the AIME to be held in Cleveland in October 1967.

A paper entitled "The Effect of Preirradiation Microstructure on Radiation Damage in Hastelloy X-280," by I. S. Levy, B. Mastel, and J. I. Brimhall, is being prepared for journal submission.

Control, unirradiated, thermomechanically-pretreated, Hastelloy $\mathrm{X}-280$ specimens which were subjected to a thermal history analogous to specimens irradiated at $1250 \mathrm{~F}(677 \mathrm{C})$ to a fluence of $1 \times 10^{20} \mathrm{n} /$ $\mathrm{cm}^{2}$ ( $\mathrm{E}-1 \mathrm{MeV}$ ) were tensile tested at $1350 \mathrm{~F}(732 \mathrm{C})$. A general increase in strength levels and a general decrease in ductility with level of cold work in the treatments was observed. Yield strength increases, relative to the standard treatment, of up to $34 \%(58,850$ vs. 44,000 psil could be achleved with retention of $2.5 \%$ uniform elongation and $21 \%$ total elongation. However, the best combination of strength increase and ductility retention was for a treatment that included $10 \%$ cold work followed by a $1500 \mathrm{~F}(815 \mathrm{C})$ age. The strength increase relative to the standard treatment was $25 \%(55,000$ vs. 44,000 psil with retention of $4.8 \%$ uniform elongation and $26 \%$ total elongation. The ductility of specimens subjected to the standard solution treatment and, therefore, having lower strength was only a little better with 5.5\% uniform elongation and $32 \%$ total elongation.

A comparison was made of this data with that previously obtained for unirradiated control specimens that had been exposed at $540 \mathrm{~F}(282 \mathrm{C})$. Exposure at the higher temperature resulted in increases in strength and losses in ductility relative to the $540 \mathrm{~F}$ $1282 \mathrm{Cl}$ exposure. Of extreme Importance was the observation that the magnitudes (and percentages) of the strength increase and ductility loss were far less for several of the thermomechanical treatments than for the standard solution treatment. For the standard treatment, the increase in yield strength was 15,500 psi (or 55\%) and the percent uniform elongation suffered an $82 \%$ reduction from the value after $540 \mathrm{~F}(282 \mathrm{C})$ exposure $(5.5 \mathrm{vs} .30 .5 \%)$. On the other hand, the $10 \%$ cold work, $1500 \mathrm{~F}(815 \mathrm{C})$ age treatment resulted in an increase in yield strength of only 5000 psi (or 10\%), while the percent uniform elongation was reduced by only $40 \%$ from the value arising from the $540 \mathrm{~F}(282 \mathrm{C})$ exposure $(4.8 \mathrm{vs} .8 .0 \%)$.

Metallography of the standard treated specimen after the $1250 \mathrm{~F}$ $(677 \mathrm{C})$ exposure showed massive matrix precipitation even in the unstressed areas that had been free of matrıx precipitate after the 
$540 \mathrm{~F}(282 \mathrm{C})$ exposure. The precipitate accounts for the strength increase in the $1250 \mathrm{~F}(677 \mathrm{C})$ treatment. In the thermomechanically treated specimens, a precipitate structure developed during the treatments the amount depended on the severity of the treatment) so that subsequent exposure at $1250 \mathrm{~F}(677 \mathrm{C})$ resulted in less additional precipitate and, therefore, less strength increases, with the most severe treatment $(20 \%$ C.w., 1500 F $(815$ C), 24-hr age) showing no strength increase. Thus, the thermomechanical treatments resulted in increased stability to a representative thermal exposure and in increased strength.

The postirradiation $1350 \mathrm{~F}(732 \mathrm{C})$ tensile test data for the Hastelloy $\mathrm{X}-280$ specimens irradiated at $1250 \mathrm{~F} 1677 \mathrm{C}$ showed that irradiation further reduced ductility of the standard treated material to only $1.8 \%$ uniform elongation $(a) 67 \%$ reduction below the $5.5 \%$ value for the unirradiated control specimen). An experimental treatment that involved high temperature aging had over three times the ductility of the standard treatment. A treatment involving cold work and aging improved the postirradiation yield strength, relative to the standard treatment, by $28 \%(53,000 \mathrm{vs}$. 41,500 psi) and maintained over three times the ductility.

SAP Alloys. The program to determine the effect of irradiation on sintered aluminum products (SAP) in support of the HWOCR Program has been discontinued as per verbal instructions from the AEC. The various work requests have been recalled.

Before the stoppage a vendor had been selected for machining the specimens and collets. The specimen material had not been shipped to the vendor. This request has been recalled also. Material characterization was in progress. The metallography and chemical analysis was partly completed on the SAP $89 \mathrm{~S}$ and SAP 930 rods received from Atomics International (AI).

The sheath capsule mockups will be discharged from the ETR sometime this week. Because of interest in the thermal monitors by other programs, the mockups will be examined.

Zirconium Alloys - In-Flux Oxidation and Hydriding. In the

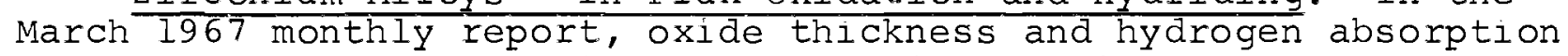
data were reported for Zircaloy-2 tensile specimens exposed 894 effective full power days in the G-7 loop of the ETR. Oxide thicknesses were reported for specimens from Quadrant 24 which had recelved a fluence of $8.7 \times 10^{2} \mathrm{n} / \mathrm{cm}^{2}$. Sections of specimens which had undergone tensile testing at room temperature were examined metallographically. Oxides had been disturbed by the tensile testing on all three specimens. However, on two of the three specimens, sections of the oxide appeared to be undisturbed. On specimen 23-1 (annealed) the mean oxide thickness was $1980 \mathrm{mg} / \mathrm{dm}^{2}$ (5.2 mils) compared to $1490 \mathrm{mg} / \mathrm{cm}^{2}$ on the corresponding annealed specimen from Quadrant 24 . on specimen 23-7 (20\% cold work: the mean oxide thickness was 
$1790 \mathrm{mg} / \mathrm{dm}^{2}$, somewhat lower than the thickness on the corresponding Quadrant 24 specimen. Damage to the oxide on specimen 23-13 (40\% cold work) was so extensive that meaningful oxide thicknesses could not be obtained.

The Quadrant 24 specimens examined metallographically were also sampled for hydrogen content. Results appear below.

\begin{tabular}{|c|c|c|}
\hline Specimen & Condition & $\begin{array}{c}\text { Total Hydrogen } \\
\text { ppm }\end{array}$ \\
\hline $24-6$ & Annealed & 445,465 \\
\hline $24-12$ & $20 \% \mathrm{CW}$ & 1402,1405 \\
\hline $24-18$ & $40 \% \mathrm{CW}$ & $1170, \quad 1184$ \\
\hline
\end{tabular}

The results agree with the results from other Quadrant 24 specimens reported last month.

Intercalibration Test of Counting Laboratories. Results have been received from four of the eleven participating laboratories. Each set of data has been ratioed to the results obtained by Isochem on the same sample. Ratios were then compared to determine the laboratory differences. Results from the four laboratories, three respondents and Isochem, are presented in the table and compared with the results of the intercalibration program conducted in 1964. These preliminary data indicate that agreement is considerably poorer than attained previously, as evidenced by the larger standard deviation on each monitor, except $46 \mathrm{Ti}(\mathrm{n}, \mathrm{p}) 46 \mathrm{SC}$. Agreement on analysis of $60 \mathrm{Co}$, which will find wide usage in fast reactors, has slipped markedly.

Comparison of Measurements at Various Sites

$\frac{1964 \text { Results }}{\text { Average }}$

Standard Deviation

\begin{tabular}{|c|c|c|c|}
\hline${ }^{60} \mathrm{Co}$ & ${ }^{58} \mathrm{Co}$ & ${ }^{46} \mathrm{SC}$ & ${ }^{54} \mathrm{Mn}$ \\
\hline $\begin{array}{l}0.996 \\
0.032\end{array}$ & $\begin{array}{l}0.99 \\
0.026\end{array}$ & $\begin{array}{l}1.04 \\
0.043\end{array}$ & $\begin{array}{l}0.99 \\
0.041\end{array}$ \\
\hline
\end{tabular}

1967 Results
(B) ased on 4 of 11
laboratories)
Average
Standard Deviation

$\begin{array}{ll}0.98 & 0.98 \\ 0.090 & 0.051\end{array}$
1.03
0.036
1.01
0.052
* Ratio of specific activity measurements at other sites to that of Isochem.

Significant disagreement in weighing activated specimens was discovered in the 1964 program. These preliminary results indicate this is not a problem at present. A standard deviation of $0.43 \%$ was calculated from the 48 weights received. 


\section{Fracture Mechanics}

Development of an ultrahigh vacuum environmental chamber is nearing completion. The chamber will be employed to determine the effect of external environments on the kinetics of subcritical crack propagation in high strength steels. Once the operating mechanisms are determined, the results will be extrapolated to lower strength steels such as those used in the construction of reactor pressure vessels. Several critical tests will then be performed on pressure vessel steels to determine empirical parameters describing the behavior of low yield strength materials.

The effect of neutron irradiation on the fracture toughness, $\mathrm{K}_{\text {Ic }}$, of cold worked as well as hydrided zircaloy-2 is presently being determined. Zircaloy-2 double cantilever beam (DCB) specimens with 0,20 , and $40 \%$ cold work were irradiated to a neutron fluence of $1 \times 1021_{\mathrm{n} / \mathrm{cm}^{2}}(\mathrm{E}, 1 \mathrm{MeV}$ at $280 \mathrm{C}$ in the ETR. The fracture toughness of the specimens is being measured in the as-discharged condition as well as after annealing at $475 \mathrm{C}$.

Hydrided Zircaloy-2 specimens containing 50, 100 , and $400 \mathrm{ppm} \mathrm{H}$ exposed to a neutron fluence of $2 \times 10^{20} \mathrm{n} / \mathrm{cm}^{2}(\mathrm{E} / \mathrm{MeV})$ at $280 \mathrm{C}$ exhlbit a lower toughness at temperatures above $0 \mathrm{C}$ than the same specimens in the unirradiated condition.

During the interim period the immediate goals of a basic study to investigate the effects of Irradiation produced defects on the fracture characteristics of crystalline materials were attained. The material studied in this investigation was single crystal lithium fluoride which had been cleaved into DCB specimens having the dimensions of $10 \mathrm{~cm} \times 1 \mathrm{~cm} \times \frac{1}{2} \mathrm{~cm}$. As an lonlc solid, LiF possesses several advantages over metallic systems in a basic study of irradiation effects on the mechanisms of fracture. Single crystal Lif has a well defined set of cleavage planes, $(100$. The operative slip system at room temperature in LiF is a/2 110 (110) which provides relatively few planes available for glide compared to many of the common bcc and fcc metals. This limited slip system coupled with the extremely low dislocation density $\left(10^{4} \mathrm{~cm}^{-2}\right.$, that can be obtained through prolonged anneals allows detalled observations of the deformation processes occurring in the region of high stresses at the crack tip. Furthermore, point defects may be produced in LIF by gamma and x-rays as well as by neutron bombardment. These irradiation induced defects, which in ionic crystals are called color centers, can give rise to irradiation hardening through mechanisms which are characteristically identical to those which occur in metallic systems subjected to neutron irradiation. Finally, many of the physical properties of LiF such as the deformation mechanisms and defect stablilty have been so extensively investigated that LiF is one of the most characterized materials available. 
Experimentally, this study consisted of two parts: (1) the measurement of the influences of gamma irradiation on the effective surface energy, (re), for crack propagation; and (2) metallographic observation of the influence of gamma irradiation on the crack tip dislocation arrangements. The original objectives of these experiments have been completed, and the results have been analyzed. Before the principal conclusions obtained from this study are presented, some of the more interesting observations made during the course of the investigation will be briefly discussed.

As the integrated exposure to gamma irradiation is increased, the effective surface energy, $1 . e .$, the energy absorption rate at the instant of initiation of forward propagation, decreases up to an exposure of $1 \times 10^{7} \mathrm{r}$. This decrease $1 \mathrm{~s}$ expected since re can be considered to represent the sum of the energy to create a new surface is (intrinsic surface energy term) and the energy absorbed In plastic deformation at the crack tip ip. As irradiation hardening must restrict the maximum distance from the crack tip at which dislocation movement can occur, yp should decrease with increasing exposure. Moreover, this same effect has been studied and measured in neutron irradiated reactor structural materials, e.g., zircaloy-2 and $\mathrm{A} 302-\mathrm{B}$. However, by increasing the gamma exposure from $1 \times 10^{7} \mathrm{r}$ to $1 \times 10^{8} \mathrm{r}$, ye was observed to increase slightly. The result is a minimum in re at an exposure of about $1 \times 107 \mathrm{r}$. It is also in this exposure range that reverse crack propagation, or crack healing, was observed to readily occur during unloading the specimens. For example, if a specimen which had been irradiated to $1 \mathrm{x} 10^{7} \mathrm{r}$ was loaded sufficiently to extend the crack in the specimen to $1 \mathrm{~cm}$ and subsequently unloaded, t:hen as zero load is approached the crack will suddenly retreat nearly the entire distance of $1 \mathrm{~cm}$. Furthermore, the velocity of the retreating crack appears to be approximately as high as for an advancing crack. Detailed examination of this effect suggests that the crack surfaces are interacting to form a true bond, although the nature of the bond is probably different from that occurring within LiF itself. Gas atoms which become physically absorbed on the crack surfaces after the crack has extended are believed to play an important role in determining the capability for subsequent healing.

The above serves to present a few of the more important and interesting observations made during this investigation. A complete report on this investigation has been written, and publication will be made in the near future. The salient conclusions made from this investigation are:

A. Confirmation of existing theorles concerning nucleation of dislocation loops in the very high stress field close to the crack tip.

B. Expansion of the loops under the action of the crack tip stresses becomes increasingly difficult as the defect concentration is increased by the gamma irradiation. 
C. Defects sufficiently close to the crack tip assist in the nucleation of loops thereby causing the dislocation loop density to increase with increasing exposure.

D. The mechanisms controlling the crack healing process are different from those controlling crack advance. First, it is suggested that deformation blunting of the crack tip after the crack has arrested affords a barrier to reverse propagation due to the increased separation of the crack surfaces. Secondly, the energy released during reverse propagation is the result of bond formation at the gas-crystal interfaces.

\section{Fast Reactor Supporting Studies}

Structural Materials and Fuel Cladding studies. The objective of this program is to determine the combined effects of sodium environment and fast reactor irradiation on the mechanical properties of candidate fast reactor structural and cladding materials. The program currently in progress is specifically directed at providing a description of material behavior in fast reactor service.

Five structural material capsules were discharged from the EBR-II after about $1.7 \times 10^{22} \mathrm{n} / \mathrm{cm}^{2}$ total neutron fluence. These capsules contain 10 specimens of AISI 304 stainless steel in the annealed condition and 12 specimens of 304 given a preirradiation heat treatment in the ex-reactor hot water loop. In addition, 28 specimens of AISI 348 are included and had received aging treatments in the ex-reactor hot water loop for times ranging from 339 to 3266 hours.

Electron microscopy of AISI 304 irradiated to $1.7 \times 10^{22}$ in the EBR-II has continued. Examination of specimens given one hour preirradiation anneals at $900,1100,1200,1300,1400,1500$, and $1600 \mathrm{~F}$ $(482,593,648,704,760,815$, and 871 C) has revealed the following:

A. After the $900 \mathrm{~F}(482 \mathrm{C})$ anneal the structure is essentially identical to the as-irradiated condition and contains Frank sessile loops and voids.

B. Annealing at $1200 \mathrm{~F}(648 \mathrm{C})$ reduces the number of Frank loops and a dislocation network presumably consisting of interacted perfect loops begins to form.

C. At $1200 \mathrm{~F}(648 \mathrm{C})$ and $1300 \mathrm{~F}(704 \mathrm{C})$ the dislocation network becomes more developed while voids remain unchanged.

D. At $1400 \mathrm{~F}(760 \mathrm{C})$ the network anneals out and voids shrink, both features being completely eliminated at $1500 \mathrm{~F}(815 \mathrm{C})$. 
The change in substructure correlates very well with changes in the proportional elastic limit. Various theoretical predictions concerning the effects of loops, network, and voids on strength have been examined with respect to the above microstructural features and found to be reasonably consistent with the experimental results.

Test Facilities. Test stands for uniaxial air atmosphere tests are now operating in the workshop of Building 32l-A. Sintered aluminum-aluminum oxide samples have been tested at a temperature of $900 \mathrm{~F}(482 \mathrm{C})$. These samples have been extremely brittle with many of them breaking next to the buttonhead. Test No. 7, made with a new buttonhead design, has completed 290 hours of exposure at $900 \mathrm{~F}(482 \mathrm{C})$ and $8000 \mathrm{psi}$. The test is expected to run about 500 hours. The Instron type sample grips are being used and appear to give much better sample support than do other types which have been tried. Samples of Hastelloy $x-280$ will be the next to be tested in air. Tests in the sodium environment stands will begin when sodium measuring and dispensing devices are completed and sodium heaters have been installed.

Funds for design for bullding renovation and installation of support facllities have been released. Several meetings have been held with Hanford Engineering Services for the purpose of passing on information necessary for design. The design work is moving rapidly, but as yet no completion date has been set. Final scoping information has been developed on the inert gas systems and inert gas purification. Avallable information on the test section of the liquid metal loop has been collected and transmitted to Engineering Services for incorporation into their design of the gamma radiation shield. During the past month this test section has been reduced in size by one to three and one-half feet in each direction as a result of careful redesign of the high temperature creep rupture apparatus for sodium service. This redesigned apparatus, which will be located within the radiation shield, has been reduced in height by 18 inches. The redesign has resulted in a reduction of manufacturing costs of approximately 50\% and an increase in the reliability of the unit. All design work for the proper instrumentation and control panel for the liquid metal loop has been completed. All but about $1 / 5$ of the equipment needed has been placed on order. The support portion of the loop has not yet been shipped from the manufacturer.

Preliminary design work has been done on the vacuum manifold system which will go in the prototype cell. This is being matched with changes in the design of the creep rupture apparatus for remote operation to make that apparatus serviceable in vacuum. Specifications have been written for an alkall metal storage and loading facility. This will consist of a glove box with a high purity inert atmosphere, gas purification unit, and a bake-out oven entry port. High purity alkali metals may be exposed within such a box without danger of contamination. A request for bids on this facility is being issued. Another set of specifications has been prepared for an alkali 
metal cleanup facility which will use nitrogen and steam for cleaning residual alkali metals from tools and equipment. The request for bids on this facilit. is being delayed pending evaluation of a less dangerous method of cleaning alkali metals. Experiments with a commercial solvent, Dowanol "EB", have given very encouraging results. This solvent will dissolve sodium metal at a rate of $1 / 8$ inch in a 3-hour period with a very slow evoluation of hydrogen. The cleaned parts exhibit no corrosion and no residual film; final metallographic examination is still pending. The resulting sodium-loaded solution may be disposed of with water dilution in any chemical drain.

An investigation into the potential fire hazards of sodium and other alkali metals disclosed that adequate fire fighting clothing is not available. The materials normally used for protecting personnel in other fire situations are dangerous when exposed to alkali metal fires. An example of this is aluminized asbestos, which flares and burns when hit with burning NaK. Two materials, which may be used together in layers to make protective blankets and clothing, appear to be suitable. The outer layer would consist of "pluton" cloth which is made of fibrous graphite. This would be backed with an insulating layer of one of the several forms of Fiberfrax, a product of the Carborundum Company. Both of these materials have an extremely high service temperature (above $2300 \mathrm{~F}(1260 \mathrm{C})$ ) and are known to be nonreactive when exposed to burning NaK. The graphite cloth retains some strength after direct contact but has essentially no insulation properties. The Fiberfrax material has excellent insulating properties; but, in low density form, it cannot withstand direct contact with burning NaK. It is hoped that a suitable composite can be made from these two basic materials. Technical personnel of the Mechanical Metallurgy Unit are working closely with the safety engineers for PNL and Atomics International on the development of this material.

Liquid Metal Capsule Irradiations. Liquid metal capsule GEH-22-3, recently discharged from the ETR, was opened in Radiometallurgy for specimen retrieval and performance evaluation. Examination of this capsule was of particular interest because radioactivity had been detected in the gas inlet tubes during the last ETR cycle of capsule operation, a condition possibly resulting from a sodium leak and partial blockage of gas flow. The capsule, however, revealed no sodium external to its normal containment chamber. Radioactive sodium vapor escaping through a fractured thermocouple and heater cable lead is the probable cause of the detected activity.

The capsule examination also revealed failure of the vacuum annulus used as a radial heat transfer spoiler. A similar condition is probably the cause of changes observed in capsule temperatures for GEH-22-4 now undergoing irradiation. Typical capsule temperatures in $F$ at specific gas mixtures for the first two cycles of capsule operation are shown below: 


\begin{tabular}{|c|c|c|c|c|c|}
\hline $\begin{array}{l}\text { Capsule } \\
\text { No. }\end{array}$ & $\begin{array}{l}\text { Thermocouple No. } \\
\text { and Location }\end{array}$ & $\begin{array}{c}1 \\
\text { Bottom } \\
\end{array}$ & $\begin{array}{c}2 \\
\text { Center } \\
\end{array}$ & $\begin{array}{c}3 \\
\text { Annulus } \\
\end{array}$ & $\begin{array}{r}4 \\
\text { Top } \\
\end{array}$ \\
\hline GEH $-22-4$ & $\begin{array}{l}\text { ETR Cycle } 87 \\
46 \mathrm{Ar}, 50 \mathrm{Hel}\end{array}$ & 1080 & 1320 & 1065 & 1418 \\
\hline GEH $-22-4$ & ETR Cycle 88 & 1260 & 1350 & 1260 & 1390 \\
\hline
\end{tabular}

Capsule $\triangle \mathrm{T}$ in the sodıum column has decreased by more than a factor of two, and the ratio of argon to helium has changed from $1: 1$ to 3:1 to attain a nominal $1400 \mathrm{~F}(760 \mathrm{C})$ peak temperature. Sodium penetration of the vacuum annulus is the most probable cause for the observed changes in capsule operating condition. Radiometallurgy examination of 22-3 weld areas, thermocouple fractures, and 304 stainless steel-sodium-sodium vapor interfaces should provide useful data for future capsule design and general sodlum-stainless steel technology.

Fast Neutron Mechanisms. Hydrogen permeation studies of the 18-8 type stainless steels at projected LMFBR temperatures are continuing with current emphasis on specimens of cladding thickness. A square root dependency of the permeation rate on the hydrogen partial pressure has been determined using gas phase hydrogen charglng techniques for diffusion membranes as thin as 0.005 "; this suggests that surface absorption and desorption processes for these alloys are normally rapid compared with matrix diffusion. If this is confirmed by the additional work now in progress, it will be possible to use permeation and desorption techniques to study gas behavior in these and similar materials over a greater range of temperatures and component dimensions and with much less experimental difficulty than had previously been anticipated.

Powder metallurgy techniques can be used to incorporate inert, helium-yielding particles into metallic matrices as a possible means of producing predetermined helium concentration profiles in irradiated specimens. Good particle distribution with no evidence of component-matrix interaction during sintering have been obtained for LiAlO $\mathrm{Al}_{2}$ and $\mathrm{Li}_{2} \mathrm{SiO}_{3}$ in some preliminary work with nickel as the matrix material.

\section{ATR Gas Loop Supporting Studies}

Model Gas Loop Studies. The model gas loop is a $2100 \mathrm{~F}(1150 \mathrm{C})$ recirculating helium loop which is being operated to determine the effect of helium atmosphere on materials and specimen holders, and to see if prolonged use will affect the operating characteristics of the new heater. This loop is a one-tenth size model of the gas loop that is being constructed in the Advanced Test Reactor at Idaho Falls. 
The model gas loop has operated a total of 3408 hours since installation of the new heater with 68 thermal cycles from room temperature to various heater outlet temperatures. Three hundred hours of operation have been completed this past month. The horizontal test assembly has accumulated a total of 1601 hours at operating condition $2100 \mathrm{~F}(1150 \mathrm{C})$; it was removed three times during the past month for examination and sample exchange. The new nickel-base vertical test assembly was installed and has accumulated a total of 228 hours at operating condition $1700 \mathrm{~F}$ (926 C). This assembly was removed once during the month for inspection.

Tests are being conducted to determine the amounts and sources of contaminating gas in-leakage. It has been found that by leaving the chromatograph manifold pressurized over a 48-hour weekend there is no signiflcant in-leakage. Similar tests are being conducted at $2000 \mathrm{~F}$ (1093 C), without specimens in the loop, by monitoring the gas quality under steady state conditions without the bypass cleanup system in operation. Results on this test have not shown any detectable impurity in-leakage during a 12 -hour period.

These tests are being conducted because the test specimens have shown substantial effects of contamination even though the loop gas purity has been maintained below the minimum detectable limits of $0.1 \mathrm{ppm}$ each of $\mathrm{H}_{2}-\mathrm{N}_{2}-\mathrm{O}_{2}-\mathrm{CH}_{4}$ and $\mathrm{CO}$.

Troubles with the gas chromatographs (both the new ATR unit and the old loop unit) prevented the loop from being operated for several days. The ATR unit was repaired, and the other is awaiting receipt of replacement parts. A new vacuum jacketed liquid nitrogen line has been installed from the storage tank to two out let locations near loop components. This new line is expected to provide better service for the loop operation.

Test Assembly. The new nickel-base alloy test assembly Inconel 600, Hastelloy $X$, and Incoloy 800 specimens in a Hastelloy $X$ container) achieved a model gas loop exposure of 230 hours at $1700 \mathrm{~F}$ $(926 \mathrm{C})$. The dimensional stability of the assembly was good, and no diffusion bonding was detected.

Specimen Surface Behavior and Contamination. Last month the strengthening of $\mathrm{Nb}$ and $\mathrm{Ta}$ as a result of model gas loop exposure $(775$ hours at $1700 \mathrm{~F}(926$ C)) was reported. Metallographic examination revealed thin reaction layers on the surface of both the $\mathrm{Nb}$ and Ta specimens, but the bulk of the specimens showed no metallographic evidence of contamination. Microhardness measurements, however, revealed that both materials were hardened uniformly throughout the cross section. Molybdenum, which showed no indication of strengthening in the tensile tests, displayed no sirface reaction layers or increase in microhardness. Metallographic examination of various portions of the refractory metal alloy contalner (Nb-10 $\mathrm{Ta}-10 \mathrm{~W}$ ) revealed three different morphologies of surface reaction layers. It 
may be that the contalner material was actually contaminated during processing before the test assembly was fabricated, rather than during model loop exposures.

New tensile specimens of $\mathrm{Nb}, \mathrm{Nb}-\mathrm{Z} \mathrm{Zr}$, and $\mathrm{Nb} 752$ ( Nb-10 $\mathrm{W}-2.5 \mathrm{Zr}$ ) were placed in the heater discharge section of the model loop and exposed for 60 hours at $2100 \mathrm{~F}(1148 \mathrm{C})$. The room temperature yield and tensile strengths of pure $\mathrm{Nb}$ were doubled as a result of exposure. The strengthening of $\mathrm{Nb}-\mathrm{l} \mathrm{Zr}$ was less pronounced, but still significant (1.e., 35\% increase in tensile strength). Both materlals showed significant reductions in ductility 1 l.e., elongation and reduction of area: after exposure, but the actual ductility values remain high le.g., 70\% reduction of areal. The Nb 752 showed no significant strengthening, but the ductility was drastically reduced il,e., from $70 \%$ reduction of area before exposure to $3 \%$ reduction of area after exposurel. Additional study of these contamination effects are in progress, but, in general, it appears that the observed effects are consistent with what one would expect for contamination of $\mathrm{Nb}$ and $\mathrm{Nb}$ alloys by oxygen and/or nitrogen.

In the previous reporting period, metal contamination (i.e., Mo, $\mathrm{Cr}, \mathrm{Mn}, \mathrm{Fe}$ ) was detected on the surface of the refractory metal alloy contalner. The pure refractory metal specimens were subsequently examined for metal contamination. The $\mathrm{Nb}, \mathrm{Ta}$, Mo, and $\mathrm{W}$ specimens all exhibited surface contamination by $\mathrm{Cr}, \mathrm{Mn}$, and $\mathrm{Fe}$; in addition, Mo exhibited traces of $\mathrm{Nl}$ and Co contamination, and $\mathrm{Nb}$ showed traces of Mo contamination. Although Mo was only a minor contaminant on pure $\mathrm{Nb}$, It was a major contaminant on the Nb alloy container. The above observations were made on the refractory metal test assembly after 775 hours of exposure at $1700 \mathrm{~F}(926 \mathrm{C})$; in order to study this metal contamination in more detail, a new set of $\mathrm{Nb}$, Ta, and Mo specimens was prepared for model loop exposure. After 230 hours at $1700 \mathrm{~F}(926 \mathrm{C})$, Mo showed a trace of Ni contamination, Nb showed a trace of $\mathrm{Cr}$ contamination, and the Ta was unaffected.

Visual examination of the new nickel-base alloy test assembly indicated that the materials in the assembly reacted with the loop environment. Prior to exposure, all specimens were bright and clean. After exposure, Inconel 600 specimens were slightly tarnished, Hastelloy $X$ specimens exhibited a glossy, gray-colored surface, and Incoloy 800 specimens exhibited a dull, black surface. The helium purlty was monitored throughout this exposure, and total impurities were apparently less than 1 ppm at all times, except for transients during initial heating. Although the visual examination would suggest that the Hastelloy $X$ and Incoloy 800 have oxidized, it is interesting to observe that the new refractory metal specimens were attached to the nickel alloy assembly, and the Mo specimen showed no evidence of oxidation. Also, Hastelloy $X$ corrosion specimens were present in the heater discharge section of the loop during this exposure; these samples showed no evidence of oxidation or contamination, but rather are undergoing evaporation. It is becoming increasingly 
apparent that the environmental effects in the model gas loop are quite complex, and additional study is required to understand and characterize the impurities in the helium gas stream.

Superalloy and Refractory Metal Corrosion Studies. Corrosion coupons placed in the heater discharge section of the model loop have exposure times to approximately 1500 hours at temperature 2025 to $2100 \mathrm{~F}(1095$ to $1148 \mathrm{C})$. These coupons continue to follow the established weight change behavior, i.e., weight gain for the niobium and tantalum samples is approximately proportional to the cube root of time, while weight loss from the superalloys is approximately proportional to the square root of time.

Pure niobium and niobium alloy tensile specimens have also been exposed in the $2100 \mathrm{~F}(1148 \mathrm{C})$ section of the loop. The following summarizes the degree of contamination to these alloys.

\begin{tabular}{|c|c|c|c|}
\hline Material & $\begin{array}{c}\text { Exposure } \\
\text { Time } \\
\text { hrs } \\
\end{array}$ & $\begin{array}{l}\text { Weight Gain } \\
\mathrm{mg} / \mathrm{cm}^{2}\end{array}$ & $\begin{array}{c}\text { Gross } \\
\text { Contamination } \\
\text { ppm }\end{array}$ \\
\hline Niobium & 67 & 1.09 & 1560 \\
\hline Niobium & 161 & 1.53 & 2160 \\
\hline Niobium 752 & 67 & 1.50 & 1970 \\
\hline Niobium 752 & 161 & 2.42 & 3240 \\
\hline Niobium-1 Zirc. & 67 & 1.28 & 1770 \\
\hline Niobium-1 Zirc. & 161 & 1.74 & 2430 \\
\hline
\end{tabular}

Assuming uniform nitrogen contamination in pure niobium of 1500 to $200 \mathrm{ppm}$, a serious reduction in the ductility of the material would be expected. (1)

"Clean" niobium and tantalum coupons were placed in the $2100 \mathrm{~F}$ $(1148 \mathrm{C})$ heater discharge section and brought to temperature. After approximately one hour at $2100 \mathrm{~F}(1148 \mathrm{C})$, the loop was brought down and the samples removed. The nioblum and tantalum coupons gained 0.35 and $0.27 \mathrm{mg} / \mathrm{dm}^{2}$, respectively. Extrapolating the longer exposure data for nioblum back to one hour, the above value is approximately 1.7 times an extrapolated value.

The weight change behavior of niobium appears to be dependent primarily on time of exposure and relatively independent of number of startups.

Continued exposure of all corrosion coupons is planned.

(1) H. E. MCCoy and D. A. Douglas, "Effect of Various Gaseous Contaminants on the Strength and Formability of Columbium," Columbium Metallurgy, edited by D. L. Douglass and F. W. Kunz, Interscience Publishers, New York, 1961, p. 85. 
Damage Mechanisms in Iron

During this reporting perlod work has continued on reading the resistivity apparatus for routine operation and preparing samples for irradiation.

Two reports have been completed, one for presentation at the Battelle Colloquium on Dislocation Dynamics and the other describing the effect of radiation damage on thermally activated flow in iron for submission to a journal.

High Pressure Studies

A document entıtled "Design and Calibration of a High Pressure $\mathrm{X}$-Ray Cell" has been approved for publication.

A device designed to generate ultrahigh hydrostatic pressures on samples in-reactor has operated successfully at $17 \mathrm{kbars}$ for the past 60 days in an ex-reactor test.

High pressure modifications representative of metallic ( $\mathrm{Zr}$ ), alloy (InTe), lonic $\left(\mathrm{PbF}_{2}\right)$, and covalent (CdS) bonding have been produced in the Diamond High Pressure X-Ray Cell. The first three have been quenched to atmospherıc conditions.

The omega (high pressure) form of $\mathrm{Zr}$ is unique in that its hexagonal c/a ratio is 0.619 compared to the c/a ratio for alpha Zr of 1.59. The lattıce parameters of the new form are $a=5.07 \AA$ and $\mathrm{c}=3.14 \AA$ corresponding to $12 \%$ density increase.

The high pressure form of InTe is a NaCl type structure compared to its normal tetragonal form. The transition is from a semiconducting material to a metaliic conductor and is accompanied by a change from black to blue in color. The lattice parameter of the high pressure form is $6.16 \AA$ compared to its normal tetragonal values of $8.437 \AA$ and $7.139 \AA$. This amounts to a 15.6\% density increase. At pressures greater than $5 \mathrm{kbar} \mathrm{PbF}_{2}$ is orthorhombic with $\mathrm{a}=3.90 \AA$, $\mathrm{b}=6.44 \AA$, and $\mathrm{c}=7.65 \AA$. The new structure corresponds to a $10.8 \%$ increase in density from its one atmosphere cubic form and has been quenched to ambient conditions.

The high pressure form of CdS is a NaCl type structure with lattice parameter of 5.41 A compared to its normal hop form with $\mathrm{a}=4.14 \AA$ and $\mathrm{c}=6.76 \AA$. This corresponds to a density increase of $20 \%$. Efforts to quench the high pressure form to ambient conditions failed, and it appears that the application of heat and pressure is required to retain the more dense form.

The final calibration of the high pressure 'Belt' system has been completed at 60 kbars. Redesign of the piston, specimen cells and changes in technique have lowered the loads required for these 
transitions by some 20\% compared to previous runs. This results in longer piston life and a possible extension of the pressure range available to this equipment.

Initial attempts to subject irradiated Mo to pressures of $20 \mathrm{kbar}$ and temperatures of $900 \mathrm{C}$ have resulted in the formation of unknown compounds and/or alloys of $\mathrm{Fe}, \mathrm{Cr}, \mathrm{Ni}, \mathrm{Ta}$, and $\mathrm{NaK}$. The Mo was placed in Ta baskets, immersed in a $78 \% \mathrm{~K}-22 \% \mathrm{Na}$ alloy which was contalned in a 303 stainless steel can. The pressure was raised to $20 \mathrm{kbar}$ and temperature to $900 \mathrm{C}$. Within one minute the whole can assembly had melted and/or fused. Preliminary examination shows that the Mo was evenly distributed through the stainless steel matrix while the Ta was distributed in a more localized manner. Efforts are proceeding to determine the cause of such a reaction which is much below the melting points of all the constituents except NaK. In the latter case, the temperature was $120 \mathrm{C}$ above its boiling point.

\section{ATR Gas Loop Operation and Maintenance (G. A. Last)}

ATR Gas Loop Support

Gas-Cooled Loop Program. Meetings have been held with ATR Critical Facility personnel to discuss timing and hardware requirements for special tests to determine ATR gas-cooled loop neutron flux levels and distributions. Dosimetry methods will be investigated and a method selected prior to the start of test runs. The tests will be conducted with an exact gas loop in-reactor tube mockup which will contain a specimen holder assembly and columbium sleeve.

Analytical Instrumentation. Substitution of a new electrometer in the Greenbrier chromatograph corrected the sensitivity of the instrument. Gas purity can now be measured to less than 0.1 ppm total level of Impurities.

Gas-Cooled Loop Meetings. A demonstration run on one of the gas-cooled loop circulator lmpellers was conducted at the General Electric plant in Schenectady, New York. The test was conducted in a closed loop designed and constructed by General Electric. One of the circulator production casings is welded into the loop and used for the test. The impeller is mounted on grease bearings rather than hydrodynamic bearings to perform the test. A labyrinth seal was used to isolate the bearings from the gas side of the pressure casing. The test setup was fully instrumented to measure and characterize all aspects of the impeller and diffuser performances. A number of static pressure probes were installed in position around the intake, impeller, and discharge areas to monitor the pressure parameters affecting thrust loadings, pressure rise, and possible instabilities. 
In addition, the loop is provided with flow and pressure (inlet) control, a volume chamber, and chromatograph to monitor gas purity. This demonstration was performed with about $0.02 \%$ (200 ppm) impurities in the helıum gas.

The test was conducted at "equivalent design conditions," that is, since the inlet temperature was below the design point, maximum speed was correspondingly reduced to avold exceeding the design mass flow rate. The demonstration was conducted at $99.5 \%$ of design mass flow rate, and about $102 \%$ of design volume flow rate.

The pressure ratio at this condition was 1.1535 , versus the predicted value for one circulator of 1.1365. From this point, the flow was throttled until at about $45 \frac{\circ}{5}$ of maximum flow, an approach to instablilty could be detected by rapid vibration of the mercury level on one or two of the pressure tap monltors. No actual surge condition was observed, nor has surge been encountered during prior testing on this impeller. This was described as extremely unusual in impeller testing but is apparently a "bonus" characteristic of this particular design, The GE proposal predicted a minimum flow of $58 \%$ for a single circulator at design speed. It should be noted that the 13\% additional "surge margin" may not be as large in the production machine, since the effect of the softer gas bearing suspension has not been tested in conjunction with the actual impeller. It should also be noted that whatever "design speed" is used it means the speed required to produce design flow at design inlet conditions.

All data taken during characterization testing of the impeller were reduced by computer to predlct the results for one, two, three, and four circulators, operating at the conditions for which the data were taken. It is normal practice to attempt to slightly overdesign the Impeller so that it can produce design head at less than design speed. The purpose is to permit a reduction in design speed thereby creating less severe operating conditions for the highly stressed impeller. In the case of the GCL circulator, an additional implication of the avallable excess head is that if permitted to exist during operation, it would impose an overload on the thrust bearing. The two alternatives are to trim the diameter of the impelier to remove the existing head capacity, or to exert automatic control of the operating conditions to prevent overload operation of the thrust bearing. PNL informed GE that we prefer the latter route since it provides maximum flexibility for future operation.

A meeting was held with Fansteel Metallurgical Corporation to discuss their section III design analysis for the primary and regenerative heat exchangers. Comments submitted by Teledyne (Section II consultants to PNL under consulting agreement BCA-319) formed the basis for discussions of the heat exchanger comments.

Personnel from PNL reviewed the major problem areas to point out that the stress analysis did not conform to the requirements of Section III of the Nuclear Code. Items such as using operating 
pressure rather than design pressure and omission of thermal stress and fatigue analysis in areas such as head-to-shell junction, tubeto-sheet junction, nozzle-to-shell junction, etc., were sufficient reasons for rejecting the report.

Fansteel was requested to resubmit the calculations and PNL would contract with a recognized qualified consultant firm to review their final report. Fansteel agreed to resubmit their calculations sending copies to the designated consultant agencies as well as to normal reviewing agencies.

Welding Examinations. Johnson Service, prime contractor for the GCL main instrument panel, submitted some welded tubing for our review. Our evaluation of the welds was based on visual examination, $x-r a y$, fluorescent penetrant, and metallographic examination. The criteria for evaluation were Ebasco specifications P-3002, Nondestructive Testing, and P-3006, Welding.

The welds were acceptable by radiography and liquid penetrant inspection, but they did not meet the requirements of the Ebasco specifications for visual inspection. There was also a black slagIike residue on the ID surfaces of the tubes that may have resulted from the use of a backing flux. While backing flux will assist in root contour and atmospheric protection, it would not be acceptable for the ATR gas loop system because of the removal problems.

Although high quality welds in small diameter tubes are not easy to make, a highly skilled welder should be capable of producing adequate welds in smail diameter tubing with training and practice. In addition to welder skills, the welding equipment should be capable

of operating at low currents, and the current decay controls should be sensitive and responsive to the welder's commands.

Metallic Fuels Development (C. A. Last)

Irradiation of Thorium-Uranium-Zirconium Fuel Elements

Three thorium - 2.5 wto uranium (93.2\% U-235) - 1.0 wto zirconium tubular fuel elements clad in Zircaloy-2 are under irradiation in the P-7 loop in the ETR. Three fuel elements which were being irradiated are being stored in the viewing basin at the ETR site.

The elements have not been examined since the last report period, but the loop operation was normal indicating the continued excellent performance of these fuel elements. At the end of the current ETR cycle, number 88, the estimated exposures will range from 8900 to $18,100 \mathrm{MWd} /$ tonne. 
High Exposure Uranium Irradiation Test

Hollow core uranium fuel elements being tested in the $M-3$ hot water loop of the ETR are now in the fourth reactor cycle of irradiation. At the conclusion of this ETR cycle, number 88 , the estimated accumulated exposure for the 24 fuel elements will range from 600 to 4200 MWd/tonne. The maximum fuel core temperatures range from approximately $360 \mathrm{C}$ to $540 \mathrm{C}$. These fuel elements, $0.45 "$ diameter by $6.25^{\prime \prime}$ long and clad with $\mathrm{Zr}-2$, are part of an irradiation test that has been designed to operate uranium fuel rods at elevated alpha phase temperatures to burnups greater than $10,000 \mathrm{MWd} / \mathrm{t}$ onne $\left(6 \mathrm{x} 10^{20} \mathrm{f}\right.$ Issions/cm33. The variables being studied in this test include fuel composition, external restraint, and internal vold volume. The combined effects of the plastic character of uranium during irradiation and the restraints from the cladding and system pressure are expected to cause the uranium swelling to be accommodated by a central hole. Two uranium compositions are being used: Alloy 1, containing U $+350 \mathrm{ppm} \mathrm{Fe}-800 \mathrm{ppm} \mathrm{Al,} \mathrm{and}$ Alloy 2 , containing $U+150 \mathrm{ppm} F e-100 \mathrm{ppm}$ Si. A fuel enrichment of $4.5 \%$ U-235 is being used to achieve the desired burnup rate (10,000 MWd/tonne in one calendar yeari and temperatures. Fuel rods of both compositions were fabricated by coextrusion to 0.450 " diameter with $0.025^{\prime \prime}$ and $0.050 "$ thick Zr-2 cladding.

Nine additional elements have been successfully brazed and TIG welded with no indications of porosity in the braze or weld area. These nine elements are being shipped to the ETR to replace fuel elements removed for interim neutron radiography at the end of cycle 88.

Fast Reactor Dosimetry and Damage Analyses

(R. E. Nightingale)

EBR-II Dosimetry Experiment

Four capsules containing a variety of neutron dosimeters have been irradiated in the EBR-II and returned to PNL for analysis. The objectives of these tests are to evaluate cross sections for neutron monitors which could be useful in materials irradiations and to measure flux gradients and spectral shifts encountered in EBR-II irradiation facilities.

The first low power test was conducted on January 17, 1967, during a short-term EBR-II physics test. The reactor was operated for one hour at $30 \mathrm{~kW}$. Monitors were irradiated in pins within special "wire" subassemblies located in the center, Row 4 and Row 6 positions of the reactor. Three of the four capsules contained seven, 14-inch, 0.020" diameter, iron, nickel, titanium, aluminum, aluminum-cobalt $10.1 \% \mathrm{Co}$, aluminum-silver (0.1\% Ag), and copper wires. Each of the three were placed in Rows 1, 4, and 6. The 
fourth capsule (placed in Row 1), contained natural uranium, depleted uranium, scandium, cobalt, and zinc in the form of small pieces approximately $0.10 "$ by $0.5 "$ by $0.10 "$.

The low power flux test was run to determine the suitability of selected monitors for fast reactor application. Primary criteria for selecting monitors were a cross section large enough to produce a measurable activation, a half-life long enough to insure some activity after removal to the counting facility, a melting point high enough to survive, and a minimum of complex activation. Several monitors whose characteristics were marginal were included to better define the criteria.

To furnish detailed reactor flux information, the wire monitors were cut into small pieces after irradiation and analyzed. Approximately 140 samples were obtained from this experiment. Activation data have been received from the counting laboratory and are being reduced and analyzed.

On March 26, 1967, a second experiment was run with the reactor operating at $50 \mathrm{~kW}$ for one hour. Several monitors used in the first low level test were eliminated in the second test because of insufficient activation and poor response. Those eliminated were Al-Co (0.1\%), Al-Ag (0.1\%), and zinc. Monitor capsules were positioned in Rows 1, 4, and 6. Row 1 and 6 capsules contalned 39-1nch-long wires of $\mathrm{Ni}, \mathrm{Fe}, \mathrm{Al}, \mathrm{Co}$, and $\mathrm{Cu}$ extending from the bottom of the core into the upper axial blanket. It was necessary to extend the monitor wire well into the axial blanket because experimenters use this test space. Also included in these capsules were small pieces of $\mathrm{Sc}, \mathrm{Co}, \mathrm{Cu}$, depleted uranium, and natural uranium located at the reactor midplane. One of the two capsules in Row 4 contained 39-1nch wires of Ni, Fe, $\mathrm{Al}, \mathrm{Ti}$, and $\mathrm{Cu}$. The other capsule had small pieces of Sc, Co, natural and depleted uranium located at midplane and 10 inches above. The remainder of the space in the capsule contained $\mathrm{Ni}$ and $\mathrm{Fe}$ wires.

The activated monitor wires were cut into l-inch pieces except for sections of the $\mathrm{Co}$ and $\mathrm{Cu}$ wires which were located in regions of extreme spectral shifts (core boundary). It was necessary to cut these wires into $\frac{1}{2}$ inch pieces because of the extreme change in $(n, y)$ cross section over these regions.

A total of nearly 700 samples from the second low level test are now being analyzed by the counting laboratory.

Spectral calculations were made to assist in the analysis of the activation monitors in the low power test and in general support of materials and fuels testing programs. Axial and radial spectra have been obtained from calculations for the 91 -element core using the onedimensional transport-theory code, DTF-IV. The cross sections were averaged over a characteristic spectrum for each region in the reactor using the FCC code and the PNL cross section data set. 
Spectral averaged cross sections were required to determine the response of the monitors over the reactor spectrum. The spectrum Analysis Neutron Detector I ISAND-I; computer code was employed to calculate these cross sections. The primary advantage of this code is to be found in its large cross section library which contains many activation monitor reactions. The calculated spectra for each position are input to SAND-I which computes saturated activities, energy sensitivity limits of each detector, and cross sections averaged over the input spectrum. The total flux was calculated using the spectral averaged cross section for each position and the measured activation of the monitor in the experiment.

Data from the monitors are now being reduced and analyzed. Preliminary results indicate that there are uncertainties in the cross sections and spectral calculations that must be resolved. Refinements in the calculations will be made, consisting of more detall in the axial spectra near the center of the core.

\section{ENGINEERING DEVELOPMENT}

Neutron Flux Monitors (W. G. Spear)

Regenerating Detectors (Thermal Neutron Flux)

Preparations to establish the comprehensive test program for regenerative detectors at the ETR were furthered. The necessary instrumentation system being developed will provide continuous monitoring of the various detector output signals and measurement of the characterıstics. Purchase orders were placed for needed components, including power supplies, prevision resistors and current meters. Recelved ETR test capsule and insertion flange cover designs are being reviewed preparatory to assembly fabrication. Only eight of the ten detectors for the test capsule are on hand; thus, the capsule insertion was necessarily rescheduled for the June cycle of the ETR in order to accommodate delivery of the remaining detectors and permit thorough laboratory testing prior to insertion in the reactor.

The original experimental U-234 - U-235 regenerating detectors continue to demonstrate expected performance during in-core use in a Hanford production reactor test facility. During detector operation the U-234 transmutes by thermal neutron capture to U-235, thereby replacing the burnup loss.

Beta Current Generator Detectors (Fast Neutron Flux)

The Be-9 isotope is being investigated as a possible detector material for fast neutron flux under the difficult environmental conditions anticipated in future fast flux reactors. This isotope undergoes an $(n, \alpha)$ reaction, with a 0.1 barn cross section at $3 \mathrm{MeV}$, to 
provide a beta particle emission (13.5 MeV) with a relatively short haif life of 0.8 second. The beta emission generates a signal current proportional to the neutron flux level to yield an estimated signal current of approximately $1 \times 10^{-6}$ A from about $1 \mathrm{~cm}^{3}$ of $\mathrm{Be}$ exposed in a flux of $10^{15} \mathrm{nv}$. In an experimental chamber, beryllium in an oxide metal state can be encapsulated in a sultable sheath opaque to the alpha particles but transparent to the generated betas, which would escape for signal generation. To avoid interference signals due to high gamma levels of $10^{10} \mathrm{R} / \mathrm{h}$, the balanced twin-lead, twin-chamber concept developed in the thermal flux detector investigations is being considered for use.

Evolved Gas Detection Concept (Fast Neutron Flux)

In this unique concept for fast neutron detection, an evolved hydrogen or helium gas would be collected through a simple evacuation tube connected to a chamber assembly inserted into the reactor core. Gamma interference problems would be minimized by the location of the electronic instrumentation in the less destructive environment external to the core. In the detector chamber $(n, \alpha)$ or $(n, p)$ reactions with B-10 or other materials would release helium or hydrogen in quantities proportional to the neutron flux. Calculations indicate that about $10^{l 1}$ atoms/sec of helium gas would evolve from one gram of $\mathrm{B}-10$ at an incident fast neutron flux level of $10^{13} \mathrm{nv}$. At these levels the evolved gas could be measured by a mass spectrographic or an optical spectrometer instrument. It is expected that a neutron flux range of $1010 \mathrm{nv}$ or greater could be detected using the evolved gas concept.

Microwave Detectors (Thermal Neutron Flux)

A plasma, created through ionization by the charged particles from an $(n, p)$ reaction in $\mathrm{He}-3$, by the fission fragments from an isotope such as $\mathrm{U}-235$, or by a special regenerating mixture of isotopes, will cause a shift of the resonant frequency of a microwave resonant cavity by an amount dependent on the free electron density of the plasma. The equilibrium density established by the generation rate of free electrons and the dissipation mechanisms will be a function of the neutron flux density, thus the resulting frequency shift of the cavity can be related to the neutron flux density.

Smaller than expected frequency shifts observed in early experiments were caused by the dielectric material (quartz) used to contain the gas within the cavity, thus a gas-tight seal to the microwave cavity is being developed. After several fallures, a seal to the cavity was achieved by joining two waveguide seals made by brazing ceramic inserts in the end of waveguide sections to the cavity with a low melting, silver-bearing solder. The disadvantage, caused by 
solder characteristics, is that the cavity cannot be baked out at temperatures greater than about $160 \mathrm{C}$. In a parallel approach, vacuum-tight cavities with waveguides attached are being fabricated offsite.

Cavity pumpdown and waveguide sections are being assembled in preparation for an in-core reactor experiment. It is not anticipated that a foil of U-235 will be included until a reliable seal can be achieved.

Mlcrowave Detectors (Fast Neutron Flux)

Microwave techniques to measure fast flux density will be similar to methods proven useful for the measurement of thermal neutron flux. It is anticipated that the necessary gamma compensation will be achieved by using a reference cavity sensitive only to gamma. By electronically locking the microwave generator to the reference cavity and measuring the difference frequency between it and the signal cavity, the neutron-caused frequency shift can be determined.

Other frequency changing techniques are also being considered. For example, the fast neutron flux could be measured by relating the incident flux to a frequency shift caused by introduction into the cavity of a gas which has evolved from a material such as Be-9. The frequency would be a function of the number of gas molecules in the cavity, and gas evolution rate should be related directly to the neutron flux density. For a reasonable gas evolution rate of $10^{-2}$ atoms/sec/nv, this method should provide neutron flux measurements down to about $10^{11} \mathrm{nv}$.

Microwave and Infrared Detection of Coolant Impurities and Measurement of In-Reactor Temperatures

Microwave Detection of Impurities in Coolant Gases

A change in dielectric constant of an otherwise pure gas, as water vapor molecules are added, can be utılızed to measure the presence and amount of water vapor in a gas system. The change in dielectric constant changes the resonant frequency of a microwave cavity operating in the one centimeter range.

A detection sensitivity of $125 \mathrm{ppm}$ water vapor in helium at room temperature and $950 \mathrm{ppm}$ at $436 \mathrm{C}$ has been achieved using the change of dielectric constant of the gas mixture, thereby causing a frequency shift of a microwave resonant cavity. It is apparent that at high temperatures, to achieve sensitivity, it will be necessary to use precise and accurate measurement techniques. The time response of such a detector is very small and depends only on the time to insert 
the sample into the cavity. For very small concentrations, however, the time constant of the detector, which is one second for these experiments, becomes important.

A second promising method involves use of the phase shift in a section of waveguide. This may be a section of the process tubing or special structure in which the coolant flows, thereby being a truly "in-line" detector. Preparations are being made to perform room temperature experiments of the phase shift to verify this concept before extension to the more difficult high temperature case.

\section{High Temperature Measurements}

Several unique methods of measuring high temperatures within an operating nuclear reactor are being investigated. To attain the longevity desired for such sensors, microwave techniques and instrumentation appear very promising. Components inserted within the reactor are entirely of metal and extraneous induced signals do not interfere with the temperature sensing microwave signal.

Fabrication of waveguides of high melting point metals will increase the measuring range to at least $1350 \mathrm{C}$. However, attenuation of microwaves within these fabricated metal waveguides restricts the length of transmission line which may be used if detectable amplitudes of the return signals are expected.

The microwave radiometric method of measuring temperature also requires that high melting point waveguide be inserted within the reactor. Because this heated waveguide contributes (as a function of its emissivity) to the total signal received at the radiometer, the emissivity of the transmission line must be known accurately over the range of temperature measured. An appropriate black body radiator usable to at least $2000 \mathrm{C}$ is available and will be incorporated into the selected transmission waveguide.

Experimental techniques which will permit the approximate measurement of response time of the microwave sensors to step changes in temperature are being developed. Because of their larger mass, it is not expected that the microwave sensors will respond as quickly as thermocouples to step temperature changes.

Infrared Techniques

Three chopper wheels for the experimental hygrometer have been successfully fabricated. The absorption quandrants peaked at 2.5li, $2.57 \mathrm{i}$, and $2.58 \mathrm{w}$ wth the corresponding reference quandrants peaking at $2.28,, 2.38 \psi$, and $2.32 \%$. The $2.28 \mu-2.51 ;$ chopper wheel had very little response to humidity changes. Before this filter was fabricated it was not known how close the filter peak had to be to the 
2.6. water absorption peak. From the data presently available, it appears that the sensitivity will be seriously affected if the absorption filter peaks are lower than $2.52 \mathrm{H}$. If the absorption filter is peaked too high, it becomes insensitive to $\mathrm{CO}_{2}$. From previous work, we know that $2.52 \mu$ absorption filter has sufficient sensitivity of $\mathrm{H}_{2} \mathrm{O}$ and is insensitive to $\mathrm{CO}_{2}$, and that a $2.65 \mathrm{i} \mathrm{ab}-$ sorption filter is sensitive to both $\mathrm{H}_{2} \mathrm{O}$ and $\mathrm{CO}_{2}$. With this information a lower limit of $2.52 \mathrm{w}$ can be set on the absorption filter. The present 2.58, absorption filter has not been checked for $\mathrm{CO}_{2}$ sensitivity. After these filters have been evaluated for $\mathrm{CO}_{2}$ sensitivity, it is possible that an upper limit for the absorption filters can be assigned.

Efforts to develop a wedge filter wheel proved to be too expensive using the original design. Presently, the wedge filter wheel is being redesigned so a rectangular wedge filter can be mounted on a disk. The wedge filter to fit the disk has already been fabricated, although additional filters may have to be fabricated with different characteristics to acquire the desired sensitivity. The sample chamber is also being modified to obtain a better air flow through the chamber.

\section{PLUTONIUM UTILIZATION PROGRAM (F. G. Dawson)}

Fuels Development

$\underline{\text { PRTR Testing }}$

A 19-rod cluster containing $\mathrm{UO}_{2}-2$ wto $\mathrm{PuO}_{2}$ pellets was charged into the FERTF. The operating requirement for this cluster of 24 hrs at $50 \%$ and 24 hrs at $75 \%$ of full power before proceeding to the next higher level was fulfilled. The estimated maximum linear rod power generation was approximately $15 \mathrm{~kW} / \mathrm{ft}$ which should produce maximum fuel temperatures of about $1800 \mathrm{C}$. Maximum fuel temperatures in adjacent vibrationally compacted $\mathrm{UO}_{2}-\mathrm{PuO}_{2}$ elements were estimated to be about $2300 \mathrm{C}$. Rods from vibrationally compacted elements will be destructively examıned after maximum power generations of $16.8,17.7$, and $18.6 \mathrm{~kW} / \mathrm{ft}$ to establish the maximum allowable PRTR operating level. The maximum allowable level is the maximum rod power that produces fuel temperatures near melting.

The results of zero power tests in the PRTR, physics calculations, and thermal hydraulics studies indicate that the present 8-rod FERTF test element design will provide the flexibility required to achieve the objectives of the fuels testing program planned for the FERTF. By changing basket material, neutron absorber plug material, and neutron absorber sleeve thickness independently, the power generation of $\mathrm{UO}_{2}-2$ wto $\mathrm{PuO}_{2} \mathrm{PRTR}$ rods in the FERTF relative to the power generation of simllar surrounding rods can be varied within the range 
of 0.87 to 1.12. With this degree of latitude, it is anticipated that the desired FERTF power generation can be achieved.

Due to an indicated inconsistency in the most recent thermal hydraulics data and the data obtained originally with the FERTF test element, the tests were rerun. The results were reproducible to within 1\%. Flow testing of a prototype FERTF test element to determine fretting, wear, and vibration characteristics of the assembly under PRTR coolant conditions was started in the EDEL loop. It is expected that the element will be tested with intermittent examinations for approximately two months before FERTF testing starts.

An abstract of a paper titled "Operating Experience with Plutonium Fuels in PRTR" for presentation at the 1967 AIME Nuclear Metallurgy Symposium on Plutonium Fuels Technology, Oct. 4-6, 1967, in Phoenix, was prepared.

\section{Instrumented Fuel Rods}

Four fuel roàs instrumented to measure fuel rod gas temperature and pressure were charged into PRTR. The pressure and temperature measuring instrumertation was checked at various reactor power levels to $35 \mathrm{MW}$. Although no fission gases have been accumulated this early in the power tests, fuel rod helium pressures versus coolant temperature have agreed well with calculated values.

\section{TREAT Transient Testing}

Previous ANL-BNW TREAT experiments involving thermal reactor oxide fuel capsules were enriched with at least 9.5 wto U-235. At this enrichment the flux depression, and thus the temperature profile in the fuel, is not typical of that which would occur in typical thermal reactor fuel. A study was initiated to determine minimum enrichment requirements in future thermal reactor-type TREAT test capsules and still achieve the destruction energy levels desired. Discussions with ANL indicate that the minimum U-235 enrichment required would be near 5 wto.

\section{High Exposure Plutonium Studies}

Isotopic analyses were completed for the shippingport backup samples, and an analytical critique is being written.

Analyses are continuing on the Yankee samples. These samples have yielded the highest $\mathrm{Pu}-236$ concentrations yet encountered with several samples containing from 3 to $9 \times 10^{-2}$ ppm. This level is still considered below the problem area concentration. 
Neodymium-148 burnup analyses were made and are proving to be compatible with Cs-137 burnup calculations.

Plutonium nitrate from Dresden reactor fuel reprocessed by Nuclear Fuel Services is scheduled for shipment to Hanford on April 24, 1967. This material, which contains approximately $21 \frac{1}{2} \circ$ $\mathrm{Pu}-240$, will be used for additional isotopic and dosimetry studies.

\section{PRTR Pellet Rod Procurement}

Three PRTR fuel rods containing cold pressed and sintered mixed oxide pellets are being procured from a commercial fuel fabricator. The fabricator has stated that delivery of one rod can be expected by July 1, 1967, and delivery of the remalning two rods can be expected by september $1,1967$.

The rods will be used to compare commerclally designed and fabricated pellet rods with BNW-designed and fabricated powder rods. Both hot pressed and cold pressed and sintered pellet rods will be used in the comparison.

\section{ETR Loop Testing}

A 7-rod cluster, intentional defect test to be performed in the ETR P-7 Loop was designed. The cluster components were fabricated, and the test proposal was written. The purpose of this test is to investigate the irradiation behavior of an intentionally defected vibrationally compacted $\mathrm{UO}_{2}$ PRTR prototype fuel rod operating under high performance conditions. It is planned to operate the defected fuel rod at a maximum linear power generation of $29 \mathrm{~kW} / \mathrm{ft}$ with approximately $60 \%$ of the radius molten at the plane of the defect. The irradiation conditions proposed for this experiment in ETR are approximately the same as the conditions that are ultimately planned in the FERTF testing program in PRTR.

The test element, approximately 33" long, will be fabricated to be as prototypic of PRTR HPD elements as possible. $\mathrm{PuO}_{2}$ enrichment will be simulated by adding fully enriched $\mathrm{UO}_{2}$ to natural $\mathrm{UO}_{2}$ in the same way that $\mathrm{PuO}_{2}$ is added to PRTR fuel.

\section{Reactor Physics}

D20 Moderated Systems

FERTF Zero Power Tests. Four additional zero power measurements have been performed with the Fuel Element Rupture Test Facility (FERTF) in the PRTR. These experiments have been performed in Channel 1550 
with the 8-rod FERTF element, all rods of $\mathrm{UO}_{2}-2$ wto $\mathrm{PuO}_{2}$. A 0.125 " stainless steel basket, with and without a $0.114 "$ stainless steel liner, has been used with both stainless steel and Hastelloy-X plugs in the center of the element.

In all four cases, rods from the FERTF element, along with rods from a standard 19-rod element in Channel 1552, were gamma-scanned to determine the power ratio between the FERTF and the first ring of the Batch core. These results are compared (in the following table) with calculations made prior to the measurements.

\begin{tabular}{|c|c|c|c|}
\hline Basket & & Power & Ratio \\
\hline Thickness & Center Rod & Calculated & Measured \\
\hline $0.125 "$ & SST & 1.02 & $0.95 \pm 0.03$ \\
\hline $0.125^{\prime \prime}$ & Hast $-\mathrm{X}$ & 1.01 & $0.95 \pm 0.03$ \\
\hline 0.239 & SST & 0.91 & $0.89 \pm 0.04$ \\
\hline 0.239 & Hast-X & 0.90 & $0.90 \pm 0.06$ \\
\hline
\end{tabular}

The worth of the FERTF element relative to the channel filled with $\mathrm{H}_{2} \mathrm{O}$ has been measured to be approximately +4 milli-k with the basket liner, and approximately $+6 \mathrm{mllli-k}$ without the basket liner.

The coolant void worth has been measured for the FERTF element without the stainless steel liner and with a Hastelloy-X plug. The loss of $\mathrm{H}_{2} \mathrm{O}$ coolant produces a positive reactivity change of 1.6 $\pm 0.2 \mathrm{milli}-\mathrm{k}$.

Reactivity Oscillator Tests. The reactivity oscillator portion of Batch Core Power Test \#8 has been completed. The oscillator was operated at 19 frequencies from 0.3 to 16 cycles per second, with the reactor power level at 250 watts and at one megawatt. Three ion chambers were suspended in a thimble $(\mathrm{C}-1352)$ at a radius of $12.7 "$, with the chambers centered about the core midplane for the test at 250 watts. A single chamber located at the same radius but withdrawn into the top primary shield, was used for the 1 megawatt test.

The data, which consisted of the reference signal from a sinepotentiometer attached to the oscillator and the signal from the ion chambers, were recorded on a dual-channel Brush recorder. Some recordings were also made on magnetic tape to determine the feasibility of recording reactivity oscillator data in this way. Analysis of the data is about $50 \%$ complete.

Attempts to record power fluctuations due to reactor noise were not successful because of excessive moderator level fluctuations.

Analysis of Plutonium Burnup Data. When the differential equations describing the transmutation of the plutonium isotopes are solved for the cross section ratios, there results two less equations than the number of uninown ratios. Our solution to this problem in 
the past hagibeen to obtain two more equations by (1) fixing the value of $\frac{1}{2} 42$ the capture to fission ratiol at 0.41 , and (2) letting $242 / 239=0$ since this ratio is small. The remaining cross section ratios were then determined and compared to calculated values. Two objections to this approach have been:

- The high value of $\ddot{\alpha} 241$ used, (0.41), and

- The low value of $\circ \underset{a}{242,0} 239$ determined, approximately equal to 1.0 when calculations show this ratıo to be 1.15 . An alternate method is to determine the value of o 241,0239
and to obtaln a better approximation of $242 / j 239$, from both calculations. The results of thís secönd approach have been evaluated ana are being summarized in the form of a Technical Note. The advantages galned are:

- Greater confidence can be placed in the value of $\hat{\sigma}_{a}^{24 l} / \hat{\mathrm{c}} \mathrm{a}$ calculated from basic cross section data than any assumed or calculated value of a 241 .

- The deduced value of 239 s not very sensitive to the assumed value of i $24 \hat{l} / \hat{\jmath} 23 \overline{9}$.

- $\dot{\alpha} 241$ is determined from the data rather than from a calculation.

- The effect on the remalning cross section ratios of the value of $242, \mathrm{c} 239$, which has been calculated to vary from 0.09 to 0.06 over the burnup range, has been incorporated into the calculations.

Gamma Scanning Facilıty. The order has been placed for the lithium-drifted germanium detector system to be used in the PNL Gamma Scanning Facility. Delivery is expected within 60 days.

Design work is continuing on a new collimator head and a new sample holder for plate-type fuel elements.

Thorium Loading in the PRTR. A burnup calculation has been performed for a thorium fuel loading in the PRTR using the ZODIAC code. The fuel is a tube-in-tube geometry containing 4 wto uranium (93\% U-235) in thorlum metal. The results indicate that a loading of 55 elements ( 1.1 tonne) could attain an average exposure of $16,000 \mathrm{MWd}$. At this exposure the fuel would contain $5 \mathrm{~kg}$ of U-233. Calculations with the ALTHAEA code for this system (reported in March 1967) indlcated that the loading would attain an exposure of 35,000 Mwd. This number was incorrect because the power for the system was somewhat less than it was thought to be. The corrected average exposure is 20,000 MWd which agrees fairly well with the results obtained using the ZODIAC code. 
Correlation of Effective Cross Section Ratios. Calculations of the neutron spectra in a PRTR cell containing Al - 1.8 wt\% Pu 19-rod clusters continued. The studies conducted during the month were directed toward determining the sensitivity of the spectra to: leakage; moderator, coolant, and fuel temperature; $\mathrm{D}_{2} 0$ density and scattering kernel, fission product concentration, and resonance spatial shielding corrections. Uncertainties in these parameters lead to uncertainties in the neutron spectrum and the effective cross sections. Thus, the purpose of these calculations is to determine the uncertainty in the effective cross sections which result from uncertainties in these parameters.

\section{$\underline{\mathrm{H}_{2} \mathrm{O}}$ Moderated Systems}

Representation of Critical Mass Data. The fitting formula for critıcal mass data, described in Reactor Physics Department Technical Activities Quarterly Report for January, February, March, 1967, has been used to fit 11 sets of data from past approach-to-critical and/or exponential experiments. All attempts at fitting were successful. The data fitted included three sets from $\mathrm{Pu}-\mathrm{Al}$ fuel $(1.8,2.0,5.0$ wto $\mathrm{Pu}$ ), four sets from $\mathrm{PuO}_{2}-\mathrm{UO}_{2}$ fuel (1.8 wto $\mathrm{PuO}_{2}$ and 2 wt\% $\mathrm{PuO}_{2}$ with 8,16 , and $24 \% \mathrm{Pu}-240)$, three sets from enriched $U(3.063 \%$ with $\mathrm{H}_{2} \mathrm{O}$ moderator, and a set of enriched $\mathrm{U}(1.007 \%)$ with graphite moderator. The details of this work are being prepared for publication in a topical report.

Analysis of Fuel Burnup from Yankee Reactor. Preliminary attempts at least squares analysis of Yankee burnup data with Program LIKELY have indlcated that the data cannot be fitted with constant cross section ratios. Further analysis awaits calculation of the shape of these cross section ratios versus exposure. The cross section ratio shapes will be incorporated into Program LIKELY which should then be able to obtain the correct normalization for these ratios.

ETR Irradiations. THERMOS calculations have been performed to determine the fuel enrichments appropriate for irradiation tests with 7-rod clusters of $\mathrm{UO}_{2}-\mathrm{PuO}_{2}$ in the $\mathrm{P}-7$ loop of ETR. Calculations have been made for $\mathrm{PuO}_{2}$ concentratıons of $1.25,1.5,2.0$, and 5.0 wto in natural $\mathrm{UO}_{2}$. This work has been done in support of irradiation experiments conducted by the Materials Department.

$\mathrm{UO}_{2}$ - 4 wto $\mathrm{PuO}_{2}$ Fuel Rods. Commission approval has been received to fabricate about 250 rods of $\mathrm{UO}_{2}-4$ wto $\mathrm{PuO}_{2}$ fuel onsite, for use in CAF, PRCF, and PCTR measurements. The plutonium will be from fuel irradiated in Dresden reactor, with nominal isotopic concentrations of Pu-239 72.5\%, Pu-24019.9\%, Pu-2416.2\%, Pu-242 1.4\%. About $57 \mathrm{~kg}$ of plutonium have been shipped from the processing plant in New York State and will be thoroughly blended here prior to use. 
Calculation of Temperature Coefficients. Temperature coefficients of reactivity have been calculated for an $\mathrm{H}_{2} \mathrm{O}$-moderated core of $\mathrm{UO}_{2}-2$ wto $\mathrm{PuO}_{2}$ fuel rods. Temperature-dependent lattice constants for the homogeneous core and $\mathrm{H}_{2} \mathrm{O}$ reflector were computed with the codes HRG, THERMOS, and TEMPEST. Effective multiplications were then calculated using these lattice constants and the HFN code. Axlal leakage effects were accounted for with temperature-dependent axial bucklings which were deduced from calculations of reflector savings as a function of temperature. To obtain good agreement between calculated and measured temperature coefficients it was necessary to calculate the effect of expansion of the lucite lattice plates. New lattice constants were calculated, taking into account the increase in lattice pitch with temperature. Multiplications were then calculated (with $\mathrm{HFN}$ ) using these new lattice constants and a temperature-dependent core radius. When all these effects are included in the calculations, good agreement is obtained between measured and calculated temperature coefficients.

Power Sharing in Zoned Cores. Calculations of power sharing between different types of fuel rods in three two-zoned loadings of $\mathrm{UO}_{2}$ - 2 wto $\mathrm{PuO}_{2}$ rods in $\mathrm{H}_{2} \mathrm{O}$ have been performed using the code $\mathrm{HFN}$. The zones were composed of rods whose plutonium contained 8,16 , or 24 wto Pu-240. Homogenized cell constants were generated using the codes THERMOS, TEMPEST, and HRG. Reflector constants were those for an infinite $\mathrm{H}_{2} \mathrm{O}$ medium, and were computed using TEMPEST and HRG.

The calculated power distributions agree reasonably well with measured distributions, with the largest discrepancies $(\therefore 7 \%$ occurring near the core-reflector boundary. The calculated and measured power sharing li.e., the ratio of power in one type of rod at the zone boundary to power in a rod of the other type at the same radius) agree consistently to within $2 \%$

$\underline{\text { PCTR FueIs }}$

Approximately $30 \mathrm{PRCF}$ fuel rods were opened, and the fuel material in them was used to load 49 similar rods to be used in a PCTR experiment. Standard PRCF hardware and fabrication techniques were used in preparing the new fuel rods.

PuO2 Particle Size Studies

Work continued on the preparation of $\mathrm{PuO}_{2}$ particle fuels. Density measurements of the $\mathrm{PuO}_{2}$ pin impacted last month revealed that approximately two-thirds of the material was too dense (>82\% TD). This material was reground through 325 mesh for reimpaction. A solid solution of $\mathrm{UO}_{2}-2$ wto $\mathrm{PuO}_{2}$ was heat treated at $1550 \mathrm{C}$. Furnace difficulties delayed this work for about three weeks. 
Plasma fusion of vacuum heat treated, pneumatically impacted, feed material results in spheres comparable to the pressed and sintered feed material. It is planned to produce spheres from arc fused $\mathrm{PuO}_{2}$ since the initial particle preparation appears to affect the vold formation in spheres during particle fusion.

Code Development*

Program UNICORN has been modified to plot Doppler broadened cross sections with the use of PLOTJ program. Now all cross section types calculated by UNICORN can be plotted in one run. The plotted cross sections may be those calculated at zero degrees Kelvin and/or at any desired temperature.

Subroutine PLOTJ has been modified to do log-log plotting. The subroutine PLOTJ now plots data on log-log or semi-log graph paper. The ability to plot linear will be added shortly.

Changes have been made in the nuclear cross section processing code, BARNS-II, to permit numerical integration of resonance region contributions to group cross sections for any of the four optional fluxes avallable in the code. Previously, only a $1 / E$ flux could be used for these contributions, and integration was done analytically. An additional benefit of these changes is that, unlike the analytically integrated cross section, the numerically integrated cross sections can be Doppler broadened. The changes are still being debugged.

Test cases have successfully been run on the well-known, two dimensional, multigroup diffusion theory code, CRAM (TRG Report 229(R)). CRAM is written in Fortran-II and FAP for the IBM 7090, and is avail$\mathrm{able}$ for further use on that computer. No conversion to UNIVAC 1107 operation is planned.

A new HRG data tape, HRG-042167, has been made which includes changes resulting from the recent revision in the BNW Master Library. A total of 56 nuclides were recalculated, and preliminary data for TM-169 were added.

The BNW Master Library was updated several times during April in preparation for publication:

Mn-55 was updated to include fast capture cross section data.

Co-59 was converted into a even record resonance parameter table isotope.

* Partially supported by 02 Program funds. 
Sm-149 was updated to eliminate a processing problem. One of the resonances was described using a linear variation of log sigma versus log energy. This description produced an exponent that was larger than the computer could handle. The range description was changed to a strictly linear variation and the problem disappeared.

Pa-233 was updated using new parameters from IN. The main change was the resonance at $0.43 \mathrm{ev}$. I y was changed from $0.05 \mathrm{ev}$ to $0.5 \mathrm{ev}$ to improve the fit.

U-238 was updated to eliminate several linear ranges below 1 ev. The ranges now vary linearly in log sigma versus $E$. The changes should affect the Westcott $G$ and $S$ factors for U-238.

Np-237, Am-241, Am-243 were updated to include fast capture cross section data from the ENDF/B library.

Tm-169, Hf-174, Hf-176, Hf-178, and Hf-179 were added to the master library in April. All of these isotopes are even record resonance parameter table isotopes.

The ENDF/B neutron cross section library is onsite and is currently being processed from a BCD card image tape into a useable binary library tape using BNL's computer program DAMMET (Delete, Alter Mode and Merge ENDF/B Tapes).

The following programs were also recelved and are being compiled for use at BNW: CRECT, EDIT, ETOE, ETOM, RETRIEVAL Subroutines, Mc-2, and FLANGE II.

The computer program CHAD which is used to calculate Legendre coefficients from differential elastic scattering data was modified to improve the integration scheme. CHAD assumes that $\frac{d \widetilde{c}}{d s_{s}}$ is linear and then integrates analytically the result together $d s_{i}$ with the appropriate Legendre polynomial. However, gold-197 at $20 \mathrm{MeV}$ exhiblts extreme peaking for $\mu=1.0$, and the linearization scheme in CHAD failed to provide the correct coefficients. The difficulty was solved by interpolating to 501 points using a 4-point lagrangian scheme. The error in the fit was reduced from approximately $10 \%$ to less than $0.1 \%$.

\section{Reactor Engineering Development}

$\underline{\text { Pu Optimization Studies }}$

Development of a digital computer code for preliminary design of BWR's and PWR's is essentially complete. The result is a system of chained computer codes called FULCYC. This chain will form the basis for a more sophisticated design package and will be expanded through a coordinated effort involving the Analytıcal Physics, Fuel Cycle 
Analysis, and Nuclear Engineering Units. Simultaneously, design work has started on commercial water reactors typical of those that will be operating in the mid-70's, but optimized for plutonium.

$\underline{\text { PRTR Fuel Element Rupture Test Facility }}$

Boiling Burnout Limits for 8-Rod Element. Calculations to determine the thermal operating limits for an 8-rod fuel element to be irradiated in the FERTF were completed, and a letter report presenting the results and conclusions was prepared and distributed.

This FERTF fuel assembly consists of elght 0.565-inch diameter fuel rods arranged in a circle around a central 0.983-inch diameter nonheat generating central rod, and enclosed by a "basket tube." The minimum spacing between fuel rods and the central rod is 0.100 inch. The basket tube is provided with a removable inner sleeve, or liner. The purpose of this liner is to reduce the quantity of water in the pressure tube. In-reactor experiments may be performed either with or without the liner in place. With the liner installed, the minimum spacing between the fuel rods and the liner will be 0.100 inch. With it removed, the minimum spacing between the fuel rods and the basket tube will be 0.214 inch.

In this analysis operating limits which would prevent occurrence of both bulk boiling at the outlet and boiling burnout were calculated. These limits were expressed in terms of minimum inlet subcooling required for operation at specified mass velocity and tube power. It was found that at coolant mass velocities greater than $1.5 \mathrm{million} / \mathrm{b} / \mathrm{hr}$ sq ft and tube powers less than $880 \mathrm{~kW}$, bulk bolling limits would be more restrictive than the boiling burnout limits for cases with the basket tube liner installed. At coolant mass velocities less than l.5 million lb/hr-sq ft, boiling burnout limits would be more restrictive in most cases. The removal of the tube liner will somewhat affect the range of operating conditions where boiling burnout or bulk boiling limits are most important. For example, with no liner, boiling burnout limits would be more restrictive for velocities greater than 1.5 million $1 \mathrm{~b} / \mathrm{hr}-\mathrm{sq}$ ft and tube powers less than $840 \mathrm{~kW}$. The maximum planned specific power for this fuel element, $28 \mathrm{~kW}$ per ft of fuel rod, corresponds to a tube power of about $810 \mathrm{~kW}$.

\section{Rupture Loop Particle Separator}

Further performance assessment of this device has been delayed because of lack of equipment to make detailed particle size distribution measurements of the material $\left(\mathrm{UO}_{2}\right)$ being removed by each of the two slots. Equipment for performing accurate seive analyses is on order. Plans are to obtain additional performance data with $\mathrm{UO}_{2}$ of accurately known particle size distribution typical of PRTR elements. The subsequent measurement of swirl angle by means of a pitot tube, 
as previously planned, now appears questionable. Probable results from a pitot tube could have up to a $12^{\circ}$ error, and separator performance is probably sensitive to a two to three degree change. Plans are under way to remove the lower portion of the separator and substitute a transparent plastic section so that the swirl angle of the water may be determined. This work will not be performed until additional separation tests with known particle size distribution are completed.

Fuel Element Testing

A new eight-pin, FERTF basket-type element has been received and installed in EDEL-I for testing. Operation of the loop at $120 \mathrm{gpm}$, 1075 psig, and $475 \mathrm{~F}$ started April 24, and will continue for approximately two months. The pressure tube was borescoped for surface imperfections prior to installation of the element.

\section{Materials Development}

PRTR Pressure Tube Evaluation

The PRTR reactor safeguards program includes study by destructive examination of the effect of reactor environment upon the zircaloy-2 pressure tubes. Work in progress is composed of determining a hydrogen limit on unirradiated tube specimens of different flaw length and crack propagation tests at various temperatures. This work is continuously improving the basis for judgment of irradiated specimens.

Tube \#5690 was pi taped every six inches and sectioned in the PRTR basin. The pi tape data had quite a bit of scatter but indicated an enlarging of the tube of about three $\mathrm{ml}$ ls in the irradiated zone. The tube was cut into five 20" specimens with six 2 " rings being cut from between the $20 "$ specimens. A 6" specimen was also cut off the flange end of the tube. The middle $20 "$ speclmen has a blister at its midpoint. It is intended to try to set up the equipment to pressure cycle this specimen to see if fatigue fallure can be induced at low pressure. The remainder of the $20 "$ specimens will be used to continue the study of crack propagation at elevated temperatures.

A crack propagation test was run on a $20 "$ specimen with 275 ppm hydrogen with a 3/4" slot milled 80\% through its maximum wall thickness. This test was run at $150 \mathrm{C}$ and burst at a pressure of 5000 psi. Using Lame's equation a hoop stress at fallure of 57,300 psi was calculated. A value of 52,000 psi would be predicted for a 150 C crack propagation test on an unhydrided tube with a 3/4" slot. This shows that there is no decrease in strength due to the hydrogen, but the hydrided tube broke in a brittle manner where an unhydrided tube would break in a ductile manner. 
Postirradiation Examination of PRTR Tubes 5690 and 5696

Results of oxide thickness measurements on PRTR Tube 5696 were reported in the March 1967 monthly progress report. Six 2-inch sections have been cut from PRTR Tube 5690 at various points through the flux zone. The tube sections are undergoing postirradiation examination in Radiometallurgy. Oxide thicknesses will be determined metallographically. Hydrogen analyses will be conducted on specimens from Tubes 5690 and 5696. Metallography on specimens from Tube 5696 indicates that the hydrogen content of the tube is low at all positions through the flux zone.

Postirradiation Examination of Test 72 Specimens

In-flux and out-of-flux weight gains on tubular zircaloy-2 and Zircaloy-4 specimens were reported in the January 1967 monthly progress report. The specimens were exposed in the PRTR at a position normally occupied by a fuel rod. The specimens were exposed 209 days in $\mathrm{pH}-10$ lithium hydroxide in $\mathrm{D}_{2} 0$. Outlet temperatures of the bulk coolant were 516 to $532 \mathrm{~F}$. Hydrogen analyses on Test 72 specimens have been completed. In-flux hydrogen absorption was determined by averaging the total hydrogen content on four in-flux specimens. Hydrogen contents of corresponding out-of-reactor specimens (due both to prefilming and subsequent exposure) were then averaged and subtraced from the in-flux average to obtain the in-flux hydrogen pickups shown below:

\begin{tabular}{ll} 
Alloy & \multicolumn{1}{c}{ Surface Condition } \\
Zircaloy-2 & $\begin{array}{l}\text { Etched } \\
\text { Prefilmed, prebreakaway } \\
\text { Prefilmed, postbreakaway }\end{array}$ \\
Zircaloy-4 & $\begin{array}{l}\text { Etched } \\
\text { Prefilmed, p re breakaway } \\
\text { Prefilmed, postbreakaway }\end{array}$
\end{tabular}

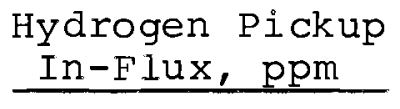

8
136
38

6

41

30

These data show that hydrogen pickups were low for specimens exposed as-etched, while in-flux hydrogen pickups were disproportionately high for Zircaloy-2 specimens prefilmed to prebreakaway weight gains $\left(17\right.$ to $\left.20 \mathrm{mg} / \mathrm{dm}^{2}\right)$. It is not possible at the present time to determine the percent theoretical hydrogen pickups due to in-reactor exposure, as hydrogen pickups resulting from prefilming operations are unknown.

Metallographic examination of hydrogen distributions and oxide thicknesses on Test 72 specimens is under way in Radiometallurgy. 
Ceramic Fuel Dissolution

During April ceramic fuel dissolution efforts were centered on continuing the study of $\mathrm{UO}_{2}$ and $\mathrm{ThO}_{2} \cdot \mathrm{UO}_{2}$ property changes in $530 \mathrm{~F}$ water. Preliminary information indicates: (1) essentially no property changes for $\mathrm{UO}_{2}$ and (2) surface color changes and small weight losses for $\mathrm{ThO}_{2} \cdot \mathrm{UO}_{2}$. These studies are being continued.

\section{Cycle Analysis}

Various Minimum Fuel Cycle Costs for the PRTR Design

Considerable activity was devoted to code development and cross section library updating. In addition, work on the text for a fuel cycle book continues. A rather extensive study was completed of thorium metal fueled $\mathrm{D}_{2} 0$ moderated reactor starting with either U-235 or plutonium enrichment. The possibility that metallic thorium may allow higher specific fuel powers than with $\mathrm{ThO}_{2}$ or $\mathrm{UO}_{2}$ was being examined to see if the corallory would hold that $\mathrm{D}_{2} 0$ costs would be reduced.

Three illustrative cases have been selected for which is shown a breakdown in the following table. In all cases the thermal-toelectrical conversion efficiency was $30 \%$. The specific power for the slightly enriched uranium oxide presented in the table is 20 MW/ MT $(172.8 \mathrm{~W} / \mathrm{CC})$ whereas the thorium based metals are at $50 \mathrm{MW} / \mathrm{MT}$ $(610.0 \mathrm{~W} / \mathrm{CC})$ because of the improved heat dissipation rates for the thorium metals. The fabrication charges are assumed to be $\$ 40 / \mathrm{kg}$ for the extrudable thorium metals. The plutonium thorium case appears to be quite competitive with the uranium oxide case due to the increased bred fuel credit and the decreased fabrication, reprocessing and $\mathrm{D}_{2} 0$ charges. The U-235 - thorium case in the table can potentially be competitive when neptunium and Pu-238 credits can be properly established. Fuel prices used are also shown at the bottom of the table.

\section{Code Development}

Considerable effort was devoted to the generation of informal documentation on the status and input requirements of both the inhouse version of PYRE and the 2-group version of ALTHAEA which contains the kinetics package. A small program of changes in PYRE and the incorporation of the kinetics package into the 4-group ALTHAEA has been undertaken with the assistance of a commercial programmer. The PYRE changes include both updating with respect to the fast reactor analysis group's version, which has undergone both correction of errors and general system improvement in the nine months since the last update, and incorporation of desirable improvements from in-house point of view. Included will be work toward firmly binding PYRE operation directly to the 4-group ALTHAEA operation in a solid automatic fashion. 
FUEL CYCLE COST BREAKDOWN FOR THREE PRTR BASED DESIGNS

The following data are from QUICK analysis of single cycle, graded fueling, zero-dimensional AITHAEA burnups. Thermal Efficiency: $30 \%$.

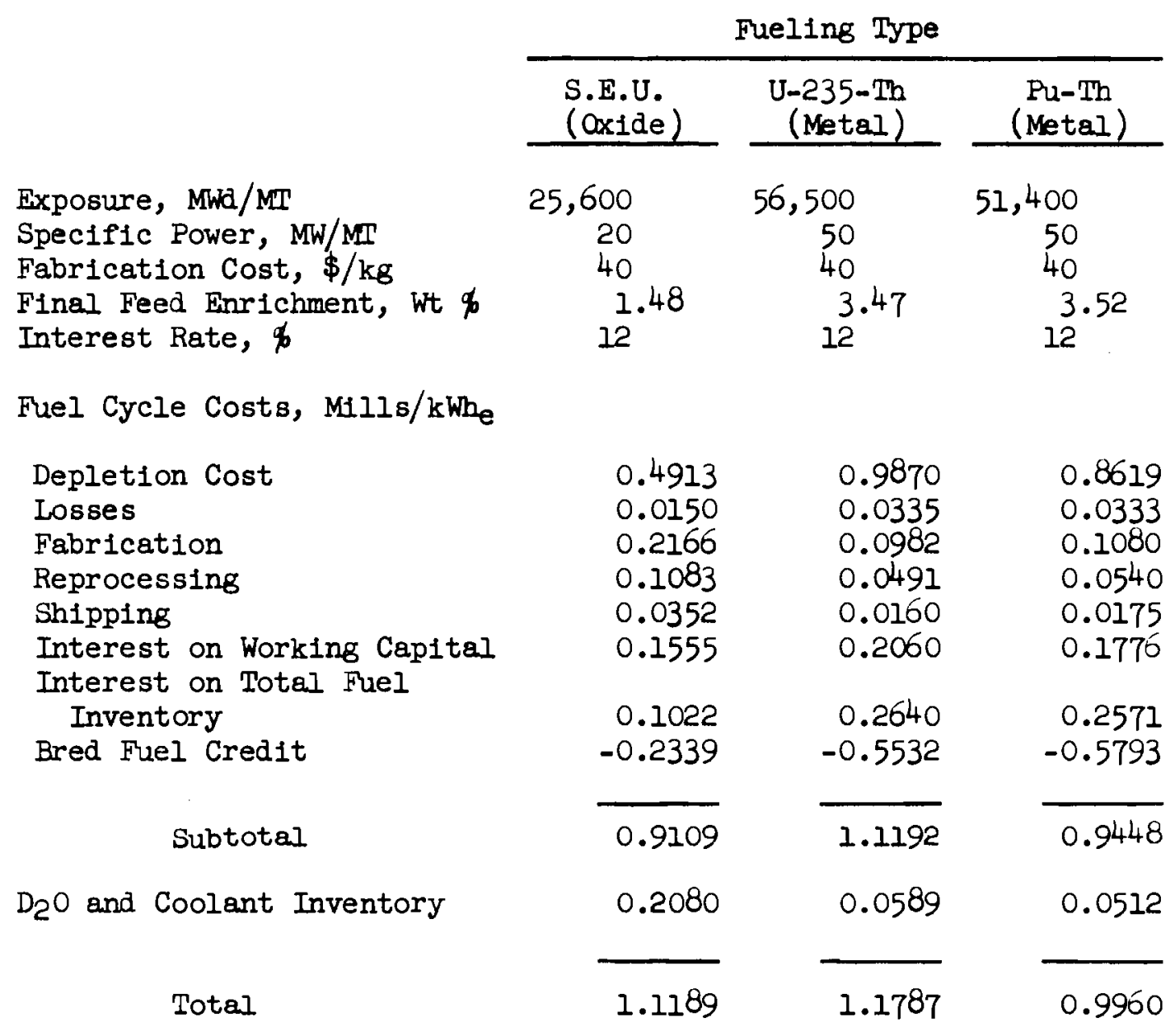

Fuel Prices:

Slightly Enriched Uranium, from price schedule. Fully Enriched Uranium, $\$ 12 / 8$. U-233 Enriched Uranium, $\$ 14 / \mathrm{g}$. Plutonium Enriched Uranium, $\$ 10 / 8$. 
Improving Diffusion Theory Leakage Calculations

A method which seems to be sufficlently simple as to warrant frequent use for improving diffusion theory leakage calculations has been ldentified. It is not known whether such has been previously suggested, but it does not seem to appear in any of the few works which have been studied. The motivation for the study was the desire to check the scattering matrix input being used by PYRE in order to (1) guarantee that it was being used correctly and to the limits of the system's capacity, particularly with respect to the isotopes of light atomic mass; and (2) to determine "if" and to what degree of approximation the system might be able to handle the isotopes hydrogen and deuterium. The problem being the necessity of considering elastic scattering which is, of course, very much nonisotropic for a given group to group energy change when the fine group structure of fast reactor calculations is used. Inelastic scattering does not appreciably suffer this handicap except for perhaps a few light isotopes and then to a much lesser extent.

Without going into detail, the key is to directly calculate exact or perhaps only semi-exact $\mathrm{Pl}$ transport theory leakage effects while only doing diffusion theory calculations. The key being that one needs only a slight increase in internal storage and internal calculations. By contrast $\mathrm{Pl}$ theory in general requires at least storage for the three components of the vector current, be they written with respect to the Cartesian coordinates or as first order spherical harmonics.

The suggested lmprovement will be most useful, from the point of view of requiring the least system changes, to zero-dimensional calculations, PYRE for example, and as a "perpendicular" correction in multidimensional calculations.

\section{Optimization Code}

The initial phase of development of an optimization code for use by fuel cycle analysis computer codes has been completed. The objectives of the initial phase were to prove that the method used to obtain an optimum solution to a multivariate problem was both adequate and practical. The next phase of development is the minor modification of the OPTIM code and then the inclusion of OPTIM in the chain of other fuel cycle analysis codes.

\section{Library Updating}

Further changes were necessary in the BARNS code and the GANDS code to obtain the recently updated isotope data on the BNW Master Library.* The cross section data are now more accurately described

\footnotetext{
$\bar{\star} \bar{K}$. B. Stewart, "BNW Master Library," USAEC Report, BNWL-CC-325, PNL, September 1965.
} 
as can be seen in the following table which shows the comparison of the " $g$ " values at $20 \mathrm{C}$ for the major fissile isotopes:

g Value Comparison

\begin{tabular}{|c|c|c|c|c|c|c|c|c|}
\hline & \multicolumn{2}{|c|}{$\mathrm{U}-233$} & \multicolumn{2}{|c|}{$\mathrm{U}-235$} & \multicolumn{2}{|c|}{$\mathrm{Pu}-239$} & \multicolumn{2}{|c|}{$\mathrm{Pu}-241$} \\
\hline & $9 \mathrm{abs}$ & $g_{\text {fiss }}$ & gabs & $9_{\text {fiss }}$ & gabs & $g_{\text {fiss }}$ & gabs & $g_{\text {fiss }}$ \\
\hline ata & 1.0091 & 1.0080 & 0.9939 & 0.9949 & 1.0817 & 1.0571 & 1.0276 & 1.0272 \\
\hline ta & 0.9970 & 0.9950 & 0.9770 & 0.9760 & 1.0783 & 1.0546 & 1.0461 & 1.0453 \\
\hline
\end{tabular}

New data for almost all isotopes used by ALTHAEA have been obtained. These will be incorporated into a new ALTHAEA nuclear library.

Work has continued on the fast cross section library. More high energy cross section data were obtained from new experimental data to fill in existing gaps. When no measurements at high energies are available for a particular isotope, a simulation of data from another isotope will temporarily be used until experimental data become avail$\mathrm{able}$,

\section{Test Reactor Operation}

\section{Operating Experience}

Pertinent data for the month are as follows:

1. Production .................226.16 MWd

2. Hours Critical . . . . . . . .... . $226.3 \mathrm{hrs}$

3. Critical Efficiency . . . . . . . . . . $30.4 \%$

4. Total Experimental Time Efficiency . . . . . $45.8 \%$

5. $\mathrm{D}_{2} 0$ Losses

a. Indicated Stack Loss (3/26/67-4/25/67) . . .1,233 lbs

b. Physical Inventory (3/30/67-4/27/67) . . . 718 lbs

6. Helium Loss . . . . . . . . . 81,513 scf.

Reactor operation was interrupted by 32 shutdowns of which 17 were intentional and 15 caused by reactor scrams. Seven of the scrams were from flow minotor trips and five from log reactor period trips. The other three scrams were from HX-1 low level, rupture loop low pressure, and pressurizer low pressure. The high incidence of flow monitor scrams was related to initial experience with the new flow distribution for the batch core.

The reactor was intentionally shut down for six major outages this month. All other intentional shutdowns and outages caused by reactor scrams were short duration, and after correcting the reason for the shutdown, reactor operation was resumed. 
The six major outages were as follows:

Date

Reason for Shutdown

April 4 Following completion of Power Test \#8, the reactor was shut down from 1 MW to remove oscillator equipment from the reactor, perform miscellaneous repair work, and prepare for low power operation. The outage lasted 63.2 hrs.

April 11 The reactor was shut down when the tube temperature monitoring equipment failed. The reactor remained shut down for 91.3 hrs while the primary cleanup ion exchanger was replaced. The old ion exchange unit had plugged to the point where it would not pass sufflclent cleanup flow. Prior to shutdown, the reactor had been operating at $20 \mathrm{MW}$.

April 19 The reactor was shut down from 35 MW to correct excessive angle valve leakage. The leakage collection Ilnes were removed from 22 angle valves and the valves and lines were plugged. The packing was also tightened on these valves. The outage lasted for 19.4 hrs.

April 20 The reactor was shut down from 2 MW when 1t was apparent the angle valve leakage rate was still excessive. Six more angle valve collection lines were removed and plugged and the packing tightened. This outage lasted 14.6 hrs.

April 21 The reactor was shut down from 35 MW because of high $\mathrm{D}_{2} 0$ stack losses. The emergency depressurization valve, $H-97$, was found to be leaklng. The outage lasted 29.4 hrs.

April 25 After operating for 56 hrs at 48 to $50 \mathrm{MW}$, the reactor was shut down because rupture loop external leakage exceeded the allowable limit. The reactor remained down for a scheduled outage to remove one rod from fuel element 6062 for radiometallurgical examination.

Operational and test data from the PRTR primary system indicated that control of solids ("crud") was fully satisfactory under present operation (to $48 \mathrm{MW}$ ) at $\mathrm{pH}$ 7. The primary system filters were steadily removing crud from the system as evidenced by an over-all flow decrease of about 3\% per day. Samples of primary coolant, filtered in the laboratory at room temperature through 0.45 . filters, showed less than limitations on instrument capability. At present, the $\mathrm{D}_{2} * \mathrm{H}_{2}$ concentration is being monitored by following the $\mathrm{O}_{2}$ concentration on the gas chromatograph and supplementing this with a dally mass spec analysis. The $\mathrm{D}_{2} 0$ disassociation rate $1 \mathrm{~s}$ aftected by recombiner flow and 
system coolant cleanup flow. The flow rate to the recombiner has been increased, and flow through the ion exchanger is maintained except when necessary to valve it out for boron conservation purposes.

The excessive vibration of the diesel well pump has been corrected. The vibration was corrected by adjustment of impeller spacıng

Seventy-three hundred gallons of hot waste were cleaned by passing it through an old undepleted rupture loop ion exchanger, then pumped to the river. This method of removing contaminants from liquid waste is potentially a significant cost reduction item.

The TW tanks were cleaned by repeated sluicing and chemical decontamination. Since completing the decontamination and starting use of the ion exchange process, tank waste has been pumped to the river.

The coolant for Process Channel 1550 has been supplied by the rupture locp since early in the month, and all pre-operational checks and tests completed. The rupture loop has operated satisfactorily all month under FERTF Test \#22. Radiation readings were obtained under FERTF Test \#21, and the data indicate that loop radiation levels are low.

\section{Process Technology}

The following status of the Batch core Power Tests was achieved during the month:

\begin{tabular}{|c|c|c|c|}
\hline Cest No. & Title & & itatus \\
\hline 1 & Ion Chamber Positioning & Comp & lete \\
\hline 2 & $\begin{array}{l}\text { Power Operation at Reduced Moderator } \\
\text { Levels }\end{array}$ & & $"$ \\
\hline 3 & $\begin{array}{l}\text { Transient Reactor Behavior Due to } \\
\text { Operation of the PRTR Chemical Shim syst }\end{array}$ & Eem & " \\
\hline 4 & Temperature Coefficient of Reactivity & $50 \%$ & Complete \\
\hline 5 & $\begin{array}{l}\text { Reactor Total Power Generation Mea- } \\
\text { surement }\end{array}$ & $60 \%$ & Complete \\
\hline 6 & Transient Fission Product Poisoning & Not & Started \\
\hline 7 & $\begin{array}{l}\text { Operation of the Traveling Wire and } \\
\text { Traveling Flux Measuring Equipment }\end{array}$ & Comp & lete \\
\hline 8 & Reactivity Oscillator Measurement & & $"$ \\
\hline 9 & $\begin{array}{l}\text { Reactor Loading Sequence for Power } \\
\text { Operation }\end{array}$ & & $"$ \\
\hline
\end{tabular}


Batch Core Crltical Tests 14-4 and 14-5, "FERTF Relative Power Generation and Reactivity Measurement," were also completed in April. Reactor power level is currently limited by PRTR Test 136, "Determination of Allowable Fuel Element Rod Power." The first step in an incremental approach to final power has been completed. With maximum fuel rod power at $16.8 \mathrm{Kw} / \mathrm{ft}$, total reactor power was $50 \mathrm{MW}$.

Startup chamber traverses were performed with $\mathrm{D}_{2} \mathrm{O}$ chamber cooling as well as with $\mathrm{H}_{2}$ O chamber cooling. The results indicated that chamber response versus radial distance was more nearly logarithmic with $\mathrm{D}_{2} \mathrm{O}$ cooling than with $\mathrm{H}_{2} \mathrm{O}$ cooling.

Power operation at up to $30 \mathrm{MW}$ with moderator heights as Iow as 86", i.e., below the lower row of orifices, was conducted. No excessive local heating in the moderator was experienced. Axial power peaking factors ranged from 1.47 at $86^{\prime \prime}$ to 1.31 at $100 "$.

Axial peaking factors, measured with the traveling flux wire at a power level of $45 \mathrm{MW}$ and at moderator level of 97.5 and $99.0 "$, were 1.29 and 1.288", respectıvely. A decrease from the values obtained at $30 \mathrm{MW}$ is due to the flattening of the axial flux profile with the growth of fission product poisons in the high flux zones.

Reactor response to the operation of the chemical shim was tested at various rates of boron removal and injection. Boron removal, with a flow rate of 50 lbs of moderator $\mathrm{D}_{2} 0$ per minute through the ion exchange unit was easily handled by the automatic controller. Injection of boron with an injection rate of 20 lbs of makeup solution per hour resulted in a slight overcompensation by the automatic controller. Injection rates of this magnitude will not be required during routine operation.

Preliminary results indicate a moderator temperature coefficient of about $1.2 \times 10^{-4}(\Delta \mathrm{k} / \mathrm{OF})$ for the temperature range from $92-140 \mathrm{~F}$. Similar results indicate a fuel coolant temperature coefficient of about $-1.9 \times 10^{-5}\left(\Delta \mathrm{k} / \mathrm{O}_{\mathrm{F}}\right)$ for the range of temperatures from $180-350 \mathrm{~F}$.

Detailed power calculations nndicate satisfactory agreement between actual total reactor power and the power level shown by the calculator.

Reactor response to the insertion and withdrawal of the traveling flux wire and traveling neutron detector was observed at various rates of travel. No problems were experienced in controlinng the reactor at the maximum rate of travel for elther the wire or the detector.

Two fission gas pressure measuring fuel elements were installed in the reactor according to PRTR Test 124 at the beginning of the power tests and have performed satisfactorlly. Seventeen pressure and temperature measurements were made on each of the four test rods. The maximum temperature and pressure observed was $505 \mathrm{~F}$ and 22 psig in 
Rod 8, Channel 1548. Data have been obtained at various power levels between zero and 50 megawatts.

Final reports were issued for:

PRTR Test 35 - Measurement of Effective Delayed Neutron Fraction

PRTR Test 38 - Fuel Element Substitution Measurements

PRTR Test 92 - Measurement of Reactor Noise in PRTR.

The HPD pellet fuel element 6700 was charged in the FERTF during the month under FERTF Test 22. As of April 25, this fuel element has accumulated an exposure of $4.0 \mathrm{MWd}$.

Corrosion Surveillance. Ultrasonic measurement showed uniform thinning of the side wall of the tank used as the brine supply for water softener regeneration. Remaining wall thickness at five levels on the tank wall ranged from 0.173 to 0.183 inch. This indlcates that appreciable corrosion of the original 0.250 inch wall had occurred, but the tank should give many years of useful service. Annual measurement of the tank wall is planned.

Process Tube Surveillance. Process tube 5690 was pi-taped and sectioned. Six 2-inch sections of the tube were shipped to Radiometallurgy.

Creep Capsule. The creep capsule micro positioner, which has been inoperable during recent months, started to function again when the capsule temperature was increased during reactor operation. The creep capsule is in service, and testing will be resumed after completion of PRTR Test 136 .

Improvement work Status

Work Physically Completed:

Project BCP-007 - waste Handling. This project provides improved waste handling capability and control of reactor system in the event of an incident. Beneficial use has been attained on all parts of the project, and it is estimated to be $98 \%$ complete. Minor cleanup items remain.

DC-272, Rev. 1 - Process Tube Filters. DC-2 72 provided 5-micron filters in two process tubes; however, the filters plugged soon after installation and reduced flow in the process tube made it necessary to shut down the reactor. Revision 1 provided bypass holes in the filter assembly to permit a minimum flow regardless of filter plugging.

NPC-429 - TW Tank Cleanup Ion Exchanger. A slightly used ion exchanger was salvaged and installed on a temporary basis in the TW waste tank area. Wastes are pumped through the resin to a clean 
holdup tank for sampling prior to disposal. Preliminary results indicate the ion exchanger will clean a large fraction of PRTR liquid waste to the extent that it can be discharged to the river. This eliminates the need for trucking this waste to the 200 Areas for cribbing.

\section{Design Work Completed:}

NPC-427 - Fuel Transfer System Modification. A stainless steel carriage has been designed to replace the present aluminum carriage on the fuel transfer system.

DC-304 - Moderator Level--Shutdown Valve Intertie. The shutdown valve will be interiocked with the servomanometer instrument such that it will open automatically when moderator level exceeds a high level set point.

\section{EBWR Demonstration Program}

Irradiation Testing of EBWR Prototype Fuel Rods

The last capsule (GEH-14-524) of the original group of 32 was iischarged from the MTR. The Zircaloy-clad $(1.07 \mathrm{~cm}$ OD) capsule contains vibrationally compacted (83.1\% TD), pneumatically impacted $\mathrm{UO}_{2}$ - 1.5 wt: $\mathrm{PuO}_{2}$. The capsule, which has an active fuel length of about $8 \mathrm{~cm}$, operated initially at an estimated maximum linear power of about $15 \mathrm{~kW} / \mathrm{ft}$. It was in the MTR for 925.7 effective full power days (55 MTR cycles), (estimated fluence - $6.7 \times 10^{20}$ neutrons/ $\mathrm{cm}^{2}$ ), and achieved an estimated burnup of $26,300 \mathrm{MWd} / \mathrm{tonne.}$

Irradiation proof tests by $\mathrm{PNL}$ with capsules and production-run rods continue to indicate that the fuel rods are satisfactorily designed to successfully perform under EBWR, 42-70 MWt conditions, and to the originally proposed goal burnup of 25,000 MWd/tonne. Burnups to 27,600 MWd/tonne (estimated) have been attained with fuel specimens.

Actual operating experience with the $1296 \mathrm{UO}_{2}-\mathrm{PuO}_{2}$ fuel rods in EBWR is limited (1300 MWd/tonne in February 1967), but predictable, trouble-free operation has been noted by ANL(1) to date.

A coauthored abstract ${ }^{(2)}$ of a paper was submitted to the AIME. 'i'he paper includes a discussion of the above capsule and rod tests and is to be presented at the IMD-AIME, 1967 Nuclear Metallurgy Symposium on "Plutonium Fuels Technology," to be held in Phoenix,

(1) C. H. Bean (ANL) to R. E. Sharp (PNL), Personal Communication, March 14, 1967 .

(2) C. H. Bean, R. E. Sharp, and W. J. Bailey, The EBWR Plutonium Recycle Demonstration Experiment, BNWL-SA-1 $199-A$. April 5, 1967. 
Arizona, in October 1967. A paper(1) describing the design features which were considered by PNL in connection with fabrication and irradiation prooftesting of the above mixed oxide fuel rods was submitted to the ASME for review for possible presentation at the 1967 Annual Winter Meeting in Pittsburgh, Pa., in November.

\section{NUCLEAR SAFETY}

\section{Containment Systems Experiment (J. M. Batch)}

Containment Leakage studies

Analysis and interpretation of data for the leakage rate tests with air was continued. Fortran programs for the PDP-7 computer were written to assist in this work. One program computes the standard deviation of small sample data sets. The other program computes the coefficients for least squares curve fits to data sets.

\section{Fission Product Transport Studies}

Condensate Holdup on Containment Surfaces. Four runs were made in the Aerosol Development Facility (ADF) to determine the amount of condensate held as liquid on the tank walls as a function of condensation rate under equilibrium condensation conditions. This factor is lmportant in the mathernatical model of aerosol mass transport.

The results show that for the $32 \mathrm{ft}^{3}$ stainless steel tank, the wall holdup averages $500 \mathrm{ml}$ for condensation rates between 16 and $20 \mathrm{ml} / \mathrm{min}$. A slight decrease of condensate holdup occurs with increasing condensation rate. This may be attributed to either variations of physical properties of the condensate with temperature, or to a peculiarity of dropwise condensation phenomena.

A comparison of one data point obtained earlier for a painted tank with these values for a stainless steel tank indicates that wall holdup is dependent primarily on tank surface area, though effective water film thickness for the painted surface may be on the order of $20 \%$ greater than that for the stainless steel surface.

Barium Aerosol Generation. Two methods to generate barium aerosols for ultimate use in containment mass transport studies were tested. These methods were:

- The reaction of pressed pellets of equal weight $\mathrm{BaCO}_{3}$ and Zr sponge at $1340 \mathrm{C}$ to produce Ba metal vapor, and

(1) R. E. Sharp and W. J. Bailey, Design, Fabrication, and Irradiation of $\mathrm{UO}_{2}-\mathrm{PuO} 2$ Fuel Rods for the Experimental Boiling Water Reactor, BNWL-SA- $\overline{1139}$. March 2, 1967. 
- The direct distillation of barium metal at $1140 \mathrm{C}$.

In each case helium was used as a carrier gas.

The reduction of $\mathrm{BaO}$ (decomposed $\mathrm{BaCO}_{3}$ ) by $\mathrm{Zr}$ metal proceeds as long as unoxidized $\mathrm{Zr}$ is avallable, and approximately $15 \%$ of the barium was found to be released from the $\mathrm{BaCO}_{3}+\mathrm{Zr}$ sponge mixture before the reaction subsided. However, using this solid-solid reaction for reproducible barium releases, especially long-term linear releases, will not be satisfactory.

This test supports the hypothesis that barium releases from oxide fuels higher than the normal 0.01 to $0.05 \%$ could be obtained, provided the molten fuel was continually in contact with unoxidized zirconium metal surfaces.

Direct distillation of barium metal into a helium carrier gas was found to be a more satisfactory method of generating barium aerosols. The barium metal was tagged by melting in a stainless steel cup containing a dried radioactive barium salt. The sample of aerosol taken over the first four minutes after melting had a specific activity $93 \%$ of the value of all later samples. The aerosol samples taken over the following hour varied only $\pm 2 \%$ from the average specific activity. The release rate was approximately $15 \mathrm{mg} / \mathrm{cm}^{2}$ (melt surface) at $1140 \mathrm{C}$ with the melt level 0.6 to $0.8 \mathrm{~cm}$ from the top of the stainless steel cup and 0.5 SCFM helium carrier gas flow.

Calculated Chemical states of Cesium Aerosol. The ratios of $\mathrm{Cs} / \mathrm{Cs}$ oxide which could be expected in the vapor phase of the mixture were calculated. These ratios are given in the following table:

Equilibrium PCs/PCsO Vapor vs. O2 in Atmosphere

\begin{tabular}{|c|c|c|c|c|}
\hline $\mathrm{T}^{\circ} \mathrm{K}$ & $100 \% \mathrm{O}_{2}$ & $20 \% \quad \mathrm{O}_{2}$ & $0.5 \% \quad \mathrm{O}_{2}$ & $0.01 \% \mathrm{O}_{2}$ \\
\hline 1000 & 0.07 & 0.17 & 1.0 & 7.2 \\
\hline 1500 & 0.5 & 1,1 & 7.3 & 50 \\
\hline 2000 & 1.2 & 2.8 & 18 & 125 \\
\hline 2500 & 2.4 & 5.3 & 36 & 250 \\
\hline
\end{tabular}

It is significant to note that even in air at $1500 \mathrm{~K}$ the cesium vapor species can contain approximately $50 \%$ cesium metal. As the vapor cools and the aerosol forms, the cesium can be oxidized as high as the superoxide $\mathrm{CsO}_{2}$. Little is known about the kinetics of cesium oxide decompositions; therefore, the $\mathrm{Cs} / \mathrm{Cs}$ oxide ratio in the $\mathrm{UO}_{2}$ melter is highly uncertain. However, at $350 \mathrm{~K}$ all Cs metal and Cs oxide species will be converted to mixtures of $\mathrm{Cs}_{2} \mathrm{CO}_{3}$ and $\mathrm{CsOH}$ by reaction with $\mathrm{CO}_{2}$ and water vapor in the containment atmospheres. 
Maypack Performance. Investigation of iodine retention in CSE Maypack components has continued. The retention of elemental $\mathrm{I}_{2}$ on treated and untreated fiberglass filters (Gelman type A) and others, has been measured at several mass loadings up to $500 \mathrm{ig}$.

The iodine was released as $\mathrm{I}_{2}$ in a solution of $\mathrm{CCl}_{4}$ by evaporation. Prior tests show that this release gives $I_{2}$ of quality similar to the $\mathrm{K}_{2} \mathrm{Cr}_{2} \mathrm{O}_{7}$ fusion method. The normal (Type A) filters retained less I2 than other types tested, except Zitex (Teflon). Treating the filter with Drifilm or $\mathrm{Cl}_{2}$ gas prior to use also reduced the retention. At carrier free levels (which are not expected in CSE), the retention of the materials tested is quite similar.

Autoclave Tests. As new coating, sealants, etc., become available, they are tested for change of properties in the ADF steam autoclave. Phenoline 368 coating has been tested at $130 \mathrm{C}$ ( $30 \mathrm{psig}$ ) in steam to 1000 hrs. It was observed to form small blisters (1/8" diameter) at 110 hrs. These blisters developed hairline cracks 1/8" long at 230 hrs and subsequently started to lift at $600 \mathrm{hrs}$. About four cracks/inch ${ }^{2}$ were noted. This smooth light gray paint seems less durable than the Phenoline 302 but is somewhat better than the Amercoat 66 .

Gamma Energy Analytical system. Gain and zero stability of the sodium iodide detector systems and analog-to-digital converter systems associated with the on-line computer, gamma energy spectrum analysis system(I) have been monitored over the past four-month period. Gain and zero-drift were found to average less than 0.04\%/ day over the 120-day period. However, gain and zero shifts during periods of continuous sample analysis were significantly higher and have necessitated as much as $20 \%$ of the available time for equipment calibration checks. Automatic gain and zero stabilizers are being evaluated to determine whether or not they can eliminate this cause of reduced sample analysis efficiency.

Gamma Analysis. An example of output data from the modified least squares method used in the spectrum analysis program is shown below for an eight-component radionuclide mixture. This table shows the output data received immediately after spectrum storage is completed, together with the actual disintegrations/min.

(1) N. P. Wilburn and L. D. Coffin. "The Combination of on-Line Analysis with Collection of Multicomponent spectra in a PDP-7," BNWL-CC-700, July 15, 1966. 


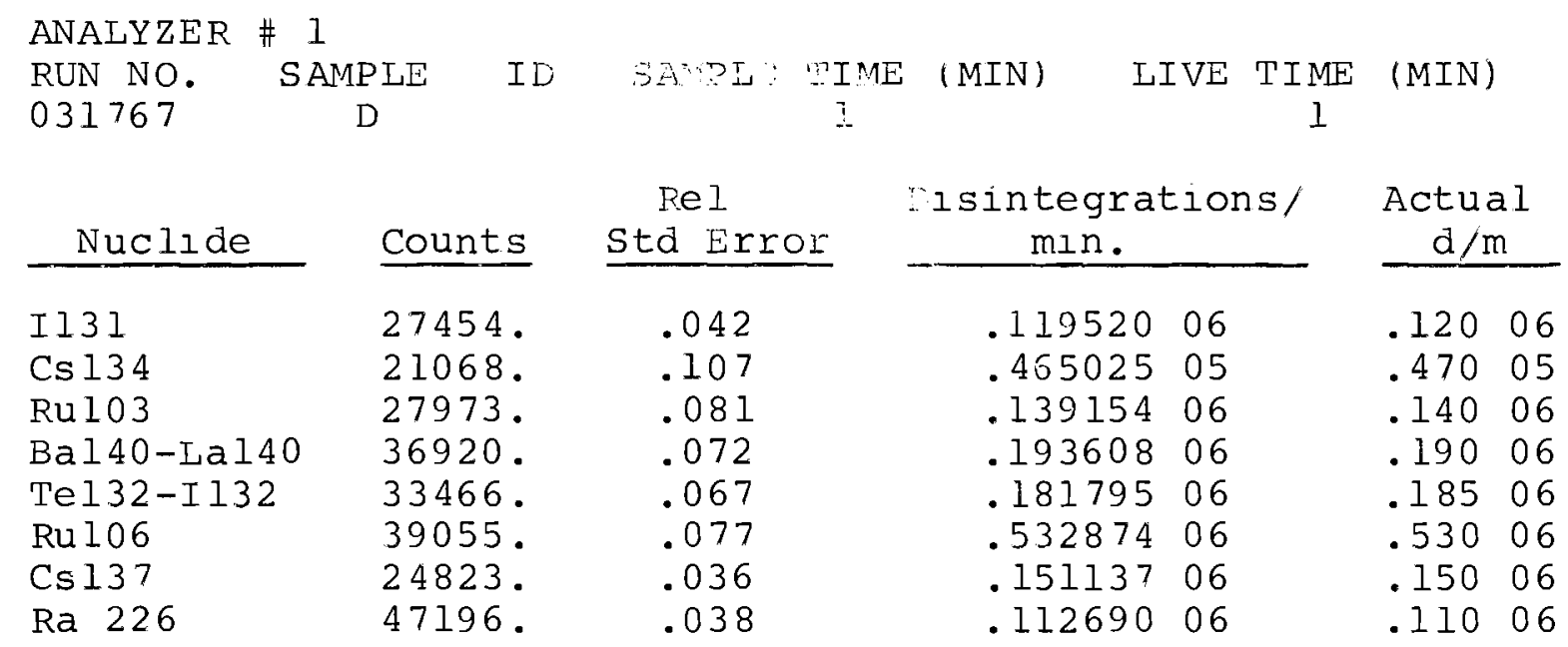

$\mathrm{CHI} * 2=-2.433$

Deg. F. $=12$

SAVE ANALYSIS, Y(YES), N(NO)

$\mathrm{N}$

These data are idealized to the extent that approximately equal counts of each radionuclide were used. Also, sample positioning and standards filing errors were minimized to exclusively evaluate the model. In the above case more than 50 individual photo peaks are readily resolvable with an $85 \%$-or-better resolution sodium iodide detector system, and many of these photo peaks are superimposed in the spectrum from which the above data were obtalned.

The relative standard error term indicates the expected accuracy of each individual radionuclide present in the spectrum, whereas the normalized chi-squared number indicates the over-all fit of the collective isotope data.

The spectroscopist must still specify what isotopes are to be used in the analysis of a given collected spectrum and the chi-square test is an extremely sensitive indicator of improper selection of these isotopes for the analytical model.

\section{Coolant Blowdown Studies}

Two blowdown tests were performed on the reactor simulator using cold water. In these tests $100 \mathrm{ft}^{3}$ of cold water was forced from the bottom nozzle by a 600 psig nitrogen dome. The purpose of these tests was to train personnel and evaluate the instrumentation employed.

The theoretıcal blowdown rate was calculated assuming adiabatic nitrogen dome expansion and an exit flow restriction in the form of an orifice with discharge coefficient of 0.648 . The liquid level and welght loadcell data were found to agree quite well with each other and with theoretical values. 
An interesting phenomenon occurred in these blowdowns. In Run $\mathrm{B}-3$, both the impact probe and the sound recording indicated discharge of gas beginning at 20.7 sec. In Run B-4, the same thing occurred, but at $11.0 \mathrm{sec}$. In both cases the liquid level as indicated by the level probe and by the load cell was about one ft above the nozzle outlet at the time gas venting started. One possible explanation is that boundary layer vorticity is increased in the outlet stream due to conservation of angular momentun, and a hollow vortex is formed. This hollow vortex allows the nitrogen to blowout early causing the observed phenomenon. A future experiment is being planned to test this theory.

\section{Instrumentation Performance}

The recorded output of the sensors during these tests showed the instrumentation to be working satisfactorily, for the most part. The rupture disk trigger wire system has proved reliable for initiating and marking the beginning of a blowdown. Pressure transducers, thermocouples, strain gages, liquid level probe, and the total weight loadcell gave good data which agreed well with calculated values. The thrust loadcell data indicated large fluctuations during the initial part of the run due to vibration; hence, a large possible error band existed. However, averages of this fluctuating reading indicated forces in good agreement with theory.

The high speed pressure transducers used to follow the effects of the acoustic decompression during the subcooled blowdown were reacl out by recording oscilloscopes. These scopes were triggered by the rupture disk wire break. The instruments and recording system indicated pressure fluctuations occurring during the first few milliseconds of flowdown and detected flucatuations which occurred on the order of $1000 \mathrm{~Hz}$.

$$
\text { Radioactive Waste Solidification (A. M. Platt) }
$$

\section{Pot Calcination}

Process Assistance. As reported previously, double salts of sodium and rare earth sulfate in the $\mathrm{PW}-2$ feed solution appear to be responsible for the caking and plugging problems encountered during runs $\mathrm{PC}-3$ and $\mathrm{PC}-4$ in WSEP. The PW-2 feed contains other solids which have now been identified and semi-quantitatively measured. The major nonsulfate precipitate is a heteropoly acid salt containing zirconium, molybdenum, and phosphate. The volume of this solid is about equal to that of the sodium-rare earth sulfate precipitate in refluxed $\mathrm{PW}-2$ at $4.0 \mathrm{M} \mathrm{HNO}_{3}$. However, its bulk density is only about one-third that of the sulfate, and it does not tend to cake. Barium and strontium sulfate and silicic acid are minor contributors to the bulk and weight of the precipitate in $\mathrm{PW}-2$. 
Product Evaluation and Characterization. Design of modifications to C-Cell, 324 Building, necessary to permit laboratory-scale studies of WSEP product characteristics is nearing completion. Work on the cell modifications will start soon.

Design Verification Tests of Phosphate Glass Unit

The continuous phosphate glass unit was successfully tested using a PW-2 waste. The run, using automated control, showed the unit could be installed for radioactive service. However, several problem areas were evident. The melter capacity is about 50\% lower than expected. Visual inspection showed corrosion is continuing on the platinum 5\% Iridium off-gas line and the platinum melter nozzle. The product was not fully vitrified. As predicted from laboratory work, no appreciable corrosion of the mild steel recelver was evident. The introduction of aluminum into the feed at the Al/Fe molar ratio of $1_{*} 0$ did not appreciably affect the operation.

Testing with $\mathrm{PW}-1$, a nonsulfate waste, remains before the unit will be placed in radioactive service.

\section{Pot Development}

The program to evaluate extruded cylinders for waste pots received a setback when the sole supplier, Harrisburg steel, "no-bid" a request-to-quote for six $304 \mathrm{~L}$ pots to be fabricated on an experimental basis. A siml lar response has been received from spincast and spin fabricators. Meanwhile, the metallurgical examination of an extruded cylinder by destructive and nondestructive methods is under way.

Continuation of the pot development program with the scoping of the "bare-bones" pot and related flll equipment is planned. Unless alternate suppliers are found, however, comprehensive process tests of extruded pots, as previously planned, will not be possible.

Advanced Atomization Studies

A system for handling liquids other than water in the test stand is being assembled.

High speed motion pictures (7000 frames per sec) were taken of the spray in an attempt to measure both droplet size and rate of fall; the film will be developed within a week. 
Spray Calciner Development

A run was made with a PW-2 flowsheet, an internal mix spray nozzle and air atomization. The calcine and powdered $\mathrm{NaPO}_{3}$ were added directly to the receiver pot, and the melting of the calcine was performed in the receiver pot. The primary objective of the run was to achieve an operating condition wherein there would be no deposition and accumulation of scale in the calciner; a secondary objective was to explore the feasibility of melting directly in the receiver. The principal purpose of the run was successful since there was only a thin film of dry, powdery calcine throughout the calciner at the conclusion of the run. Erratic flux addition caused nonuniform and incomplete melting toward the end of the run. Nothing occurred, however, to disprove the approach of melting directly in the receiver, and this technique will be investigated further.

The feed flow during the run ranged from 12 to 17 liters/hour with an average rate for the run of 13.3 liters/hour. The atomization during the run was satisfactory since no deposition occurred in the calciner. Inspection of the nozzle after the run revealed a deposit of calcine around the outside of the nozzle tip and extending $\frac{1}{4}-\frac{1}{2}$ " beyond it. The area immediately around the nozzle orifice was clear, and it does not appear likely that the deposit could have grown into the high pressure spray since it was very fragile. The internals of the nozzle were clean.

During a portion of this run sugar solution $(700 \mathrm{gm} / 1)$ was injected into the feed line to give sugar concentration in the feed of approximately 25 and $50 \mathrm{gm} / 1$ (feed at $120 \mathrm{gal} /$ tonne). The analyses of the ruthenium behavior during these additions are not available at this time.

Analyses available from Run DSC-3 which was reported last month indicate that sodium nitrite additions to the feed, at concentration levels of $0.025 \mathrm{M}$ and $0.05 \mathrm{M}$ (concentrations based on $100 \mathrm{gal} / \mathrm{tonne}$ feed) have little effect upōn ruthenium volatility. The over-all decontamination factor (feed to condensate) for ruthenium for the run was 1.8 .

The prototype vibrating trough solids feeder has been received from maintenance and is being tested to determine the modifications which might improve its reliability and operability.

\section{Pot Sampling by Core Drilling}

The following activities are required for in-cell drilling:

1. Receipt of vendor drawings for the drill unit (due 5/15/67).

2. Preview of the scope design and issued approved drawings (due $6 / 1 / 67$ ). 
3. Fabrication of mounting plates and details (due 6/15/67).

4. Installation in EDL-102 and DVT's (due 8/1/67).

5. Modifications to the drill unit and development of a trepanning cutter (for off-center and radial sampling) (due $10 / 1 / 67$ ).

6. Development of sample handling flowsheet and adaptation to in-cell use.

Installation in cell and operational use should be possible, at least for centerline sampling of glass pots, during the second quarter of FY-68.

\section{Product Evaluation}

Leak testing of a pot filled with radioactive calcine was achleved. The weld on Pot No. 23 (from Run PC-3) was shown to be a reasonably good weld, that is, the leak detection system could be pumped down to 15 microns for testing while connected to the pot. When helium was sprayed on the weld, no leak indication was given by the helium detector. Successful pump-down was achieved only after the lines between the vacuum pumps and the in-cell rack face were replaced with high vacuum hose and stainless steel tubing with welded connections. Formerly the line had included five metal tubing fittings. Before a final quantitative leak rate can be determined, a calibrated leak must be connected into the system near the pot. This leak has been designed, and fabrication has been started.

\section{Pot Leak Testing}

Pot leak testing indicates that the radiation contamination problem due to outgassing of pots during vacuum leak testing is not a serious problem, at least for pot calcination containers. Based on this result, it is recommended to proceed with the design and fabrication of a shielded vacuum pump/cold trap unit which could be used in the gallery. The gallery unit provides a simplified, minimumconnector system which would be more reliable for high vacuum leak testing.

\section{Materials of Construction}

Haynes LT-1B cermet ( $59 \mathrm{Cr}-20$ Mo-19 $\mathrm{Al}_{2} \mathrm{O}_{3}-2 \mathrm{TiO}_{2}$ ) was exposed for one week at $1000 \mathrm{C}$ to $\mathrm{CSCM}-9$ (PW-2) and DSC-3 (PW-1) melts. Samples were then mounted, polished, and examined for penetration by the melts. There was no evident penetration, and there appeared to be no preferential attack of the metal or ceramic components of the alloy. 
Continuous Melter Development

Several small test crucibles of Haynes-Stellite LT-1 and LT-lB have been ordered. These crucibles will be used to evaluate both corrosion and possible mechanical failure due to unequal shrinkage of melt and the crucible during cooling.

\section{Waste Solidification Engineerlng Prototypes - Spray Solidification}

Since the spray solidifier walls were scaled during the last run, the walls were de-scaled by spraying with acid for 50 hours. Visual inspection by television showed $70-80 \%$ of the scale was successfully removed down to bare metal. Scale up to $\frac{1}{2}$ inch thick remains in spots near the top two feet of the barrel and in the upper portion of the cone. The descaling operation was successful enough to permit startup of the next radioactive run.

The descaling method involved spraying the solidifier walls with nitric acid pumped through a tank-cleaning nozzle (Spraying Systems Co. \#7250-1-7 and \#4900-1-7). The nozzle was mounted on a movable wand which was inserted into the solidifier barrel through a hole in the top flange. Acid was sprayed against the walls at an average rate of 150 liters/hour and collected in the melter where it was continuously jetted back to the head tank to be recycled to the spray nozzle. Only 400 liters of nitric acid was used for descaling. Although diluted by a factor of 7 during recycle, concentration reduced the volume of final waste to the original quantity of acid.

Solids Storage Engineering Testing

The installation and connection of Environmental Test Pod No. 1 in $A-C e l l$ for design verification testing is about $95 \%$ complete. Preliminary handing studies indicate that remote removal of the cubicle plug and installation of a pod in-cell should be no problem.

The interim installation of four pods in B-Cell is planned to meet controlled environment storage requirements until the beneficial occupancy of A-Cell. Access to both B-Cell cubicles is impaired since the 4C rack partially covers the B-14 cubicle plugs and the spray calciner off-gas line block entry to the B-12 cubicle plugs. Detailed procedure development is required for pod installation to define operating difficulties and auxiliary hardware.

Project funds for design, equipment procurement, and construction on Project BAP-016, Solids Storage Engineering Test Facility, have been released. Window specifications, HWS-8649, have been issued for comment; manipulator specifications are in process; and detail design is under way. Construction will begin with removal of the second floor "soft plug," to permit detall design of the upper window installation. 
Intermediate Level Waste Treatment (C. H. Touhı11)

Scavenging Mechanisms

Studies of the ion exchange properties of hydrous manganese dioxide were continued. Adsorption of trace amounts of Cs-137 ion from solutions containing macro-quantıties of elther $\mathrm{Na}^{+}$or $\mathrm{K}^{+}$as the competing cation was investigated. Distribution coefficients for the exchange between $\mathrm{Na}^{+}$or $\mathrm{K}^{+}$and $\mathrm{Cs}^{+}$were determined at selected $\mathrm{pH}$ values. Experimental data indicated that at high $\mathrm{pH}$ (9), $\mathrm{Cs}^{+}$exchange with $\mathrm{Na}^{+}$and $\mathrm{K}^{+}$on the hydrous oxide obeyed the law of mass action.

In addition to the Cs-137 adsorption studies, some preliminary experiments on the sorption of $\mathrm{Sr}-85$ ion were conducted. It was observed that $\mathrm{Sr}^{+2}$ removals were about $100 \%$ at all values above $\mathrm{pH}$.

Fission Product Aerosol Containment (L. C. Schwendiman, L. L. Burger)

Removal of Organic Iodıdes with Hydrazıne

Two spray removal experiments were performed in the $3.6 \mathrm{~m}^{3}$ chamber using a Bete fog nozzle. Flow through the nozzle was approximately $2.5 \mathrm{gpm}$. In contrast to the inltial run, the spray drops had a mass median diameter of 360 i, rather than 220 . The hydrazine concentratıon was increased from 5 to 6.3 and 8.6 wto in the two experiments, respectively.

These modifications resulted in a significant change in the methyl iodide removal rate. Removal of $99 \%$ of the alrborne methyl lodide was achleved during six hours of recirculation through the spray nozzles. The removal of methyl lodide from the air was nearly exponential with time. Half-time for removal was about 55 minutes. Although the hydrazine concentration was different in the two runs, the removal efficiencies were nearly the same. The greater flow of hydrazine solution in these two experiments is probably the cause of the faster rate of removal than was achieved in the first of the three runs completed to date.

The influence of the wetted surfaces on removal rate has not yet been determined but is believed to be of significance and will be investigated in subsequent experiments.

Dissolved, but unreacted methyl lodide in the recirculated hydrazine may be a significant factor in limiting the removal rate in the spray chamber. This conclusion is drawn from the reaction rate data, the inventory of hydrazine, and the flow rate of hydrazine through the system. Any unreacted methyl iodide in the liquid would tend to slow the transfer of methyl iodide to the liquid spray 
droplet. Increasing the inventory of hydrazine would decrease this effect. Further study on this point will be undertaken.

Observations to date continue to show that hydrazine in quite low concentrations may be a useful scavenger for methyl iodide.

Physical Chemistry of the Hydrazine-Methyl Iodide Reaction

At a concentration $0.2 \mathrm{M} \mathrm{N}_{2} \mathrm{H}_{4}$ (or ca. $0.6 \mathrm{wt} \%$ ), the reaction between hydrazine and methyl iodide in an aqueous alkaline environment is first order with respect to the methyl iodide concentration over a 300-fold change in concentration.

The second order rate constant is calculated to be $1.3 \mathrm{M}^{-1} \mathrm{~min}^{-1}$ when the reaction is also assumed to be first order with respect to the hydrazine concentration. At lower $\mathrm{N}_{2} \mathrm{H}_{4}$ concentrations, i.e., $0.01 \mathrm{M}$ to $0.03 \mathrm{M}$, the reaction appears to be a higher order with respect to the methyl iodide concentration. A test of the experimental approach was made by observing the rate of hydrolysis of methyl iodide by hydroxide ion. The hydrolysis of methyl iodide by water must be taken into account. The experimentally observed value at $22 \mathrm{C}$ is $4.0 \times 10^{-5} \mathrm{M}^{-1} \mathrm{sec}^{-1}$ compared to a value calculated from previous work of $4.41 \times 10^{-5} \mathrm{M}^{-1}$ sec $^{-1}$. The results which have been obtained are indicative of another reaction mechanism as the rate controlling step for the reaction of methyl iodide. This effect may be due solely to the interaction of hydrazine and/or methyl iodide with another component of the system.

Future work will concentrate on the reaction at the lower hydrazine concentrations in order to understand better the mechanism of the hydrolysis of methyl iodide in dilute hydrazine solutions.

Disposal of Reactor Off-Gas into Soil Systems (L. G. King)

Computer programs have been altered to accommodate the variable grid spacing necessary for economical solution to the heterogeneous (layered) soils problems at the NRTS site. Results should soon be available on the problems to be solved to choose permeability values as input to description of gas movement. Work is progressing toward obtaining minimum travel times for the homogeneous media solutions.

Geophysical Exploration of Rattlesnake \#1 Well (J. R. Raymond)

Some temporary contractual problems were encountered concerning Rattlesnake Hills \#1 Well re-opening, cleanout, and mud reconditioning. These problems have been resolved, but a projected delay of work initiation to mid-May 1967 resulted. It is anticipated that all work can be completed by the end of the fiscal year if the drilling contractor arrives on site no later than May 15, 1967. 
Columbia River Sedimentation Studies (D. R. Kalkwarf)

Analyses for radionuclides in water and suspended sediment samples from 2 I vertical sections in the Columbia River estuary were completed. Samples Irom at least three depths per vertical section were analyzed, many of whlch were from the salt-water wedge underlying the estuary. Radionuclides in solution were found to be aistributed uniformly with depth. In the salt-water wedge most radionuclides in solution and on suspended sediment were found to be in lower concentrations due to the diluting action of the wedge. In the case of Cs-13?, however, the wedge appeared to contain a higher concentration than did the overlying fresh water.

Simulation Modeling of Expected Thermal Generation in Selected River Systems (R. T. Jaske)

Computer runs for simulation operations using 1963 and 1964 weather data have now been completed as far downstream as ottawa, Illinols, $(47 \mathrm{mlles})$. The resulting data indicate a significant effect on downstream water conditions at that point. While statistical evaluation of the information is not complete, the following observations appear pertinent:

1. Mixed river temperature immediately below the plants can be expected to be from 3.5 to $5.5 \mathrm{C}$ higher.

2. Temperatures at Marseilles can be expected to be from 2 to $4 \mathrm{C}$ higher than presently experienced.

3. Temperatures at ottawa will range from 1 to $3 \mathrm{C}$ higher.

4. Lesser effects can be expected downstream although a basis exists tor indlcating that the proposed plants will have measurable effects below Pekin, Illinols. At this point a series of large thermal plants already exists.

The above observations assume a continuous thermal input of 3500 MW. Other lesser inputs and the effects of load cycling have also been computed.

Further prog!:ess at this time 1 s dependent on receipt of river soundings down to mile $801190 \mathrm{mlles}$ below the plants). Arrangements for confirmatory thermograph installation on the upper Iilinois are still in progress with the USGS. The scope of the assistance and technical quality of the work have been established in writing and await administrative approval.

Verbal arrangements have been concluded with the New England Power Company by which they will furnish soundings, storage computations, flow and temperature data pertinent to a test of the ålgital 
simulation system in that region. A three-year record of thermograph information on the Deerfield River is available.

Pressure Vessel Crack Monitoring (J. C. Spanner)

Detection of Metal Overstress by Acoustic Emission

Progress during the third quarter of FY-67 in the program to apply acoustic emission to detect flaw growth in pressure piping was summarized in a quarterly report and submitted for inclusion in the 04 Nuclear safety composite report.

A meeting was held April 4, 1967, by the Division of Reactor Development, USAEC, at Germantown, Md., for the purpose of integrating work being done in the area of acoustic emission application by various contractors. PNL; Phillips Petroleum Co., Idaho Falls, Idaho; and Aerojet General, Sacramento, California, reviewed their work to date, and areas of the technology requiring greater emphasis were discussed.

Data derived from ductile failure of two burst test specimens show a better definition between the various stages of acoustic emission than was true of earlier testing with flat plate specimens of similar material. The burst test specimens were fabricated from 3" diameter, 3/4" wall, Type A-106B carbon steel pipe with a throughwall flaw. During the pressurization, emission occurred as sporadic bursts starting at about 50\% of failure pressure. At $70 \%$ of failure, continuous emission with occasional bursts appeared as a result of metal deformation around the flaw. At $90 \%$ of failure pressure, where the flaw began to propagate, the acoustic emission became a profusion of burst signals which continued until final

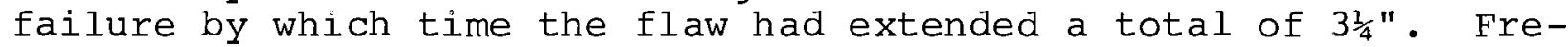
quency content of the burst signals was 20 to $30 \mathrm{kHz}$ while the continuous emission showed a frequency content of 15 to $20 \mathrm{kHz}$. The source of burst signals sampled in all stages of the test was located at the flaw area by triangulation from multiple transducers. Signal propagation velocity was very near nominal shear velocity for the material. An emission rate curve for the full test showed a very pronounced identification of the flaw growth period preceded by a uniformly increasing count rate during the metal deformation stage.

Acoustic emission detected during brittle fracture of an $\mathrm{A}-302 \mathrm{~B}$ carbon steel, double cantilever beam tested at $-140 \mathrm{C}$ consisted exclusively of transient type signals. These were about $100 \mathrm{kHz}$ in frequency content and persisted for only about two to five cycles $(20$ to $50 \mathrm{usec})$. These data were generally consistent with earlier observations of acoustic emission from brittle fracture.

Adjustment of the detection threshold has been a problem in routine application of the emission rate analyzer. In the process of refining this system to a single integrated instrument, an improved 
detection circuit has been designed and incorporated. The new circuit, using bipolar transistors, has the required broad frequency response as well as good hysteresis and voltage control characteristics.

Twelve reusable fuzed quartz, substrate elements have been completed for use in fabricating multilayer electrostatic transducers. The necessary masks have also been fabricated in preparation for assembling test transducers by vapor depositing multiple electrodedielectric layers on the quartz substrates. These transducers should be completed and ready for testing within a month.

Two commercial, low noise, broad band amplifiers being evaluated in an effort to improve the resolution capabilities of the acoustic emission detection system look very promising. They will be used to monitor emission data in a forthcoming series of tests as a final evaluation step. 


\section{DISTRIBUTION}

Number of Copies

8

1

1

1

1

1

7

1

1

3

54 $\frac{\text { AEC-AECL, Chalk River, Canada }}{\text { M. H. Hudson }}$

AEC Division of Technical Information Extension

Aerojet-Nucleonics

P. O. Box 77

San Ramon, California

F. W. Titus

Aeroprojects, Inc.

W. B. Tarpley

Air Force Materials Laboratory

Wright-Patterson AFB

S. W. Bradstreet

Allis Chalmers Manufacturing Co. Virginia D. Rose

Ames Laboratory

F. H. Spedding

Argonne National Laboratory

R. M. Adams

L. R. Link (4)

C. E. Stevenson

R. C. Vogel

Armour Research Foundation

W. Loewe

Atomic Energy Commission, Division of Compliance Region IV, P. O. Box 15266, Denver

Atomic Energy Commission, DRD\&T Site Representative P. G. Holsted

Atomlc Energy Commission, Washington

Advisory Committee on Reactor Safeguards

R. F. Fraley (17)

Division of Compliance

L. Kornblith, Jr.

Division of Licensing and Regulation (7) 
Division of Operations Analysis and Forecasting

Division of Production

F. P. Baranowskı

Division of Reactor Development \& Technology

R. A. Brodsky

Col. K. Cooper

A. Gi ambusso

J. E. Robb

S. A. Szawlewcz

M. Shaw (16)

G. W. Wensch

Division of Research

G. A. Kolstad

Division of Safety Standards

M. Bolotsky

A. B. Holt

Office of Assistant General Counsel for Patents

R. A. Anderson

Space Electrical Propulsion Office

Col, G. K, Dicker

Atomic Power Development Associates, Inc.

W. H. Jens

Atomics International

A. A. Jarrett (2)

H. Pearlman

Babcock and Wi lcox Company

Lynchburg, Virginia

H. S. Allen

R. A. Webb

Battelle Memorial Institute

D. L. Morrison

Bechtel Corporation

R. F. Griffın

Brookhaven National Laboratory

A. E. Castleman

Elizabeth J. Edwards

C. J. Raseman

D. G. Schweltzer 
1

2

1

1

1

1

11

I

4

응

1

2
Canoga Park Area Office R. W. RIchards

Carolinas-Virginia Nuclear Power Associates H. T. Babb

Chicago Operatıons office Argonne, Illinois

D. M. Gardiner

$\frac{\text { Columbia Universıty, New York }}{\text { J.E. Casterline }}$

Combustion Engineering

P. O. Box 500

Windsor, Connecticut

W. P. Chernock

$\frac{\text { Dow Chemical Company, Rocky Flats }}{\text { J. R. Seed }}$

DUN

$\overline{\mathrm{P}}$. A. Carlson

R. E. Dunn

G. C. Fullmer

D. R. Hogle (Atomics International)

C. G. Lewis

W. M. Mathis

J. H. Soehnlein

H. G. Spencer

J. R. Spink

W. K. Woods

Ebasco Services, Inc.

T. A. Flynn, Jr.

E. I. duPont de Nemours and Co., Aiken

General Atomic Division

D. B. Coburn

E. Creutz

A. J. Goodjohn

S. L. Koutz

D. V. Ragone

General Electric Company, Cincinnati S. Naymark, NMPO

General Electric Company, Pleasanton

L. P. Bupp

E. A. Evans 
6

5

2

6

1

1

3

2

1

1

General Electric Company, Richland

W. J. Dowis

A. E. Guay

M. Lewis

J. S. McMahon

J. W. Nickolaus

J. W. Riches

General Electric Company, San Jose

K. P. Cohen

E. R. Kilsby

R. B. Richards

C. H. Robbins

E. L. Zebroski

General Electric Company, Schenectady

W. M. Cashin, KAPL

J. L. Michaelson, Advanced Technology Lab., Bldg. 5

Idaho Operations Office

Nuclear Technology Div. (3)

J. F. Kaufman

D. S. King

D. E. Williams

IIT Research Institute

P. O. Box 327

Argonne, Illinois

W. J. McGonnagle

IIT Research Institute

10 W. 35 th street

Chicago, Illinois

T. A. Zaker

Isochem, Inc.

H. H. Hopkins

H. P. Shaw

R. E. Tomlinson

Los Alamos Scientific Laboratory

H. F. Redman

D. B. Hall

Massachusetts Institute of Technology Manson Benedict

National Bureau of Standards

C. Muehlhause 
National Reactor Testing Station (INC)

J. A. Buckham

D. R. de Borsblanc

New York Operations Office

A. J. Rizzo

C. Stahle

Nuclear Development Corporation of America W. A. Loeb

Nuclear Materials and Equipment Corporation C. S. Caldwell

Oak Ridge Operations Office

D. F. Cope

W. J. Larkin

Phillips Petroleum Company

Ätomic Energy Division, Idaho Falls

G. O. Bright (2)

S. G. Forbes (2)

E. O. Meals

F. Schroeder (2)

T. R. Wilson (2)

4

Richland Operations Office

P. M. Midkiff

C. L. Robinson

R. K. Sharp (2)

1

Sandia Corporation

J. Jacobs

1

San Francisco Operations Office

1

Sargent and Lundy

W. A. Chittenden

8

Union Carbide Corporation (ORNL)

F. L. Culier

W. B. Cottre11

J. H. Frye

R. W. McClung

O. Sisman

D. B. Trauger (2)

M. $S$ : Wechsler

1

United Nuclear Corporation

C. Graves

1

University of California

\author{
V. E. Schrock
}


Westinghouse Electric Corporation R. H. Fillnow

E. J. Kreh

R. G. McGrath

R. A. Wiesemann

$\frac{\text { Batteile-Northwest }}{\text { F.W. Albaugh }}$

G. J. Alkire

R. J. Anicetti

J. M. Atwood

J. A. Ayres

Q. I. Baird (ANL Liaison, Idaho Falls)

J. M. Batch

A. L. Bement

C. A. Bennett

T. K. Bierlein

J. G. Bradley

S. H. Bush

G. J. Busselman

J. J. Cadwell

T. T. Claudson

E. L. Clayton

T. B. Correy

R. E. Dah 1

F. F. Dawson

I. J. Defferding

D. R. de Halas

R. F. Dickerson

R. L. Dillon

K. Drumilier

E. A. Eschbach

- ت. Farnsworth

S. L. Fawcett

J. R. Fishbaugher

J. C. FOX

M. D. Freshley

E. P. Galbraith

S. M. Gill

S. Goldsmith 
L. A. Hartcorn

H. Harty

R. E. Heineman

R. J. Hennig

H. L. Henry

P. L. Hofmann

D. D. Lanning

H. V. Larson

G. A. Last

R. D. Leggett

B. R. Leonard

R. C. Liikala

C. W. Lindenmeier

W. W. Little

J. E. Minor

T. C. Nelson

C. E. Newton

R. E. Nightingale

H. M. Parker

R. S. Paul

L. T. Pedersen

A. M. Platt

W. D. Richmond

W. E. Roake

G. J. Rogers

C. A. Rohrmann

L. C. Schmid

L. C. Schwendiman - C. E. Linderoth

R. J. Sorenson (3)

W. G. Spear

A. J. Stevens

R. W. Stewart

G. L. Tingey

C. R. Tipton, Jr.

L. D. Turner

C. M. Unruh

F. W. Van Wormer

J. B. Vetrano

E. E. Voiland

R. G. Wheeler

O. J. Wick

F. W. Woodfield

D. C. Worlton

H. H. Yoshikawa

Technical Information Files

Technical Publications (2) 